Universidade de São Paulo

Instituto de Física

\title{
Cálculos $A b$ Initio de Interações entre Cd e Bases Nitrogenadas do DNA
}

Philippe Alexandre Divina Petersen

Orientadora: Prof. Dra. Helena M. Petrilli

Tese apresentada ao Instituto
de Física para a obtenção do
título de Mestre em Ciências

Comissão Examinadora:

Profa. Dra. Helena Maria Petrilli (IF-USP)

Prof. Dr. Mario Rentería (UNLP-Argentina)

Profa. Dra. Ana Maria da Costa Ferreira (IQ-USP)

São Paulo

2011 


\section{FICHA CATALOGRÁFICA \\ Preparada pelo Serviço de Biblioteca e Informação do Instituto de Física da Universidade de São Paulo}

Petersen, Philippe Alexandre Divina

Cálculos ab initio de interações entre cd e bases nitrogenadas do DNA. São Paulo, 2011.

Dissertação (Mestrado) - Universidade de São Paulo. Instituto de Física. Depto. de Física dos Materiais e Mecânica.

Orientador: Profa. Dra. Helena Maria Petrilli Área de Concentração: Física da Matéria Condensada

Unitermos: 1. Física da Matéria Condensada;

2. Física Computacional; 3. Estrutura Eletrônica;

4. Compostos Oraganometálicos (Química Inorgânica);

5. DNA. 

"O único lugar em que vi que o sucesso vem antes do trabalho foi no dicionário".

\section{Albert Einstein}





\section{Agradecimentos}

Os meus sinceros agradecimentos

À Prof. Dra. Helena Maria Petrilli, que foi minha orientadora, pela atenção e paciência que sempre teve e pelos sábios conselhos que levarei comigo em minha jornada.

À Prof. Dra. Lucy vitória Credido Assali e Prof. Marília Junqueira Caldas, pela ajuda em momentos delicados.

Ao Prof. Dr. Kazunori Watari e Prof. Dr. Luiz Guimarães Ferreira, pelas conversas instigantes e discussões pertinentes sobre Física.

Ao Prof. Dr. Artur W. Carbonari, Prof. André Luis Lapolli e Prof. Dr. Rajendra Naraian Saxena, pela a grande ajuda e colaboração neste trabalho.

À prof. Dra. Ana Maria da Costa Ferreira e seu grupo de pesquisa do IQ, pela ajuda ao tratar e entender a Química envolvida neste presente trabalho.

Aos meus amigos e companheiros de trabalho Rafael Rodrigues Nascimento, Ney Sodré, Jośe Maximiano Júnior, Leonardo Marion Jorge, Regina L. Sousa, Rodrigo Ramos, Filipe Dalmatti, Francisco Nogueira, Rolando Larico Mamani, Marcelo Alves dos Santos, Michel Lacerda, Jarlesson Amazonas, Samuel, Rodrigo Amorim, Joelson Cott (grande amigo), Ricardo Igarashi, Laís Banov, Sérgio Maracajá, Antônio Claúdio Padilha, Jeconias, Denille, Bruno Anghinoni, Amaury Melo, André, Fábio Lombardi, Andréia dos S. Silva, Luciano Pereira, Acleto e todo o grupo do prof. Carbonari. Peço sinceras desculpas se esqueci de algúem. 
Agradecimentos especiais para o meu grande amigo Marcos Brown, por ser uma pessoa muito íntegra e ter me ajudado muito para que este trabalho fosse realizado. À Sandra e família, por serem pessoas muito boas e terem tido muita paciência comigo. À Rosana, pela sua calma e prontidão para resolver os problemas.

Ao meu orientador de iniciação científica Prof. Dr. Elso Drigo Filho por me fazer gostar de ser físico.

À meus irmãos Nick, Chris e principalmente à minha irmã Andrea, por seu amor e por sempre acreditar em mim.

À minha mãe, por estar do meu lado e ter tido a compreensão nos momentos difíceis.

À Mariana Corrêa de Lima, por seu amor e por ser a pessoa que mais me incentivou e me ajudou nos momentos difíceis.

À Pró-Reitoria da USP e ao comitê organizador do congresso HFI/NQI 2010, pelo apoio financeiro para a participação do evento HFI/NQI 2010 na Suiça.

Ao INEO (MCT/FAPESP/CNPQ), rede Nanobiomed (CAPES) e redes nacionais dos quais se realizou o presente trabalho.

À CAPES pelo apoio financeiro. 


\section{Resumo}

As interações hiperfinas são uma ótima ferramenta para estudar um sítio específico e obter informações importantes sobre o sistema. No presente trabalho analisamos de forma teórica as propriedades eletrônicas, estruturais e hiperfinas do Cádmio (Cd) ligado às bases nitrogenadas do DNA. A motivação surgiu da colaboração com o grupo do prof. Artur W. Carbonari do Instituto de Pesquisas Energéticas e Nucleares (IPEN) e que tem como objetivo investigar o DNA e anticorpos de linhagens de camundongos infectados pela cepa Y de Trypanosoma cruzi, protozoário causador da doença de Chagas. A técnica Time Differential Perturbed Angular Correlation (TDPAC) foi utilizada para obter as medidas das interações hiperfinas do DNA. O núcleo de prova das medidas foi o ${ }^{111} \mathrm{Cd}$. Utilizamos uma abordagem quântica ab initio all-electron, dentro da Teoria do Funcional da Densidade (DFT), através do código computacional CP-PAW que combina o método Projector Augmented Wave (PAW) e a dinâmica molecular quântica de Car-Parrinello (CPMD). Ressaltamos que, até o presente momento, nenhum estudo com esta abordagem teórica e com este código computacional foi realizado para investigar as propriedades hiperfinas do Cd ligado as bases nitrogenadas do DNA. 


\section{Abstract}

The Hyperfine interactions are good tools to study specific sites and obtain important information about a given system. In this work we study electronic, structural and hyperfine properties of the Cadmium $(\mathrm{Cd})$ coordinated to the DNA nitrogenous bases. The motivation for this study arose from a collaboration with the group of prof. Arthur W. Carbonari at the Institute of Energy and Nuclear Research (IPEN), which aims to investigate DNA and antibodies to strains of mice infected with the Trypanosoma cruzi, the protozoan that causes Chagas disease. The Time Differential Perturbed Angular Correlation (TDPAC) technique was used to obtain hyperfine interactions measurements at a $\mathrm{Cd}$ probe bonded to DNA. We use ab initio all-electron calculations, within the Density Functional Theory (DFT) and we use the computer code CP-PAW that combines the Projector Augmented Wave (PAW) method and the Car-Parrinello (CP) quantum molecular dynamics approach to. We emphasize that, until now, no study with this theorectical approach and with this computer code was conducted to investigate the hyperfine properties of the Cd binding to the DNA bases. 


\section{Conteúdo}

Agradecimentos vi

Resumo viii

$\begin{array}{ll}\text { Abstract } & \text { ix }\end{array}$

1 Introdução 1

2 Metodologia $\quad 8$

2.1 Introdução . . . . . . . . . . . . . . . . . 8

2.2 A Teoria do Funcional da Densidade . . . . . . . . . . . . . 11

2.2.1 O Teorema de Hohenberg-Kohn . . . . . . . . . . . . . 12

2.2.2 As equações de Kohn-Sham . . . . . . . . . . . . . . 13

2.3 Dinâmica Molecular de Primeiros Princípios de Car-Parrinello . . . 16

2.3.1 A Lagrangeana e as Equações de Movimento de Car-Parrinello 17

2.3.2 Desacoplamento Adiabático e Conservação da Energia . . . . 18

2.4 Bases de Ondas Planas . . . . . . . . . . . . . . . . 19

2.5 O Método PAW . . . . . . . . . . . . . . . 21

2.5.1 Construção das Funções de Onda . . . . . . . . . . . . . . 22

2.5.2 Operador de Transformação e Valores Esperados . . . . . . . 24 
3 Gradiente de Campo Elétrico no Núcleo 29

3.1 Interações Hiperfinas . . . . . . . . . . . . . . . . . . 29

3.2 As Interações Hiperfinas Elétricas . . . . . . . . . . . . . . . 30

4 Resultados e Discussões $\quad 36$

4.1 Bases Nitrogenadas Isoladas . . . . . . . . . . . . . . . 38

4.1.1 Otimização de Geometria para as Bases Nitrogenadas Isoladas 39

4.1.2 Cálculos de GCE para as bases nitrogenadas . . . . . . . . 45

4.2 Cd ligado a bases nitrogenadas . . . . . . . . . . . 57

4.2.1 Otimização de Geometria do Cd Ligado as Bases Nitrogenadas 59

4.2.2 GCE para o Cd Ligado as Bases Nitrogenadas . . . . . . . 65

4.3 Inserindo Moléculas de Água no Sistema . . . . . . . . . . . . . 72

4.3.1 Otimização de Geometria dos Sistemas Estudados . . . . . . 73

4.3.2 Cálculos de GCE para os sistemas estudados . . . . . . . . 79

4.4 Estudo do $C d^{+2}$ Ligado a Pares de Bases Nitrogenadas . . . . . . . 81

4.4.1 Adenina-Timina . . . . . . . . . . . . . 82

4.4 .2 Guanina-Citosina . . . . . . . . . . . . . . 84

4.4 .3 Discussão dos Resultados de GCE . . . . . . . . . . . . 86

4.5 Densidade de Estados (DOS) e Orbitais Moleculares . . . . . . . . 90

4.5.1 Adenina e Timina . . . . . . . . . . . . . . . . 90 90

4.5.2 Guanina e Citosina . . . . . . . . . . . . . . 95

5 Conclusões 102

$\begin{array}{ll}\text { A Técnica TDPAC } & 105\end{array}$

$\begin{array}{lr}\text { Referências Bibliográficas } & 120\end{array}$ 


\section{Capítulo 1}

\section{Introdução}

O ácido desoxirribonucléico (deoxyribonucleic acid - DNA) é a molécula orgânica que contêm as informações genéticas de um organismo. Além de ser responsável pelo armazenamento do código genético, é responsável também pela transmissão da informação genética o que garante a construção de uma célula ou um organismo multicelular [1]. A exata multiplicação do DNA assegura a manutenção das espécies, mantendo sua herança gênica de geração em geração.

A estrutura da molécula de DNA mais comumente encontrada na literatura é a de dupla hélice. Foi descoberta simultaneamente pelo norte-americano James Watson e o britânico Francis Crick em 1953 [1]. Do ponto de vista químico, o DNA é considerado um polímero orgânico constituído por subunidades denominados nucleotídeos. Cada nucleotídeo contém açúcar, grupo fosfato $\left(\mathrm{H}_{3} \mathrm{PO}_{4}\right)$ e bases nitrogenadas [2]. A molécula de DNA possui quatro tipos de bases nitrogenadas que são divididos em dois grupos: bases púricas e bases pirimídicas, conforme apresentado na figura 1.1. As bases púricas são compostos heterocíclicos e são caracterizadas por conter em suas estruturas um anel pirimidínico fundido ao anel imidazólico; possuem baixa solubilidade em água (pH neutro). As bases púricas do DNA são a Adenina e a Guanina. 
As bases pirimídicas são substâncias orgânicas com algumas características semelhantes ao benzeno; possuem baixa basicidade e sua mais importante propriedade é realizar reações de oxi-redução, formando ligações de hidrogênio. As bases pirimídicas do DNA são a Citosina e Timina (figura 1.1).

$\underline{\text { Purinas }}$<smiles>Nc1ncnc2[nH]cnc12</smiles>

Adenina<smiles>Nc1nc2[nH]cnc2c(=O)[nH]1</smiles>

Guanina

Pirimidinas<smiles>Nc1ccn([TlH])c(=O)n1</smiles><smiles>Cc1cn(C)c(=O)[nH]c1=O</smiles>

Citosina

Timina

Figura 1.1: Desenho ilustrativo em 2D das bases púricas (adenina e guanina) e pirimídicas (citosina e timina) do DNA.

Cada base nitrogenada do DNA faz ligação com um tipo específico de base na outra cadeia da dupla hélice, no que é chamado de complementariedade de bases [3](figura 1.2). A guanina faz ligação de hidrogênio somente com a citosina e a adenina faz ligação de hidrogênio somente com a timina. No entanto, com a inserção de metais no DNA, podemos ter o fenômeno conhecido como miss pairing onde não necessariamente ocorre a complementariedade das bases da forma guanina-citosina (GC) e adenina-timina (AT) [4]. O par de bases GC possui três ligações de hidrogênio e o par AT possui duas ligações de hidrogênio (figura 1.2). 


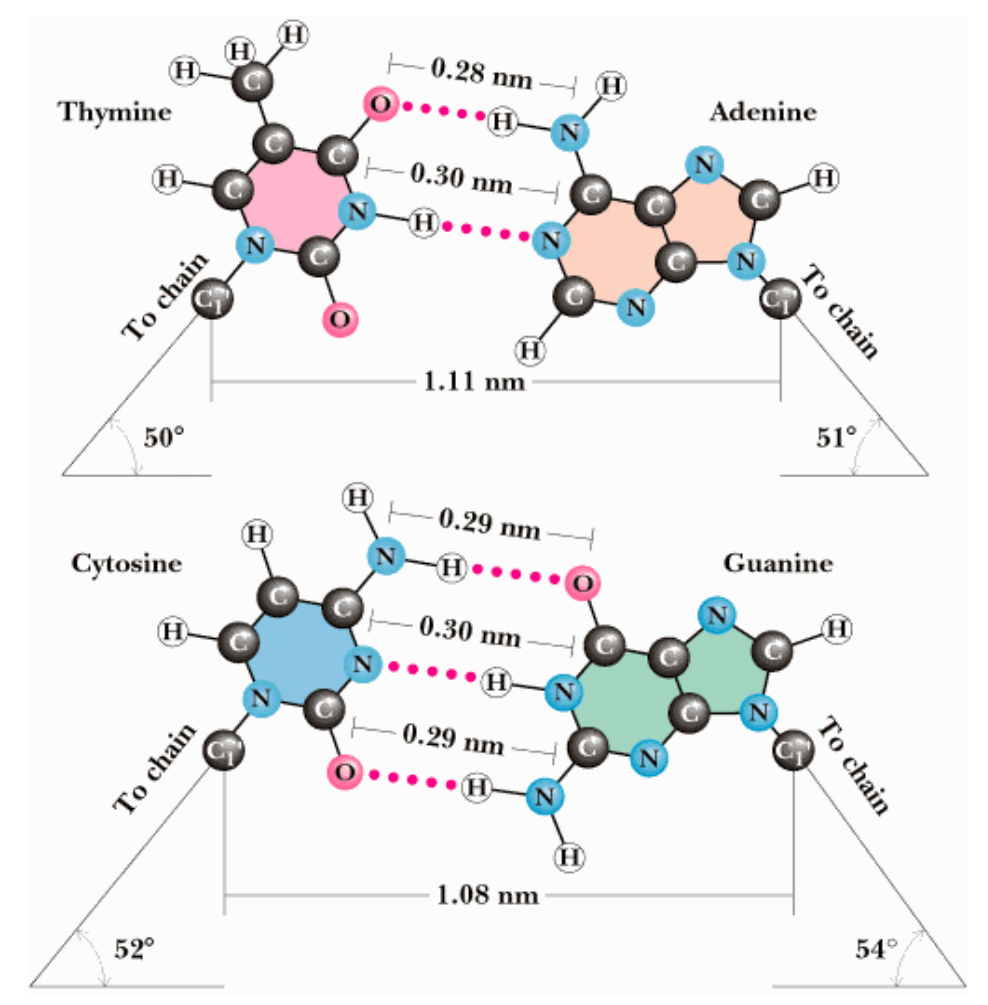

Figura 1.2: Desenho ilustrativo em 2D dos pares de bases AT e GC do DNA, (figura extraída de http://www.enq.ufsc.br/labs/probio/disc_eng_bioq/trabalhos_pos2003, acessado em 18/03/11.)

A interação entre os cátions metálicos ou complexos metálicos com o DNA é extremamente importante nas funções estruturais, regulatórias das expressões gênicas e reações catalíticas do DNA [4]. Entender como os complexos metálicos interagem com o DNA é hoje uma grande área de pesquisa na interface entre a química, física, biologia molecular e medicina. Estudos realizados por Eichhorn e Shin [5] mostram que a afinidade dos metais catiônicos pelo fosfato do backbone do DNA obedece a sequência $\mathrm{Mg}^{2+}>\mathrm{Co}^{2+}>\mathrm{Ni}^{2+}>\mathrm{Mn}^{2+}>\mathrm{Zn}^{2+}>\mathrm{Cd}^{2+}>$ $\mathrm{Cu}^{2+}$ (sequência de Irving-Willians). No entanto, a afinidade dos íons metálicos muda quando inseridos na matriz da dupla hélice do DNA [4]. De acordo com as ref. $[6,7]$ um grande número de íons metálicos (entre eles o $C d^{2+}$ ) tem a preferência de se ligar em bases ou em pares de bases nitrogenadas (figura 1.3). Apesar de 
existir a possibilidade do metal se ligar ao backbone do DNA, esta possibilidade é pequena se comparada com a de encontrar o metal interagindo com as bases nitrogenadas [8]. Os cátions metálicos podem se ligar ao DNA de duas formas: 1) ligação de forma difusa com o DNA ou 2) ligação num sítio específico do DNA [4]. A interação de forma difusa é entre moléculas de água, isto é, tanto o metal quanto o DNA conservam suas primeiras camadas de hidratação [9]. Esta é uma interação Coulombiana de longo alcance na qual os cátions metálicos se acumulam em torno do DNA de forma delocalizada. Na interação sítio específico, o metal é coordenado a ligantes específicos do DNA. De acordo com a literatura [6, 7], os possíveis sítios desta interação são: as bases nitrogenadas, a região entre os pares de base, intercalados entre pares de bases e ligados em diferentes nucleotídeos como mostrado na figura 1.3. Esta coordenação pode ser direta (denominada primeira esfera de coordenação) ou pode existir uma interface de moléculas de água entre o metal e o ligante (comumente chamado de esfera externa ou segunda esfera de coordenação). Na primeira esfera de coordenação, o metal está ligado diretamente ao DNA sem a interface de água entre o metal e o sítio do DNA. Na segunda esfera de coordenação, somente as camadas mais internas de hidratação do metal são mantidas intactas [4] e a coordenação do metal é ajustada de tal forma que compartilha com o ligante do DNA a camada de solvatação.

Avanços recentes em cálculos computacionais têm permitido um progresso no nível dos cálculos ab initio. Diversos trabalhos têm sido publicados sobre estudos das interações entre diferentes cátions e as bases nitrogenadas, pares de bases e nucleotídeos $[10,11,12,13]$. No entanto, não é do nosso conhecimento na literatura estudos através de cálculos ab initio de interações hiperfinas para o Cd ligado ao DNA, bases nitrogenadas isoladas ou pares de bases.

As interações hiperfinas são interações entre as cargas elétricas e momentos magnéticos nucleares e as cargas e momentos magnéticos externos ao núcleo. Es- 
tas interações podem nos permitir identificar os sítios específicos de ligação na primeira esfera de coordenação do $C d^{2+}$ com as bases nitrogenadas do DNA uma vez que dependem da densidade de cargas e momentos ao redor de um dado sítio nuclear. $\mathrm{O}{ }^{111} \mathrm{Cd}$ é importante por ser um isótopo muito utilizado na técnica Time Differential Perturbed Angular Correlation (TDPAC) [14, 15]. No presente trabalho, vamos estudar as interações hiperfinas do íon metálico cádmio $\left(C d^{2+}\right)$ com as bases nitrogenadas e pares de bases nitrogenadas do DNA. Simulamos a interação direta entre o íon $C d^{2+}$ e as bases nitrogenadas através da inserção do metal diretamente nos sítios mais reativos das bases.

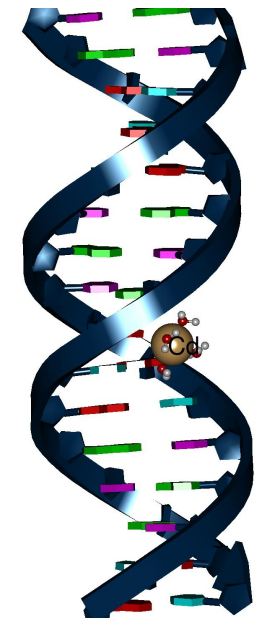

(a)

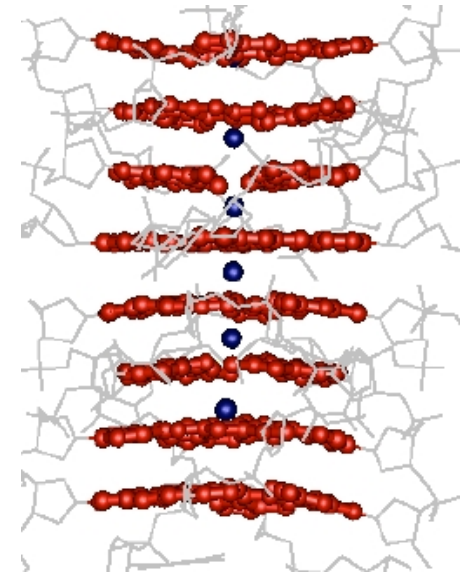

(b)

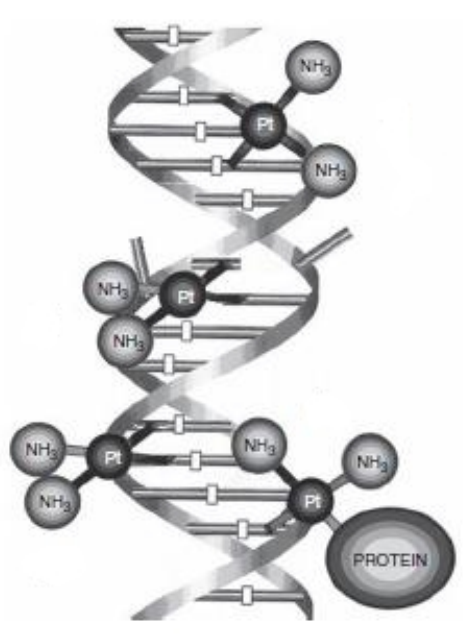

(c)

Figura 1.3: Em (a) esquema ilustrativo do metal divalente (íon $C d^{2+}$ ) ligado diretamente na base nitrogenada do DNA. Em (b) temos a ilustração do metal intercalado com os pares de bases e em (c) esquema proposto na literatura para as interações entre os íons metálicos com diferentes nucleotídeos da molécula de DNA. As figuras (b) e (c) foram retiradas das referências [16] e [4] respectivamente.

O cádmio na sua forma iônica, $C d^{2+}$, possui um raio iônico de $0,95 \AA$ e tem uma grande similaridade química com dois íons metálicos muito presentes em sistemas biológicos que são $Z n^{2+}$ (raio iônico de $0,74 \AA$ ) e o $C a^{2+}$ (raio iônico de $1,00 \AA$ ) que os tornam semelhantes em relação ao volume ocupado [17]. É extremamente tóxico 
e ainda não se sabe ao certo se é necessário ao corpo humano. No corpo humano e em outros organismos menores, o $\mathrm{Cd}^{2+}$, quando ingerido, pode ser encontrado nos rins e no fígado. Os números de coordenação mais comumente encontrados nestas situações são 4, 5 e 6 e podemos citar alguns complexos que envolvem o íon $\mathrm{Cd}^{2+}$ e suas estruturas, como: tetraédrica $\left(\left[\mathrm{CdCl}_{4}\right]^{2-},\left[\mathrm{Cd}\left(\mathrm{NH}_{3}\right)_{4}\right]^{2+}\right)$, trigonal bipiramidal $\left(\left[\mathrm{CdCl}_{5}\right]^{3-}\right)$, octaédrica $\left(\left[\mathrm{Cd}(\mathrm{DMSO}-\mathrm{O})_{6}\right]^{2+},\left[\mathrm{CdCl}_{6}\right]^{4-}\right)$ e hexagonal bipiramidal [17].

O presente trabalho se constitui na primeira etapa de um estudo mais amplo motivado pelo estudo do comportamento do DNA em camundongos com a doença de Chagas. Estes estudos estão sendo realizados por pesquisadores do Instituto de Pesquisas Energéticas e Nucleares (IPEN) [18]. A doença de Chagas é causada por um protozoário flagelado, Trypanosoma cruzi (T. cruzi), que é transmitido ao homem pelas fezes ou urina do inseto (vetor) conhecido aqui no Brasil pelo nome de Barbeiro. Este vetor pertence à classe dos hemípteros hematófagos da subfamília Triatominae [19]. Devido à ausência de vacinas e a indisponibilidade, em grande escala, de tratamento específico, a principal estratégia adotada no controle da doença de Chagas tem sido a prevenção da transmissão, principalmente na eliminação do vetor (barbeiro) [20]. No entanto, estes métodos carecem de uma profunda investigação científica que podem auxiliar na maior eficiência destes métodos e colaborar com a erradicação da doença.

A observação da diferença na resistência de pessoas infectadas com a T. cruzi conduziu à hipótese de que a constituição genética do hospedeiro pode influenciar no desenvolvimento da doença e na sobrevida dos doentes [21]. Desta forma, os pesquisadores passaram a investigar a genética de camundongos com a idéia de buscar ferramentas para o entendimento dos mecanismos de controle da infecção [18]. A análise das linhagens de camundongos infectados com a T. cruzi sugeriu a importância da constituição genética do hospedeiro na sobrevivência. Os 
acasalamentos entre os camundongos selecionados com o protozoário e camundongos saudáveis, contribuiu para a investigação do fenômeno da resistência à cepa Y do T. cruzi, revelando o padrão de resposta imunológica apresentado por eles [18]. Os estudos do DNA de camundongos infectados pela T. cruzi realizados pelo grupo do professor A. Carbonari do IPEN utiliza a técnica TDPAC. Uma breve descrição da técnica TDPAC é feita no apêndice A.

O objetivo do presente trabalho é investigar a interação do núcleo de prova ${ }^{111} \mathrm{Cd}$ com a molécula de DNA de forma a correlacionar os parâmetros hiperfinos obtidos pela técnica TDPAC com os sítios específicos de interação no DNA (grupos coordenantes, geometria, etc...). Nossos cálculos de parâmetros hiperfinos são obtidos de método computacional ab initio e all electron. A metodologia utilizada neste trabalho é apresentada nos capítulos 2 e 3 . No capítulo 2 apresentamos os fundamentos teóricos da Teoria do Funcional da Densidade (DFT) e também abordamos a metodologia empregada no código computacional Car-Parrinello Projector Augmented Wave (CP-PAW) [22] que combina a dinâmica molecular de Car-Parrinello [23] com o método PAW desenvolvido por Peter E. Blöchl [24]. No capítulo 3 apresentamos a grandeza aqui estudada que é o Gradiente de Campo Elétrico no Núcleo (GCE). No capítulo 4 apresentamos os resultados obtidos nos sistemas estudados neste trabalho e discutimos estes resultados. No capítulo 5 apresentamos nossas conclusões sobre este estudo e apresentamos também algumas perspectivas futuras para a continuidade deste trabalho. 


\section{Capítulo 2}

\section{Metodologia}

\subsection{Introdução}

A descrição das propriedades químicas e físicas da matéria é um problema complexo de ser resolvido. Geralmente lidamos com sistemas de muitos átomos que estão interagindo entre si e que também podem ser afetados por campos externos. Estes conglomerados (ensembles) de partículas se apresentam na forma gasosa (moléculas e clusters) ou em forma de matéria condensada que podem ser sólidos, líquidos ou amorfos, homogêneos e heterogêneos ( moléculas em solução e interfaces) [25]. Em todos estes casos descrevemos o sistema por um número de núcleos atômicos e elétrons que interagem através das interações Coulombianas. Formalmente, podemos escrever a Hamiltoniana não relativística de um sistema da seguinte maneira:

$$
\hat{H}=\hat{T}_{n}(\mathbf{R})+\hat{T}_{e}(\mathbf{r})+\hat{V}_{n n}(\mathbf{R})+\hat{V}_{e e}(\mathbf{r})+\hat{V}_{n e}(\mathbf{R}, \mathbf{r})
$$

$\mathrm{Ou}$ 


$$
\begin{aligned}
\hat{H} & =-\sum_{I=1}^{P} \frac{\hbar^{2}}{2 M_{I}} \nabla_{I}^{2}-\sum_{i=1}^{N} \frac{\hbar^{2}}{2 m} \nabla_{i}^{2}+\frac{e^{2}}{2} \sum_{I=1}^{P} \sum_{J \neq I}^{P} \frac{Z_{I} Z_{J}}{\left|\mathbf{R}_{I}-\mathbf{R}_{J}\right|} \\
& +\frac{e^{2}}{2} \sum_{i=1}^{N} \sum_{j \neq i}^{N} \frac{1}{\left|r_{i}-r_{j}\right|}-e^{2} \sum_{I=1}^{P} \sum_{i=1}^{N} \frac{Z_{i}}{\left|\mathbf{R}_{I}-r_{i}\right|}
\end{aligned}
$$

onde $\mathbf{R}=\mathbf{R}_{I}$ e $I=1,2 \ldots P$, são as coordenadas nucleares. $\mathbf{r}=\mathbf{r}_{i}$ e $i=1 \ldots N$ são as coordenadas dos $\mathrm{N}$ elétrons do sistema. $Z_{I}$ e $M_{I}$ são, respectivamente, as cargas e massas para o $\mathrm{P}$ núcleos atômicos. Ao aplicarmos a função de onda na Hamiltoniana dada pela equação (2.1) geramos os seguintes valores esperados:

- $\left\langle\Psi\left|\hat{T}_{n}\right| \Psi\right\rangle$ : energia cinética dos núcleos;

- $\left\langle\Psi\left|\hat{T}_{e}\right| \Psi\right\rangle$ : energia cinética dos elétrons;

- $\left\langle\Psi\left|\hat{V}_{n e}\right| \Psi\right\rangle$ : energia potencial dos elétrons gerado pelo núcleo ou íon;

- $\left\langle\Psi\left|\hat{V}_{e e}\right| \Psi\right\rangle$ : energia potencial devido à interação elétron-elétron;

- $\left\langle\Psi\left|\hat{V}_{n n}\right| \Psi\right\rangle$ : energia potencial devido às interações entre os núcleos ou íons.

Devido os elétrons serem férmions, a função de onda total eletrônica deve ser necessariamente antissimétrica.

A princípio, todas as propriedades de um sistema podem ser obtidas resolvendo a equação de Schrödinger independente do tempo para muitos corpos

$$
\hat{H} \Psi_{i}(\mathbf{r}, \mathbf{R})=E_{i} \Psi_{i}(\mathbf{r}, \mathbf{R})
$$

Na prática, resolver a equação (2.3) é um problema quase insolúvel quando o tratamos somente com as ferramentas da mecânica quântica. Existem muitos fatores que contribuem com esta dificuldade e dentre estas podemos destacar dois problemas fundamentais. O primeiro é devido ao sistema ser de muitos corpos e 
com muitas componentes espaciais na qual cada componente (dos núcleos e dos elétrons) obedecem a uma estatística particular (para os elétrons a estatística de Fermi-Dirac e para os núcleos normalmente são tratados classicamente na distribuição de Boltzmann). O segundo problema está no fato da função de onda completa não pode ser facilmente fatorizada devido às correlações coulombianas, isto é, a equação de Schrödinger não pode ser facilmente transformada em um conjunto de equações independentes. Portanto, temos que lidar com $3 \mathrm{P}+3 \mathrm{~N}$ graus de liberdade do sistema. Logo, se faz necessário utilizar recursos (aproximações) que facilitam o cálculo do sistema. No tópico seguinte discutiremos a aproximação de Born-Oppenheimer [26] que é uma ferramenta essencial para os cálculos quânticos de propriedades de moléculas e sólidos.

\section{Aproximação Adiabática (Born-Oppenheimer)}

A massa do núcleo é em torno de 1836 vezes a massa do elétron. É razoável considerar que ,devido a este fato, a velocidade do elétron é muito maior que a do núcleo. Logo, o movimento do núcleo é muito menor que o movimento do elétron. Partindo desta idéia, M. Born e J.R. Oppenheimer [26] propuseram que o movimento dos elétrons pode ser descrito para cada configuração instantânea dos núcleos, permanecendo sempre no mesmo estado estacionário do Hamiltoniano eletrônico. Isto significa que com o movimento do núcleo, os elétrons instantaneamente ajustam as suas funções de onda de acordo com a função de onda do núcleo. Desta forma, podemos analisar separadamente o movimento do núcleo e o movimento dos elétrons. Com estas aproximações, podemos escrever a função de onda total, na forma reduzida [25], da seguinte forma

$$
\Psi(\mathbf{R}, \mathbf{r}, t)=\Theta_{m}(\mathbf{R}, t) \Phi_{m}(\mathbf{R}, \mathbf{r})
$$


onde $\Theta_{m}(\mathbf{R}, t)$ são as funções de onda que descrevem a evolução temporal dos núcleos em cada autoestado adiabático eletrônico $\Phi_{m}(\mathbf{R}, \mathbf{r})$.

A equação 2.4 é válida para dinâmica dos núcleos que não causam transições eletrônicas e os elétrons permanecem sempre no mesmo $m$ estado adiabático (fundamental ou excitado) e satisfaz a equação de Schrödinger independente do tempo

$$
\hat{H}_{e} \Phi_{m}(\mathbf{R}, \mathbf{r})=E_{m}(\mathbf{R}) \Phi_{m}(\mathbf{R}, \mathbf{r})
$$

onde a Hamiltoniana eletrônica $\left(\hat{H}_{e}\right)$ é dada por

$$
\hat{H}_{e}=\hat{T}_{e}+\hat{V}_{e e}+\hat{V}_{n e}=\hat{H}-\hat{T}_{n}-\hat{V}_{n n}
$$

A energia potencial de interação elétron-elétron $\left(\hat{V}_{e e}\right)$ compreende a energia potencial coulombiana e as interações de troca e correlação eletrônicas.

\section{$2.2 \quad$ A Teoria do Funcional da Densidade}

Mesmo com a aproximação dos núcleos em posições fixas resolver a equação de Schrödinger para muitos corpos (eq. 2.3) ainda é muito trabalhoso e, dependendo do número de núcleos atômicos e elétrons do sistema, muito complexo. Para contornar esta situação, duas aproximações em mecânica quântica são bastante utilizadas para os cálculos das propriedades dos materiais. A aproximação de Hartree-Fock (HF), que tem sua origem na Química Quântica, e a Teoria do Funcional da Densidade (DFT). A aproximação de HF tem como variável fundamental a função de onda total do sistema e consiste na idéia de que a função de onda total de muitos elétrons pode ser escrita como um produto de funções de onda de um elétron. Foi durante muito tempo a aproximação escolhida pelos químicos para calcular a estrutura eletrônica das moléculas. A aproximação DFT 
tem como variável fundamental a densidade eletrônica. Os dois elementos principais da DFT são o teorema de Hohenberg-Kohn [27] e as equações de Kohn-Sham [28]. A DFT propõe uma solução exata para o problema de muitos corpos e nos leva a bons resultados com o uso de cálculos de primeiros princípios. Nos últimos 30 anos a DFT tem sido usada pela comunidade da Física da Matéria Condensada e também está sendo aceita pela comunidade de Química Quântica devido suas vantagens computacionais em relação aos métodos baseados em HF.

\subsubsection{O Teorema de Hohenberg-Kohn}

Em 1964, P. Hohenberg e W. Kohn [27] propuseram dois teoremas que se tornaram as bases fundamentais da DFT:

- O potencial externo é determinado, de forma unívoca, pela densidade eletrônica a menos de uma constante aditiva.

O primeiro teorema de HK nos mostra que a energia total do estado ligado de um sistema de elétrons interagentes é um funcional único, porém desconhecido, da densidade eletrônica. O segundo teorema é baseado no princípio variacional da energia

- Desde que a densidade eletrônica $\rho(\mathbf{r})$ determina univocamente o potencial externo $V_{\text {ext }}(\mathbf{r})$, então também determina o estado fundamental da função de onda $\Phi_{m}$. A energia do estado fundamental $E\left(\rho_{0}(\mathbf{r})\right)$ é mínima para a densidade $\rho(\mathbf{r})$ exata, então $E\left(\rho_{0}(\mathbf{r})\right)<E_{v}(\rho(\mathbf{r}))$ para qualquer $\rho(\mathbf{r}) \neq \rho_{0}(\mathbf{r})$.

Uma vez que um sistema no estado fundamental com $n$ elétrons descrito por uma função de onda de $3 \mathrm{~m}$ variáveis (eq. 2.5) pode ser determinado pela densidade eletrônica, podemos substituir a função de onda de $3 \mathrm{~m}$ variáveis por uma função de onda com apenas 3 variáveis. Desta forma, a energia do estado fundamental de 
um sistema de muitos corpos fica

$$
\begin{gathered}
E[\rho(\mathbf{r})]=\left\langle\Phi\left|\hat{T}_{e}+\hat{V}_{e e}+\hat{V}_{e x t}\right| \Phi\right\rangle= \\
\left\langle\Phi\left|\hat{T}_{e}+\hat{V}_{e e}\right| \Phi\right\rangle+\left\langle\Phi\left|\hat{V}_{e x t}\right| \Phi\right\rangle=F[\rho(\mathbf{r})]+\int \rho(\mathbf{r}) V_{e x t}(\mathbf{r}) d \mathbf{r}
\end{gathered}
$$

onde $F[\rho(\mathbf{r})]$ é chamado de funcional universal e é válido para qualquer sistema de $n$ elétrons. Sua forma funcional em termos da densidade não é conhecida. As demonstrações dos teoremas de HK não serão vistos aqui, pois fogem do escopo do nosso estudo, mas podem ser obtidos nas referências [25, 27].

\subsubsection{As equações de Kohn-Sham}

Um dos mais importantes problemas da teoria quântica de muitos corpos é encontrar o estado fundamental de um sistema não homogêneo de N elétrons interagentes. O problema se concentra mais precisamente no termo do potencial de interação elétron-elétron $\left(\hat{V}_{e e}\right)$. Reescrevendo na forma funcional a energia total de um sistema no estado fundamental (eq. 2.7)

$$
E[\rho(\mathbf{r})]=T_{e}[\rho]+V_{e e}[\rho]+V_{n e}[\rho] .
$$

Separamos o termo do potencial de interação elétron-elétron $\left(V_{e e}[\rho]\right)$ em dois ter$\operatorname{mos} V_{C}[\rho]$ e $V_{x c}[\rho]$.

$$
E[\rho(\mathbf{r})]=T_{e}[\rho]+V_{C}[\rho]+V_{x c}[\rho]+V_{n e}[\rho]
$$

$V_{C}[\rho]$ define a energia de interação elétron-elétron de origem Coulombiana e $V_{x c}[\rho]$ define as interações de troca e correlação eletrônicas. Apesar de se obter bons resultados separando as interações eletrostáticas das relações de troca e correlação eletrônicas, o maior desafio ainda é saber como lidar com o termo de correlação 
inserido no potencial de troca e correlação $\left(V_{x c}[\rho]\right)$.

Em 1965, W. Kohn e L. Sham [28] propuseram substituir a energia cinética dos elétrons interagentes por uma energia cinética de um sistema de elétrons não interagentes. O sistema de elétrons não interagentes, que aqui chamaremos de sistema de referência, é mais fácil de calcular devido à energia cinética total do sistema ser simplesmente a soma da energia cinética de cada elétron individualmente. Desta forma, mapeamos o sistema de elétrons interagentes em um sistema de elétrons não-interagentes [29]. A densidade eletrônica do estado fundamental do sistema de referência $\rho(\mathbf{r})$ é a mesma obtida por um sistema de muitos corpos interagentes e é dada por

$$
\rho(\mathbf{r})=\sum_{i}^{N} f_{i}\left|\phi_{i}(\mathbf{r})\right|^{2},
$$

onde $f_{i}$ são os estados ocupados do elétron e $\phi_{i}(\mathbf{r})$ são orbitais de uma partícula chamados de orbitais de Kohn-Sham (KS) e é a solução da equação de Schrödinger de um elétron

$$
\hat{H}_{K S} \phi_{i}(\mathbf{r})=\varepsilon_{i} \phi_{i}(\mathbf{r})
$$

onde $\hat{H}_{K S}$ é a Hamiltoniana de um elétron no esquema de KS

$$
\hat{H}_{K S}=-\frac{\hbar^{2}}{2 m} \nabla^{2}+v_{R}(\mathbf{r})
$$

onde $v_{R}(\mathbf{r})$ é o potencial de referência (potencial de KS) e $m$ a massa do elétron.

Considerando $T_{R}[\rho]$ como energia cinética dos elétrons não interagentes do sistema de referência, podemos reescrever o funcional universal dentro do formalismo de KS da seguinte forma

$$
F[\rho(\mathbf{r})]=T_{R}[\rho]+\frac{1}{2} \iint \frac{\rho(\mathbf{r}) \rho\left(\mathbf{r}^{\prime}\right)}{\left|\mathbf{r}-\mathbf{r}^{\prime}\right|} d \mathbf{r} d \mathbf{r}^{\prime}+\tilde{E}_{X C}[\rho]
$$

onde o termo $\tilde{E}_{X C}[\rho]$ se refere a energia de troca e correlação no formalismo de 
KS.

Substituindo a expressão dada em (2.13) para $F$ no funcional da energia total (2.9) obtemos o funcional da energia de KS

$$
E_{K S}[\rho]=T_{R}[\rho]+\int \rho(\mathbf{r}) V_{e x t}(\mathbf{r}) d \mathbf{r}+\frac{1}{2} \iint \frac{\rho(\mathbf{r}) \rho\left(\mathbf{r}^{\prime}\right)}{\left|\mathbf{r}-\mathbf{r}^{\prime}\right|} d \mathbf{r} d \mathbf{r}^{\prime}+\tilde{E}_{X C}[\rho]
$$

O potencial de KS assegura que a densidade eletrônica do sistema de referência no estado fundamental é a mesma do sistema de elétrons não interagentes. Obtemos este potencial através da minimização do funcional de KS em relação a densidade. Usando o cálculo variacional [30, 25] temos

$$
V_{K S}(\mathbf{r})=V_{C}(\mathbf{r})+V_{X C}[\rho(\mathbf{r})]+V_{e x t}(\mathbf{r})
$$

onde

$$
V_{x c}[\rho(\mathbf{r})]=\frac{\delta \tilde{E}_{X C}}{\delta \rho(\mathbf{r})}
$$

Toda a ignorância sobre o problema de muitos corpos está inserida no termo $\tilde{E}_{X C}[\rho]$. Necessitamos de aproximações para o termo de troca e correlação para resolver as equações de KS. Apesar de conseguirmos calcular o termo de troca [30], o termo de correlação ainda é desconhecido.

Diversas abordagens são encontrados na literatura para a construção da melhor aproximação para o funcional $\tilde{E}_{X C}[\rho]$. A aproximação da Densidade Local (LDA - Local Density Approximation) é ainda a mais utilizada para tratar deste problema. A idéia principal é considerar um sistema eletrônico não homogêneo e o tratar de forma localmente homogênea e utilizar o termo de troca e correlação correspondente ao sistema homogêneo. O termo de correlação do sistema de gás de elétrons homogêneo tem aproximações muito boas e cálculos exatos de dinâmica quântica de Monte Carlo [31]. A LDA, apesar de ser uma aproximação muito 
boa, apresenta falhas [25] e diversos métodos foram propostos para melhorar a aproximação do termo $\tilde{E}_{X C}[\rho]$. Neste trabalho, utilizamos a aproximação conhecida como expansão dos gradientes generalizados (GGA - Generalized Gradient Approximation) que corrige os efeitos não-homogêneos do LDA com a inclusão de termos de gradiente e derivadas de ordem superiores da densidade [32].

\subsection{Dinâmica Molecular de Primeiros Princípios de Car-Parrinello}

A dinâmica molecular ab initio descreve o sistema a partir de cálculos de primeiros princípios. As forças que interagem na dinâmica são obtidas do estado instantâneo do sistema, onde a geometria do sistema é resolvida em $t_{0}$ e após um deslocamento temporal $\delta\left(t_{0} \rightarrow t_{1}\right)$ calcula-se novamente a configuração do sistema. Aproximações de dinâmica molecular de primeiros princípios auto-consistentes são usados no DFT, dentro do esquema de Kohn-Sham, para resolver a dinâmica da estrutura eletrônica no estado fundamental. Neste caso temos que o funcional total da energia $E_{K S}$ é dado por

$$
\begin{aligned}
E_{K S}[\rho] & =T_{R}[\rho]+\frac{1}{2} \iint \frac{\rho(\mathbf{r}) \rho\left(\mathbf{r}^{\prime}\right)}{\left|\mathbf{r}-\mathbf{r}^{\prime}\right|} d \mathbf{r} d \mathbf{r}^{\prime}+\tilde{E}_{X C}[\rho] \\
& +\sum_{I=1}^{P} \int \rho(\mathbf{r}) V_{\text {ext }}\left(\mathbf{r}-\mathbf{R}_{I}\right) d \mathbf{r}+\frac{1}{2} \sum_{I=1}^{P} \sum_{J \neq I}^{P} \frac{Z_{I} Z_{J}}{\left|\mathbf{R}_{I}-\mathbf{R}_{J}\right|}
\end{aligned}
$$

As forças nos íons são obtidos por derivação simples

$$
\begin{aligned}
\mathbf{F}_{I} & =-\frac{\partial E_{K S}[\rho](\mathbf{R})}{\partial \mathbf{R}_{I}} \\
& =-\int \rho(\mathbf{r}) \frac{\partial V_{e x t}\left(\mathbf{r}-\mathbf{R}_{I}\right)}{\partial \mathbf{R}_{I}} d \mathbf{r}+\sum_{J \neq I}^{P} Z_{I} Z_{J} \frac{\mathbf{R}_{I}-\mathbf{R}_{J}}{\left|\mathbf{R}_{I}-\mathbf{R}_{J}\right|^{3}}
\end{aligned}
$$


Em 1985 R. Car e M. Parrinello [23] desenvolveram um método ab initio de dinâmica molecular no qual integra as equações de movimento dos íons mantendo uma dinâmica suave das funções de onda. Esta metodologia utiliza a DFT, no esquema de KS, para descrever a estrutura eletrônica instantânea e as equações de movimento de Newton para descrever a evolução das variáveis eletrônicas e nucleares. A idéia é minimizar o custo computacional eliminando os cálculos de auto-consistência eletrônica em cada passo da dinâmica [33], isto é, não é necessário a diagonalização da matriz Hamiltoniana da estrutura eletrônica em cada evolução temporal da dinâmica do sistema. O método de Car-Parrinello introduz os graus de liberdade dos elétrons como variáveis dinâmicas fictícias, escrevendo uma Lagrangeana que leva a um acoplamento das equações de movimento dos íons e dos elétrons.

\subsubsection{A Lagrangeana e as Equações de Movimento de Car- Parrinello}

Na dinâmica molecular de Car-Parrinello as variáveis eletrônicas e nucleares são descritas através da Lagrangeana fictícia:

$$
\begin{aligned}
\mathcal{L}_{C P} & =\frac{1}{2} \sum_{I=1}^{P} M_{I} \dot{\mathbf{R}}_{I}^{2}+m_{\phi} \sum_{i=1}^{N} f_{i} \int\left|\phi_{i}(\mathbf{r})\right|^{2} d \mathbf{r} \\
& -E_{K S}\left[\phi_{i}(\mathbf{r})\right](\mathbf{R})+\sum_{i=1}^{N} f_{i} \sum_{j=1}^{N} \Lambda_{i j}\left(\int \phi_{i}^{*}(\mathbf{r}) \phi_{j}(\mathbf{r}) d \mathbf{r}-\delta_{i j}\right)
\end{aligned}
$$

O primeiro termo é energia cinética dos núcleos e o terceiro termo é o potencial de primeiros princípios representado pelo funcional de energia de KS. N é o número de elétrons e os coeficientes $f_{i}$ são os estados de ocupação associados aos orbitais dinâmicos de Kohn-Sham (ODKS) $\phi_{i}(\mathbf{r})$ [25]. O segundo termo é a energia cinética fictícia das funções de onda eletrônicas e não possui relação com a cinética quântica 
real e $m_{\phi}$ é a massa fictícia. O último termo da equação 2.19 é a restrição de ortonormalidade para as funções de onda, onde os multiplicadores de Lagrange $\Lambda_{i j}$ determinam esta condição.

As equações de movimento de Car-Parrinello obtidas através da $\mathcal{L}_{C P}$ são:

$$
\begin{gathered}
M_{I} \ddot{\mathbf{R}}_{\mathbf{I}}=-\frac{\partial E_{K S}\left[\rho_{i}(\mathbf{r})\right](\mathbf{R})}{\partial \mathbf{R}_{I}} \\
m_{\phi}\left|\ddot{\phi}_{i}\right\rangle=-\frac{1}{f_{i}}\left[-\frac{\delta E_{K S}\left[\phi_{i}(\mathbf{r})\right](\mathbf{R})}{\delta \phi_{i}^{*}(r)}\right]+\sum_{j}^{N} \Lambda_{i j} \phi_{j}(\mathbf{r}, t) \\
=-\hat{H}_{K S}\left|\phi_{i}\right\rangle+\frac{1}{f_{i}} \sum_{j}\left|\phi_{j}\right\rangle \Lambda_{i j}
\end{gathered}
$$

O acoplamento das equações 2.20 e 2.21 descreve a evolução temporal simultânea dos sistemas nucleares e eletrônicos. Porém, vale ressaltar que a dinâmica fictícia gerada pela equação (2.21) é em geral diferente da evolução dos orbitais de KS no estado fundamental. Devemos considerar como boa aproximação das trajetórias físicas somente os ODKS $\left(\phi_{i}\right)$ obtidos das equações de movimento de CarParrinello que permanecem próximos das soluções auto-consistentes das equações de KS.

\subsubsection{Desacoplamento Adiabático e Conservação da Energia}

Em uma dinâmica molecular, a energia total do sistema necessariamente tem que permanecer constante durante toda a evolução temporal do sistema. A $\mathcal{L}_{C P}$ dada pela equação 2.19 nos dá a seguinte relação para energia constante:

$$
\begin{aligned}
E_{\text {cons }} & =\frac{1}{2} \sum_{I} M_{I} \dot{\mathbf{R}}_{I}^{2}+\sum_{i} m_{\phi} f_{i}\left\langle\dot{\phi}_{i} \mid \dot{\phi}_{i}\right\rangle+E\left[\phi_{i}(\mathbf{R})\right]\left(\mathbf{R}_{I}\right) \\
& =T_{n}+T_{\phi}+E_{K S} .
\end{aligned}
$$


A equação (2.22) introduz uma temperatura física relacionada à energia cinética dos núcleos $\left(T_{n}\right)$ e uma temperatura fictícia para as funções de onda (energia cinética fictícia $T_{\phi}$ ). Os núcleos vão esquentando à medida que evoluem no tempo enquanto as funções de onda vão resfriando ao se aproximar do estado fundamental. Para a aproximação de Car-Parrinello ser bem sucedida, os dois subsistemas, nuclear e eletrônico, precisam estar adiabaticamente desacoplados impedindo que a energia flua do núcleo quente para a função de onda resfriada durante a simulação.

Para o sistema ficar desacoplado adiabaticamente é necessário que o espectro vibracional nuclear e eletrônico estejam bem separados. Em sistemas com grande diferença (gap) entre o maior nível de energia eletrônico ocupado (HOMO - Highest Occupied Molecular Orbital e o menor nível de energia desocupado (LUMO - Lowest Unoccupied Molecular Orbital) a CPMD fornece uma $E_{\text {cons }}$ "bem comportada" e uma energia física $\left(E_{f i s}=T_{n}+E\right)$ com baixas oscilações em torno do seu valor médio. Estas baixas oscilações são provocadas pela energia cinética fictícia $T_{\phi}$ e a $E_{f i s}$ deve ser necessariamente equivalente a $E_{\text {cons }}$. No entanto, para sistemas em que a diferença entre o HOMO e o LUMO tende a zero $\left(\Delta E_{\text {gap }} \rightarrow 0\right)$ a aproximação de CP deixa de ser válido. Uma possível solução seria acoplar termostatos nos dois subsistemas para compensar o fluxo de energia dos núcleos para as funções de ondas e assim ter um controle das temperaturas destes sistemas [34].

\subsection{Bases de Ondas Planas}

O uso de ondas planas (OPs) para a expansão das funções de onda eletrônica é muito comum no estudo da matéria condensada. Isto se deve ao fato de as OPs serem uma solução da equação de Schrödinger para um gás de elétrons não interagentes sob ação de um potencial externo constante. Porém próximo ao núcleo atômico, o potencial externo não é constante e a solução da equação de Schrödinger 
é escrito como uma combinação linear de OPs. As ondas planas são ortonormais por construção, sua matriz da Hamiltoniana possui solução analítica e é relativamente simples de trabalhar. Não são bases locais, não se deslocam com os átomos e representam todas a regiões do espaço com a mesma precisão.

A expressão geral para a expansão das funções de onda de KS, em termos de uma combinação de ondas planas, é dada por:

$$
\phi_{i}(\mathbf{r})=\frac{e^{i \mathbf{k} . \mathbf{r}}}{\sqrt{\Omega}} \sum_{\mathbf{G}=0}^{\infty} C_{i \mathbf{k}}(\mathbf{G}) e^{i \mathbf{G} \cdot \mathbf{r}}=\sum_{\mathbf{G}=0}^{\infty} C_{i \mathbf{k}}(\mathbf{G}) \frac{1}{\sqrt{\Omega}} e^{i(\mathbf{k}+\mathbf{G}) \cdot \mathbf{r}}
$$

onde $\mathbf{G}$ são os vetores da rede recíproca, $\mathbf{k}$ os vetores da primeira zona de Brillouin (ZB) e $\Omega$ é o volume da célula periódica.

Os vetores $\mathbf{G}$ permitem a expansão das OPs para os vetores da rede recíproca e um infinito número destes vetores são necessários para uma base completa. Porém, os coeficientes de Fourier $C_{i \mathbf{k}}(\mathbf{G})$ das funções de onda decrescem com o aumento de $|\mathbf{k}+\mathbf{G}|$, isto é, a convergência das propriedades físicas em relação ao tamanho da base é muito simples. Podemos truncar a expansão das OPs em um número finito de termos e estabelecer uma energia de corte $\left(E_{c u t}\right)$ para as energias cinéticas de todas as ondas do sistema:

$$
\frac{\hbar^{2}}{2 m}|\mathbf{k}+\mathbf{G}|^{2}<E_{c u t}
$$

Por razões históricas é mais comum especificar a energia de corte em Rydberg (Ry) ao invés de unidades atômicas, onde $1 \mathrm{Ry}=13,6 \mathrm{eV}=0,5$ a.u ou Hartree. A expressão da densidade eletrônica para a base de ondas planas é dada por

$$
\rho(\mathbf{r})=\sum_{\mathbf{k}} \omega_{\mathbf{k}}\left|\psi_{\mathbf{k}}(\mathbf{r})\right|^{2}
$$

onde $\omega_{\mathbf{k}}$ são os fatores de peso que dependem da simetria da célula unitária. 
Aplicando a equação (2.25) para a densidade eletrônica de KS (equação 2.10) temos

$$
\rho(\mathbf{r})=\sum_{\mathbf{k} \in Z B} \omega_{\mathbf{k}} \sum_{i=1}^{N_{k}} f_{i}\left|\phi_{i}(\mathbf{r})\right|^{2}
$$

onde $N_{\mathbf{k}}$ é o número de estados eletrônicos ocupados em cada ponto $\mathbf{k}$ e $f_{i}$ é o estado ocupado da banda $i$. Se o sistema está isolado, então $f_{i}=1$ e $N_{\mathbf{k}}=N$. Se o sistema possui degenerescência de spin, a soma dada em (2.26) carrega o termo $\frac{N}{2}$ e multiplicado por um fator de degenerescência $f_{i}=2$.

\subsection{O Método PAW}

O método Projector Augmented Wave (PAW) desenvolvido por Blöchl em 1994 [24] tem como motivação solucionar a inabilidade das ondas planas de descrever, de forma eficiente, o comportamento das rápidas oscilações das funções de onda próximas ao núcleo. O estudo do comportamento oscilatório nas regiões do núcleo requer um grande número de ondas planas para o descrever corretamente. O método PAW é um método ab initio all-electron, dentro do formalismo da DFT [27] e no esquema de KS [28] e nos fornece informações da função de onda total [35]. Isto é essencial para cálculos de propriedades que dependem da densidade eletrônica próxima do núcleo, como o Gradiente de Campo Elétrico (GCE) ou parâmetros de acoplamento hiperfinos. Os elétrons do núcleo são tratados dentro do método PAW pela aproximação de caroço congelado (frozen-core)[22]. As funções de onda de átomos isolados são os que descrevem os elétrons não envolvidos em ligações químicas. Estas funções de onda são fixados de tal forma que não se misturam com as funções de onda dos elétrons da camada de valência. O método PAW se mostra muito eficiente para sistemas metal-orgânicos e por isso optamos por utilizar este método nos nossos cálculos [36]. Descreveremos a seguir, de forma resumida, a construção das funções de onda das bases de ondas planas, obtenção de valores 
esperados de operadores e expressão para o cálculo da energia total utilizados no método PAW conforme referência [24].

\subsubsection{Construção das Funções de Onda}

A construção da função de onda $\left|\psi_{i}\right\rangle$ de todos os elétrons é a essência do método PAW. Podemos decompor a função de onda em três partes:

$$
\left|\psi_{i}\right\rangle=\underbrace{\left|\tilde{\psi}_{i}\right\rangle}_{\text {OndasPlanas }}+\underbrace{\sum_{q}\left|\phi_{q}\right\rangle\left\langle\tilde{p}_{q} \mid \tilde{\psi}_{i}\right\rangle-\sum_{q}\left|\tilde{\phi}_{q}\right\rangle\left\langle\tilde{p}_{q} \mid \tilde{\psi}_{i}\right\rangle}_{\text {Augmentation }} .
$$

O termo $\left|\tilde{\psi}_{i}\right\rangle$ é comumente chamado de pseudo função de onda e pode ser extendido por todo o espaço através da expansão das ondas planas (eq. 2.23). As pseudo funções de onda descrevem adequadamente a parte suave das funções de onda longe do núcleo atômico (região intersticial) e as funções augmentation descrevem as propriedades das funções de onda próximas ao núcleo. As funções augmentation são construídos a partir da combinação linear das funções dos átomos centrados (funções de onda all-electron (AE) parciais $\left|\phi_{q}\right\rangle$ e pseudo funções de onda $\left|\tilde{\phi}_{q}\right\rangle$ ) e estão localizados dentro das regiões da esfera de augmentation $\Omega_{I}$ em torno de cada átomo [35]. As expansões dos coeficientes são obtidas a partir do produto escalar entre as funções chamadas projetoras, $\left\langle\tilde{p}_{q}\right|$, e as pseudo funções de onda. O termo $q$ se extende aos sítios atômicos $I$, os números quânticos de momentos angulares $l$ e $m$ por sítio $I$ e os números de ondas parciais por momento angular por sítio $n$, isto é, $q=\{I, l, m, n\}$. As funções de ondas parciais $\left|\phi_{q}\right\rangle$ são soluções da equação de Schrödinger para o átomo isolado e são obtidos por uma função radial $\left|\chi_{q}\right\rangle$ multiplicada por harmônicos esféricos $Y_{l, m}$, tal que $\phi_{q}(\mathbf{r})=\chi_{q}(\mathbf{r}) Y_{l, m}(\mathbf{r})$. 


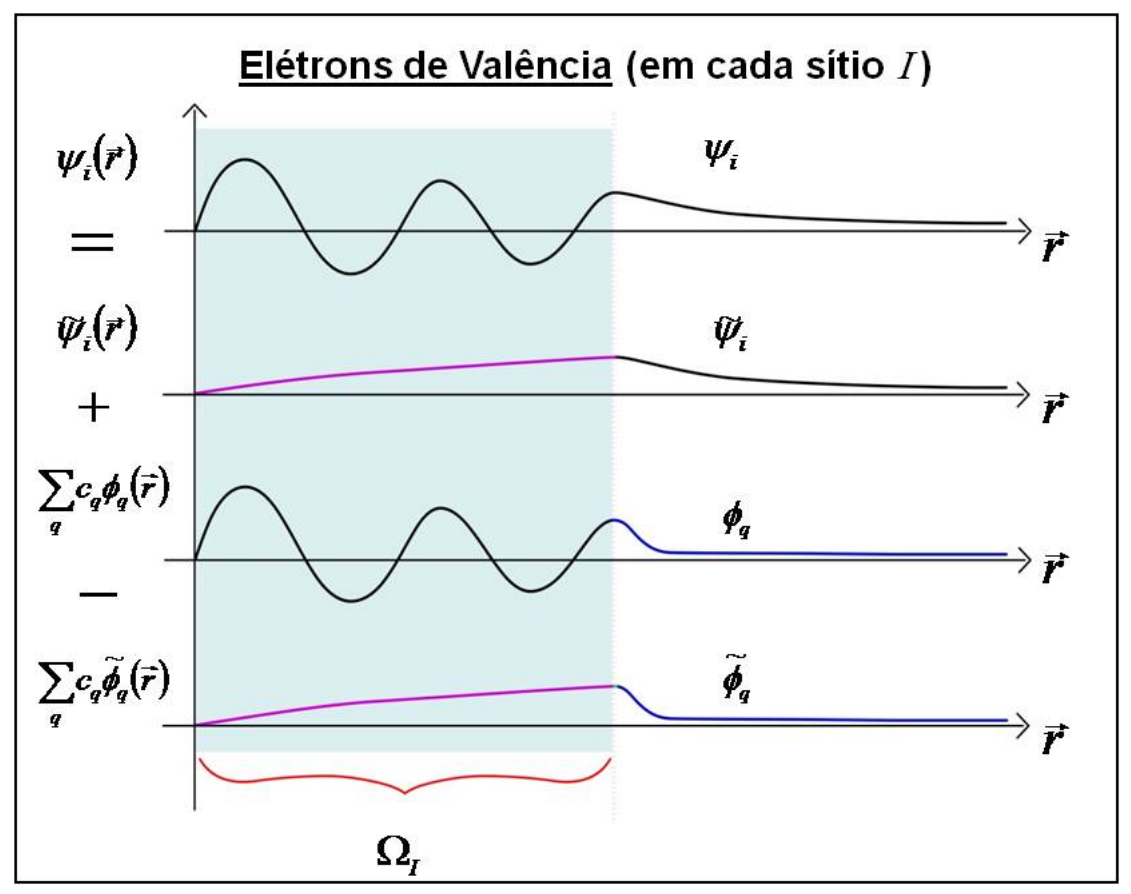

Figura 2.1: Representação esquemática das contribuições da pseudo função de onda,$\left|\tilde{\psi}_{i}\right\rangle$, função de onda parcial, $\left|\phi_{q}\right\rangle$ e pseudo função de onda parcial, $\left|\tilde{\phi}_{q}\right\rangle$, para a função de onda total (AE) no método PAW (eq.2.27). (Figura retirada da referência [35].

Devido à impossibilidade de utilizar uma base completa, isto é, base infinita de ondas planas e ondas parciais, se faz necessário analisar a eq. (2.27) utilizando bases incompletas de ondas parciais [35]. Para um melhor entendimento da eq. (2.27) sugerimos na Figura 2.1 uma representação esquemática para um sítio $I$, quando utilizamos uma base de ondas parciais incompleta. 
Dentro da região de augmentation $\left(\Omega_{I}\right)$ a expansão das pseudo funções de ondas parcias precisam coincidir com a pseudo função de onda e fora de $\Omega_{I}$ a expansão das pseudo funções de onda parciais devem coincidir com a expansão da função de onda AE parcial,

$$
\sum_{q}\left|\tilde{\phi}_{q}\right\rangle\left\langle\tilde{p}_{q} \mid \tilde{\psi}_{i}\right\rangle=\left|\tilde{\psi}_{i}\right\rangle \quad \text { dentro de } \Omega_{I}
$$

e

$$
\sum_{q}\left|\tilde{\phi}_{q}\right\rangle\left\langle\tilde{p}_{q} \mid \tilde{\psi}_{i}\right\rangle=\sum_{q}\left|\tilde{\phi}_{i}\right\rangle\left\langle\tilde{p}_{q} \mid \tilde{\psi}_{i}\right\rangle \quad \text { fora de } \Omega_{I}
$$

A parte de augmentation some fora de $\Omega_{I}$ e a função de onda total AE $\left|\psi_{i}\right\rangle$ é representado nesta região por $\left|\tilde{\psi}_{i}\right\rangle$. Dentro da região de $\Omega_{I},\left|\psi_{i}\right\rangle$ é descrito pelas funções de ondas parciais AE:

$$
\left|\psi_{i}\right\rangle=\sum_{q}\left|\tilde{\phi}_{i}\right\rangle\left\langle\tilde{p}_{q} \mid \tilde{\psi}_{i}\right\rangle \quad \text { dentro de } \Omega_{I}
$$

$\mathrm{e}$

$$
\left|\psi_{i}\right\rangle=\left|\tilde{\psi}_{i}\right\rangle \quad \text { fora de } \Omega_{I}
$$

A eq. 2.27 é válida para os elétrons de valência. Os elétrons de caroço (que pertencem as camadas mais internas do átomo) são tratados dentro da aproximação de caroço congelado de tal forma que a densidade dos elétrons de caroço é mantida constante em relação ao átomo isolado corresponde.

\subsubsection{Operador de Transformação e Valores Esperados}

A função de onda total dada pela eq. 2.27 pode ser formalizada pela transformação linear entre $\left|\psi_{i}\right\rangle$ e $\left|\tilde{\psi}_{i}\right\rangle$

$$
T=1+\sum_{q}\left[\left|\phi_{q}\right\rangle-\left|\tilde{\phi}_{q}\right\rangle\right]\left\langle\tilde{p}_{q}\right|
$$


A função de onda $\mathrm{AE}\left|\psi_{i}\right\rangle$ é obtido da pseudo função de onda $\left|\tilde{\psi}_{i}\right\rangle$ aplicando a transformação

$$
\left|\psi_{i}\right\rangle=T\left|\tilde{\psi}_{i}\right\rangle=\left|\tilde{\psi}_{i}\right\rangle+\sum_{q}\left[\left|\phi_{q}\right\rangle-\left|\tilde{\phi}_{q}\right\rangle\right]\left\langle\tilde{p}_{q} \mid \tilde{\psi}_{i}\right\rangle
$$

que é idêntica a eq. 2.27. Usando as relações das transformações para as funções de onda AE,

$$
\begin{aligned}
\left|\psi_{i}\right\rangle & =T\left|\tilde{\psi}_{i}\right\rangle \\
\left\langle\psi_{i}\right| & =\left\langle\tilde{\psi}_{i}\right| T^{\dagger}
\end{aligned}
$$

e dessa forma podemos escrever o valor esperado para um operador arbitrário $A$, em relação a função de onda total AE da seguinte forma

$$
\langle A\rangle=\sum_{i} f_{i}\left\langle\psi_{i}|A| \psi_{i}\right\rangle=\sum_{i} f_{i}\left\langle\tilde{\psi}_{i}\left|T^{\dagger} A T\right| \tilde{\psi}_{i}\right\rangle=\sum_{i} f_{i}\left\langle\tilde{\psi}_{i}|\tilde{A}| \tilde{\psi}_{i}\right\rangle
$$

Assim, podemos obter o valor esperado de $A$ da pseudo função de onda, transformando na função de onda AE e usando o operador original $A$ ou transformando o operador em um operador auxiliar, $\tilde{A}=T^{\dagger} A T$, e calcular o valor esperado do operador auxiliar com respeito a pseudo função de onda.

O operador auxiliar $\tilde{A}$, devido as relações da transformação, pode ser escrito da seguinte forma:

$$
\tilde{A}=A+\sum_{q, l}\left|\tilde{p}_{q}\right\rangle\left[\left\langle\phi_{q}|A| \phi_{l}\right\rangle-\left\langle\tilde{\phi}_{q}|A| \tilde{\phi}_{l}\right\rangle\right]\left\langle\tilde{p}_{l}\right|=A+A^{1}-\tilde{A}^{1}
$$

onde os termos sobrescritos com (1) tem origem no augmentation e estão definidos apenas na região $\Omega_{I}$ (para cada valor de I) [35]. 
Se incluirmos os elétrons da região do caroço teremos:

$$
A=\tilde{A}+A^{1}-\tilde{A}^{1}+A^{c}
$$

onde obtemos a seguinte expressão geral do cálculo dos valores esperados no método PAW

$$
\begin{aligned}
\langle A\rangle & =\sum_{i} f_{i}\left(\left\langle\tilde{\psi}_{i}|A| \tilde{\psi}_{i}\right\rangle+\sum_{q, l}\left\langle\tilde{\psi}_{i} \mid \tilde{p}_{q}\right\rangle\left[\left\langle\phi_{q}|A| \phi_{l}\right\rangle-\left\langle\tilde{\phi}_{q}|A| \tilde{\phi}_{l}\right\rangle\right]\left\langle\tilde{p}_{l} \mid \tilde{\psi}_{i}\right\rangle\right) \\
& +\sum_{i=1}^{N_{c}}\left\langle\psi_{i}^{c}|A| \psi_{i}^{c}\right\rangle
\end{aligned}
$$

Os valores obtidos, pelo método PAW, para as variáveis observáveis se dá pela equação (2.38). Desta forma, os resultados do presente trabalho para a densidade de carga e o Gradiente de Campo Elétrico no Núcleo (GCE), são obtidos utilizando a equação (2.38).

\section{Densidade}

A densidade eletrônica é o valor esperado obtido do operador projeção do espaço real, $|r\rangle\langle r|$,

$$
\rho(\mathbf{r})=\sum_{i} f_{i}\left|\psi_{i}(\mathbf{r})\right|^{2}=\sum_{i} f_{i}\left\langle\psi_{i} \mid r\right\rangle\left\langle r \mid \psi_{i}\right\rangle
$$

Aplicando a densidade na equação (2.36) obtemos o valor de $\rho(\mathbf{r})$ como valor esperado do operador auxiliar correspondente em relação as pseudo funções de onda $\left|\tilde{\psi}_{i}\right\rangle$, particionado em três componentes somado a densidade do caroço:

$$
\begin{aligned}
& \rho(\mathbf{r})=\tilde{\rho}(\mathbf{r})+\rho^{1}(\mathbf{r})-\rho^{-1}(\mathbf{r})+\rho^{c}(\mathbf{r}) \\
& \rho(\mathbf{r})=\sum_{i} f_{i}\left\langle\tilde{\psi}_{i} \mid r\right\rangle\left\langle r \mid \tilde{\psi}_{i}\right\rangle
\end{aligned}
$$




$$
\begin{aligned}
& +\sum_{i, q, l} f_{i}\left\langle\tilde{\psi}_{i} \mid \tilde{p}_{q}\right\rangle\left\langle\phi_{q} \mid r\right\rangle\left\langle r \mid \phi_{l}\right\rangle\left\langle\tilde{p}_{l} \mid \tilde{\psi}_{i}\right\rangle \\
& -\sum_{i, q, l} f_{i}\left\langle\tilde{\psi}_{i} \mid \tilde{p}_{q}\right\rangle\left\langle\tilde{\phi}_{q} \mid r\right\rangle\left\langle r \mid \tilde{\phi}_{l}\right\rangle\left\langle\tilde{p}_{l} \mid \tilde{\psi}_{i}\right\rangle \\
& +\sum_{i=1}^{N_{c}}\left\langle\psi_{i}^{c} \mid r\right\rangle\left\langle r \mid \psi_{i}^{c}\right\rangle
\end{aligned}
$$

$\tilde{\rho}(\mathbf{r})$ é chamada de pseudo densidade e é uma função suave expandida em ondas planas. $\rho^{1}(\mathbf{r})$ e $\rho^{-1}(\mathbf{r})$ são, repectivamente, a densidade e a pseudo densidade na região de augmentation e são definidas apenas dentro de $\Omega_{I}$. E $\rho^{c}(\mathbf{r})$ é a densidade eletrônica da região de caroço.

\section{Energia Total}

Reescrevendo a energia funcional de KS dada pela equação 2.14 com todas as interações Coulombianas (elétron-elétron, elétron-núcleo e núcleo-núcleo) em um único termo temos:

$$
\begin{aligned}
E\left[\left\{\psi_{i}\right\},\left\{\mathbf{R}_{I}\right\}\right] & =\sum_{i} f_{i}\left\langle\psi_{i}\left|-\frac{1}{2} \nabla^{2}\right| \psi_{i}\right\rangle \\
& +\frac{1}{2} \int d \mathbf{r} \int d \mathbf{r}^{\prime} \frac{\left(\rho(\mathbf{r})+\rho^{Z}(\mathbf{r})\right)\left(\rho\left(\mathbf{r}^{\prime}\right)+\rho^{Z}\left(\mathbf{r}^{\prime}\right)\right)}{\left|\mathbf{r}-\mathbf{r}^{\prime}\right|} \\
& +\int d \mathbf{r} \rho(\mathbf{r}) \varepsilon_{X C}[\rho(\mathbf{r})]
\end{aligned}
$$

onde as cargas pontuais nucleares são expressas como $\rho^{Z}\left(\mathbf{r}=\sum_{I}-Z_{I} \delta\left(\mathbf{r}-\mathbf{R}_{I}\right)\right.$ e $Z_{I}$ é o número atômico. Dentro do método PAW podemos decompor a energia total em três partes,

$$
E=\tilde{E}+E^{1}-\tilde{E}^{1}
$$

onde

$$
\tilde{E}=\sum_{i} f_{i}\left\langle\tilde{\psi}_{i}\left|-\frac{1}{2} \nabla^{2}\right| \tilde{\psi}_{i}\right\rangle
$$




$$
\begin{aligned}
& +\frac{1}{2} \int d \mathbf{r} \int d \mathbf{r}^{\prime} \frac{(\tilde{\rho}(\mathbf{r})+\hat{\rho}(\mathbf{r}))\left(\tilde{\rho}\left(\mathbf{r}^{\prime}\right)+\hat{\rho}\left(\mathbf{r}^{\prime}\right)\right)}{\left|\mathbf{r}-\mathbf{r}^{\prime}\right|} \\
+ & \int d \mathbf{r} \tilde{\rho}(\mathbf{r}) \bar{v}(\mathbf{r})+\int d \mathbf{r} \tilde{\rho}(\mathbf{r}) \varepsilon_{X C}[\tilde{\rho}(\mathbf{r})] \\
E^{1}= & \sum_{i, q, l} f_{i}\left\langle\tilde{\psi}_{i} \mid \tilde{p}_{q}\right\rangle\left\langle\phi_{q}\left|-\frac{1}{2} \nabla^{2}\right| \phi_{l}\right\rangle\left\langle\tilde{p}_{l} \mid \tilde{\psi}_{i}\right\rangle \\
+ & \frac{1}{2} \int d \mathbf{r} \int d \mathbf{r}^{\prime} \frac{\left(\rho^{1}(\mathbf{r})+\rho^{Z}(\mathbf{r})\right)\left(\rho^{1}\left(\mathbf{r}^{\prime}\right)+\rho^{Z}\left(\mathbf{r}^{\prime}\right)\right)}{\left|\mathbf{r}-\mathbf{r}^{\prime}\right|} \\
+ & \int d \mathbf{r} \rho^{1}(\mathbf{r}) \varepsilon_{X C}\left[\rho^{1}(\mathbf{r})\right] \\
\tilde{E}^{1} & =\sum_{i, q, l} f_{i}\left\langle\tilde{\psi}_{i} \mid \tilde{p}_{q}\right\rangle\left\langle\tilde{\phi}_{q}\left|-\frac{1}{2} \nabla^{2}\right| \tilde{\phi}_{l}\right\rangle\left\langle\tilde{p}_{l} \mid \tilde{\psi}_{i}\right\rangle \\
& +\frac{1}{2} \int d \mathbf{r} \int d \mathbf{r}^{\prime} \frac{\left(\tilde{\rho}^{1}(\mathbf{r})+\hat{\rho}(\mathbf{r})\right)\left(\tilde{\rho}^{1}\left(\mathbf{r}^{\prime}\right)+\hat{\rho}\left(\mathbf{r}^{\prime}\right)\right)}{\left|\mathbf{r}-\mathbf{r}^{\prime}\right|} \\
+ & \int d \mathbf{r} \tilde{\rho}^{1}(\mathbf{r}) \bar{v}(\mathbf{r})+\int d \mathbf{r} \tilde{\rho}^{1}(\mathbf{r}) \varepsilon_{X C}\left[\tilde{\rho}^{1}(\mathbf{r})\right]
\end{aligned}
$$

Duas quantidades foram introduzidas nas equações $(2.44,2.45,2.46)$ : o potencial $\bar{v}(\mathbf{r})$ e a densidade de carga de "compensação" $\hat{\rho}(\mathbf{r})$. O potencial $\bar{v}(\mathbf{r})$ é usado para minimizar os erros que surgem com o truncamento da expansão de ondas planas parciais incompletas. Este potencial está localizado dentro da região de argumentation, entretanto, sua forma pode ser escolhida arbitrariamente. Isto ocorre devido a pseudo densidade, $\tilde{\rho}(\mathbf{r})$, e a pseudo densidade local,$\tilde{\rho}^{1}(\mathbf{r})$, serem iguais dentro da região de augmentation $\left(\Omega_{I}\right)$ onde não ocorre a contribuição do potencial $\bar{v}(\mathbf{r})$ para energia total [24].

A densidade de carga de "compensação", $\hat{\rho}(\mathbf{r})$, é utilizada para cancelar as interações elétrostáticas entre a densidade de carga local dentro da região $\Omega_{I}$ e a densidade de carga fora da região de augmentation, isto é, $\left[\rho^{1}(\mathbf{r})+\rho^{Z}(\mathbf{r})\right]-\left[\tilde{\rho}^{1}(\mathbf{r}+\hat{\rho}(\mathbf{r})]\right.$ $[24]$. 


\section{Capítulo 3}

\section{Gradiente de Campo Elétrico no}

\section{Núcleo}

\subsection{Interações Hiperfinas}

As interações hiperfinas são interações entre as propriedades eletromagnéticas (momento magnético e momento elétrico) do núcleo atômico e os campos magnético e elétrico externos ao núcleo. Estes campos são gerados por elétrons e por outros núcleos próximos ao núcleo atômico observado. Estas interações foram descobertas da espectroscopia atômica e , desde então, têm sido extensivamente estudadas [14]. A detecção das interações hiperfinas é o objetivo de muitos métodos experimentais como espectroscopia Mössbauer, Ressonância Paramagnética Eletrônica (EPR), Time Differential Perturbed Angular Correlation (TDPAC) e Ressonância Magnética Nuclear (NMR)[37, 38]. As interações do tipo dipolar magnética e quadrupolar elétrica são as mais importantes e dominantes [39].

O estudo das interações hiperfinas permite obter informações detalhadas sobre o sítio no qual o núcleo atômico está inserido. Em particular, a interação hiperfina elétrica Gradiente de Campo Elétrico (GCE) é uma importante ferramenta para 
entender em detalhes a densidade eletrônica do sítio. Informações sobre o GCE de um núcleo atômico também auxiliam na análise do ambiente químico local [40].

\subsection{As Interações Hiperfinas Elétricas}

Em um sólido, molécula ou aglomerado de moléculas, o núcleo está rodeado por cargas elétricas que produzem um potencial eletrostático $\Phi(\mathbf{r})$. Analisando, do ponto de vista clássico, as interações entre o núcleo e a densidade eletrônica juntamente com o potencial dos demais íons, a energia de interação entre distribuição de cargas do núcleo $\rho(\mathbf{r})$ e o potencial externo $\Phi(\mathbf{r})$ é dado por:

$$
E_{\text {electr }}=\int \rho(\mathbf{r}) \Phi(\mathbf{r}) d^{3} r
$$

onde,

$$
\int \rho(\mathbf{r}) d^{3} r=Z e
$$

é a carga do núcleo.

Devido a complexidade em estudar o potencial externo $\Phi(\mathbf{r})$, é conveniente expandir o potencial elétrico em séries de Taylor em torno de $\mathbf{r}=0$. Logo, podemos reescrever o potencial elétrico na forma:

$$
\Phi(\mathbf{r})=\Phi_{0}+\mathbf{r} \nabla \Phi(0)+\frac{1}{2} \sum_{i} \sum_{j} x_{i} x_{j} \frac{\partial^{2} \Phi_{0}}{\partial x_{i} \partial x_{j}}+\ldots
$$

onde $x_{i}$ e $x_{j}$ são coordenadas cartesianas.

Com esta expansão obtemos para energia de interação,

$$
E_{\text {electr }}=E^{(0)}+E^{(1)}+E^{(2)}+\ldots
$$


onde,

$$
\begin{gathered}
E^{(0)}=\Phi_{0} \int \rho(\mathbf{r}) d^{3} r \\
E^{(1)}=\sum_{i=1}^{3}\left(\frac{\partial \Phi}{\partial x_{i}}\right)_{0} \rho(\mathbf{r}) x_{i} d^{3} r \\
E^{(2)}=\frac{1}{2} \sum_{i, j}\left(\frac{\partial^{2} \Phi}{\partial x_{i} \partial x_{j}}\right)_{0} \int \rho(\mathbf{r}) x_{i} x_{j} d^{3} r .
\end{gathered}
$$

Desde que tenhamos $\Phi_{0}$ como o potencial na origem $(\mathbf{r}=0)$, a equação 3.5 é a energia de Coulomb de uma distribuição de cargas em um ponto externo em relação ao núcleo. A equação 3.6 representa a interação de dipolo elétrico entre o campo elétrico $(\mathbf{E}=-\nabla \Phi)$ na origem e o momento de dipolo elétrico da distribuição de carga no núcleo [14]. Pela mecânica quântica se espera que o valor do momento de dipolo elétrico nuclear seja 0 . Logo, o valor de $E^{(1)}$ é zero, desde que os estados nucleares tenham paridade definida. A equação 3.7 representa a interação entre o momento de quadrupolo elétrico nuclear e o GCE no Núcleo.

A relação

$$
\left(\frac{\partial^{2} \Phi}{\partial x_{i} \partial x_{j}}\right)_{0}=\Phi_{x_{i} x_{j}}
$$

dá origem a uma matriz simétrica $3 X 3$ que pode ser diagonalizada por rotação do sistema de coordenadas [14]. Após a diagonalização obtemos a seguinte expressão

$$
E^{(2)}=\frac{1}{6} \sum_{i} \Phi_{i i} \int \rho(\mathbf{r}) r^{2} d^{3} r+\frac{1}{2} \sum_{i} \Phi_{i i} \int \rho(\mathbf{r})\left(x_{i}^{2}-\frac{r^{2}}{3}\right) d^{3} r
$$

onde temos que $r^{2}=\sum_{i} x_{i}^{2}$.

O primeiro termo da equação 3.9 é o termo de monopolo $E_{C}$ que depende somente do raio nuclear quadrático médio. Este termo dá origem a um deslocamento mas não um desdobramento dos níveis de energia. 
O segundo termo da equação 3.9 é o termo que descreve a interação quadrupolar elétrica e podemos reescrevê-lo da seguinte forma

$$
E_{Q}=\frac{e}{6} \sum_{i} \Phi_{i i} Q_{i i}
$$

onde

$$
Q_{i i}=\frac{1}{e} \int \rho(\mathbf{r})\left(3 x_{i}^{2}-r^{2}\right) d^{3} r
$$

$Q_{i i}$ é o Momento de Quadrupolo Elétrico.

Analisando o termo $\Phi_{i i}$ da equação 3.10 definimos

$$
\Phi_{i i}=V_{i i}+\frac{1}{3}(\Delta \Phi)
$$

em que $V_{i i}$ é uma matriz de traço nulo. Substituindo a equação 3.12 na equação 3.10 temos que o termo $\frac{1}{3}(\Delta \Phi)$ não contribui para $E_{Q}$ devido $\sum Q_{i i}=0$. Logo, podemos reescrever a equação 3.10

$$
E_{Q}=\frac{e}{6} \sum_{i} V_{i i} Q_{i i}
$$

onde $V_{i i}$ é definido como tensor de GCE.

Somente as cargas que estão fora do sítio do núcleo contribuem com o $V_{i i}$. Para distribuições de cargas esféricamente simétricas, $V_{x x}=V_{y y}=V_{z z}$. Desde que $\sum V_{i i}=0$, todas as componentes do GCE não contribuem com $E_{Q}$.

A condição $\sum V_{i i}=0$ garante que o GCE pode ser completamente descrito por apenas dois parâmetros. Escolhendo apropriadamente o sistema de eixos de tal forma que $\left|V_{z z}\right| \geq\left|V_{y y}\right| \geq\left|V_{x x}\right|$ podemos descrever o GCE através da maior componente do tensor na direção principal escolhida $\left(V_{z z}\right)$ e pelo parâmetro de assimetria $(\eta)$, este definido por 


$$
\eta=\frac{\left|V_{y y}-V_{x x}\right|}{\left|V_{z z}\right|}
$$

O parâmetro de assimetria nos fornece informações sobre a distribuição de cargas em torno do núcleo atômico.

Em NMR e Ressonância de Quadrupolo Nuclear (NQR), as medidas de interações quadrupolares são expressadas através de uma frequência $\nu_{q}$ [41]:

$$
\nu_{q}=\frac{3 e Q V_{z z}}{2 h I(2 I-1)}
$$

onde Q é o momento de quadrupolo nuclear, $I$ é o número quântico de spin do núcleo e $h$ é a constante de Planck. Ressaltamos que são encontrados muitas vezes na literatura $[42,43,44]$ a definição de $\nu_{q}$ da seguinte forma:

$$
\nu_{q}=\frac{e^{2} q Q}{h}
$$

onde $V_{z z}=e q$.

Podemos reescrever a equação 3.15 da seguinte forma:

$$
V_{z z}\left[10^{21} V / m^{2}\right]=0.027571 \frac{I(2 I-1))}{Q[b]} \nu_{q}[M h z],
$$

onde Q é expresso em unidades de barn $\left(1\right.$ barn $\left.=100 \mathrm{fm}^{2}=10^{-28} \mathrm{~m}^{2}\right)$. Os valores de Q utilizados neste trabalho são obtidos da referência [45].

Para calcular o GCE teórico necessitamos de um cálculo de estrutura eletrônica bem preciso, all electron, e que descreve bem o potencial total em todas as regiões do espaço. Dentre os métodos all electron, o método PAW se mostrou bastante adequado para o cálculo de GCE em diversos sistemas [41, 46, 47] com precisão comparável ao método FP-LAPW [41]. A vantagem do código CP-PAW está no menor custo computacional no caso de sistemas moleculares envolvendo grande 
número de átomos.

No CP-PAW o GCE é calculado diretamente do potencial total $\nu(\mathbf{r})$ através da relação [41]

$$
V_{i, j}=\lim _{\mathbf{r} \rightarrow \mathbf{R}}\left(\partial_{i} \partial_{j}-\frac{1}{3} \delta_{i, j} \nabla^{2}\right) \nu(\mathbf{r})
$$

calculado no sítio R do núcleo. No método PAW, o potencial total é dado pela soma de três termos,

$$
\nu(\mathbf{r})=\tilde{\nu}(\mathbf{r})-\sum_{R} \tilde{\nu}_{R}^{1}(\mathbf{r})+\nu_{R}^{1}(\mathbf{r})
$$

O primeiro termo da equação 3.19 é chamado de pseudopotencial. No método PAW, o pseudopotencial é simplesmente a parte do potencial all electron da função de onda [41]. Os termos restantes são as expansões de um centro atômico do pseudopotencial e do potencial all electron num sítio atômico denominado R [41]. Cada termo da equação 3.19 contribui individualmente com o GCE:

$$
V_{i, j}=\tilde{V}_{i, j}-\tilde{V}_{i, j}^{1}+V_{i, j}^{1}
$$

A contribuição do pseudopotencial $(\tilde{\nu}(\mathbf{r}))$ para o EFG é dado por:

$$
\tilde{V}_{i, j}=-\sum_{\mathbf{G}}\left(G_{i} G_{j}-\delta_{i, j} \frac{1}{3}|\mathbf{G}|^{2}\right) \tilde{\nu}(\mathbf{G}) e^{i \mathbf{G R}} f(|\mathbf{G}|),
$$

onde $\mathbf{G}$ é o vetor da rede recíproca. 
A contribuição das expansões de um centro para o EFG são obtidas diretamente da grade radial

$$
\begin{aligned}
\delta_{i} \delta_{j} \sum_{L} \nu_{R, L}^{1}(s) Y_{L}(\mathbf{s}) & =\lim _{s \rightarrow 0} \sum_{L}\left[\left(\partial_{i} \partial_{j} \nu_{R, L}^{1}(s) s^{-l}\right)\left(Y_{R, L}(\mathbf{s}) s^{l}\right)\right] \\
& +\left(\partial_{i} \nu_{R, L}^{1}(s) s^{-l}\right)\left(\partial_{j} Y_{L}(\mathbf{s}) s^{l}\right) \\
& +\left(\partial_{j} \nu_{R, L}^{1}(s) s^{-l}\right)\left(\partial_{i} Y_{L}(\mathbf{s}) s^{l}\right) \\
& \left.+\nu_{L}^{1}(s) s^{-l}\left(\partial_{i} \partial_{j} Y_{L}(\mathbf{s}) s^{l}\right)\right] .
\end{aligned}
$$

Devido às funções $Y_{L}(\mathbf{s}) s^{l}$ serem polinomiais de ordem $l$, podemos reduzir a expressão 3.22. O primeiro termo se anula exceto para a contribuição em $l=0$, o segundo e terceiro termos se anulam exceto para a contribuição em $l=1$ e o ultimo termo se anula exceto para a contribuição em $l=2$ [41]. O termo obtido em $l=0$ é proporcional a $\delta_{i, j}$ devido ser esfericamente simétrico e, portanto, não contribui com o tensor de GCE. A contribuição de $l=1$ também não contribui com o tensor de GCE devido a $\nu_{L}(s) s^{l}$ serem funções esféricas e portanto não tem um GCE nulo na origem. Somente os termos em $l=2$ contribuem para o tensor de GCE. Desta forma, podemos escrever a relação da contribuição das expansões como

$$
V_{i, j}^{1}=\sum_{m ; l=2}\left(\lim _{s \rightarrow 0} \frac{\nu_{R, L}^{1}(s)}{s^{2}}\right)\left[\left(\partial_{i} \partial_{j}-\frac{1}{3} \delta_{i, j} \nabla^{2}\right) Y_{L}(\mathbf{s}) s^{2}\right] .
$$

Na equação 3.23 mostramos a contribuição dada pelo potencial $\nu^{1}$. A contribuição dada pelo potencial $\tilde{\nu}^{1}$ é calculada de forma equivalente ao cálculo da contribuição de $\nu^{1}$. 


\section{Capítulo 4}

\section{Resultados e Discussões}

Neste capítulo mostraremos os resultados obtidos, através da metodologia apresentada nos capítulos 2 e 3, do estudo das interações hiperfinas entre o Cádmio (Cd) ligado as bases nitrogenadas do DNA. Calculamos as grandezas hiperfinas que definem o tensor Gradiente de Campo Elétrico no Núcleo (GCE) (a maior componente do tensor diagonalizado, $V_{z z}$, e o parâmetro de assimetria $\eta$ ) e propriedades eletrônicas como a Densidade de Estados (DOS) e orbitais moleculares visando obter informações do sítio de interação do $\mathrm{Cd}$ com a base nitrogenada. Valores de GCE e $\eta$ obtidas por Ressonância Magnética Nuclear (NMR) e por Time Differential Perturbed Angular Correlation (TDPAC) são mostrados. Estes valores experimentais são usados neste trabalho para comparar com os nossos resultados de GCE e $\eta$ obtidos com o CP-PAW.

A figura 4.1 apresenta, de forma ilustrativa, as diferentes etapas dos cálculos realizados no presente trabalho. Inicialmente obtivemos os parâmetros geométricos e hiperfinos de cada base nitrogenada que compõe o DNA (figura 1.1). Numa segunda etapa obtivemos os valores do GCE e das distâncias de ligação entre um átomo de $\mathrm{Cd}$ e as bases (figura 4.1b) otimizadas pelo método CP-PAW. Inserimos moléculas de água no sistema com o objetivo de simular o ambiente químico ob- 
servado do Cd ligado à base nitrogenada conforme ilustrado na figura 4.1c. Nestas 3 etapas comparamos nossos resultados com outros resultados teóricos e experimentais disponíveis na literatura $[10,4]$. Numa etapa completamente inédita, estudamos o GCE no sítio de Cd nos sistemas: bases isoladas e pares de bases guanina-citosina (GC) e adenina-timina (AT) complexados com Cd e moléculas de água (figura 4.1d).

A ferramenta utilizada no estudo computacional foi o código computacional Car-Parrinello Projector Augmented Wave (CP-PAW) que tem como metodologia o Projector Augmented Wave (PAW) combinado com a Dinâmica Molecular Quântica de Car-Parrinello (CPMD) descritos no capítulo 2. A abordagem aqui utilizada simula a molécula isolada (à temperatura $\mathrm{T}=0 \mathrm{~K}$ ) através de um cálculo de células unitárias periódicas no espaço recíproco onde a distância entre as moléculas de células unitárias vizinhas são maiores que 6 A. Esta distância deve ser suficiente para que não ocorra a sobreposição das funções de onda das moléculas em células adjacentes [22] e, além disto, utilizamos também o recurso de "cancelamento de imagens eletrostáticas periódicas" [22] para anular as interações coulombianas de longo alcance entre a molécula e suas imagens periódicas [22]. Garantimos, desta forma, o isolamento das moléculas por meio de uma região de vácuo. As otimizações de geometria dos sistemas estudados foram feitas com apenas um ponto $\mathrm{k}$. 


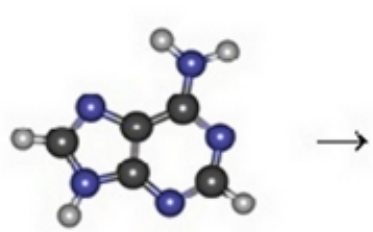

(a)

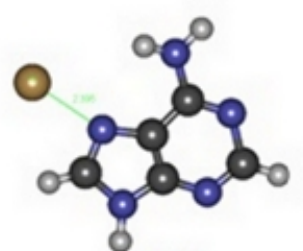

(b)

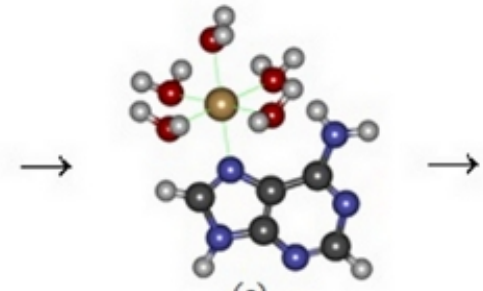

(c)

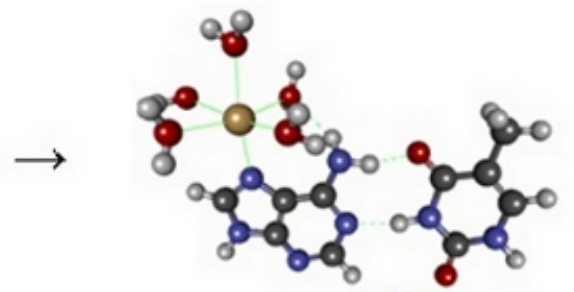

(d)

Figura 4.1: Representação esquemática dos sistemas estudados: a) base nitrogenada isolada; b) base nitrogenada com um átomo de $\mathrm{Cd}$; c) base nitrogenada com um átomo de $\mathrm{Cd}$ e moléculas de $\mathrm{H}_{2} \mathrm{O}$; d) pares de bases nitrogenadas com um átomo de $\mathrm{Cd}$ e moléculas de $\mathrm{H}_{2} \mathrm{O}$. As bases estudadas foram a adenina, citosina, timina e guanina e o número de moléculas de $\mathrm{H}_{2} \mathrm{O}$ foi variado entre 3 e 5 .

Discutiremos agora cada uma das etapas apresentadas na figura 4.1 para cada base nitrogenada.

\subsection{Bases Nitrogenadas Isoladas}

As geometrias iniciais das bases isoladas são bem conhecidas na literatura tendo sido investigadas com técnicas como NMR e cristalografia de raios-X [4, 44, 42]. Não encontramos na literatura um consenso sobre a influência dos metais no tautomerismo ${ }^{1}$ das bases nitrogenadas [13, 12]. Entretanto no presente trabalho

\footnotetext{
${ }^{1}$ Tautomeria é o caso particular de isomeria funcional em que os dois isômeros ficam em equilíbrio químico [48].
} 
realizamos o estudo das bases nitrogenadas na forma canônica.

\subsubsection{Otimização de Geometria para as Bases Nitrogenadas Isoladas}

Partindo das estruturas obtidas por cristalografia de raios-x [4], realizamos cálculos de otimização de geometria através da minimização da energia total para as bases nitrogenadas isoladas utilizando o CP-PAW. Comparamos nossos resultados de parâmetros estruturais com os da literatura [43]. Fizemos testes de convergência do GCE e distâncias de ligação entre os átomos com relação à base de ondas planas. Conforme discutido na seção 2.4, o parâmetro $E_{c u t}$ (equação 2.24) é quem controla o tamanho da base de ondas planas.

\section{Bases Púricas: Adenina e Guanina}

Nas tabelas 4.1 e 4.2 apresentamos respectivamente as distâncias de ligação entre os átomos das moléculas isoladas adenina e guanina obtidas no presente trabalho utilizando o CP-PAW. A nomenclatura dos átomos é apresentada nas figuras 4.2 (adenina) e 4.3 (guanina). Podemos ver que os valores das distâncias de ligação tanto para adenina quanto para guanina concordam bastante bem com os valores experimentais [49] e valores teóricos obtidos por outra abordagem da literatura [43] que apresentamos também nas tabelas 4.1 e 4.2. Na tabela 4.1 observamos que a maior diferença encontrada na comparação entre os resultados obtidos com o CP-PAW e medidas de raios-X [49] foi de 1,65\% para a ligação C14N3. Quando comparamos os resultados obtidos com o CP-PAW e os obtidos com o Gaussian94 [43], vemos que o maior desvio (1,7\%) foi para ligação N3-H7(H8). A mesma análise para os resultados apresentados na tabela 4.2 mostra que o maior desvio percentual $(2,90 \%)$ encontrada na comparação entre os resultados obtidos com o CP-PAW e medidas de raio-X [49] foi para ligação N4-C13. Quando 
comparamos os resultados obtidos com o CP-PAW com os resultados obtidos com

o Gaussian94 [43], vemos que o maior desvio (1,0\%) foi para ligação N2-C12.

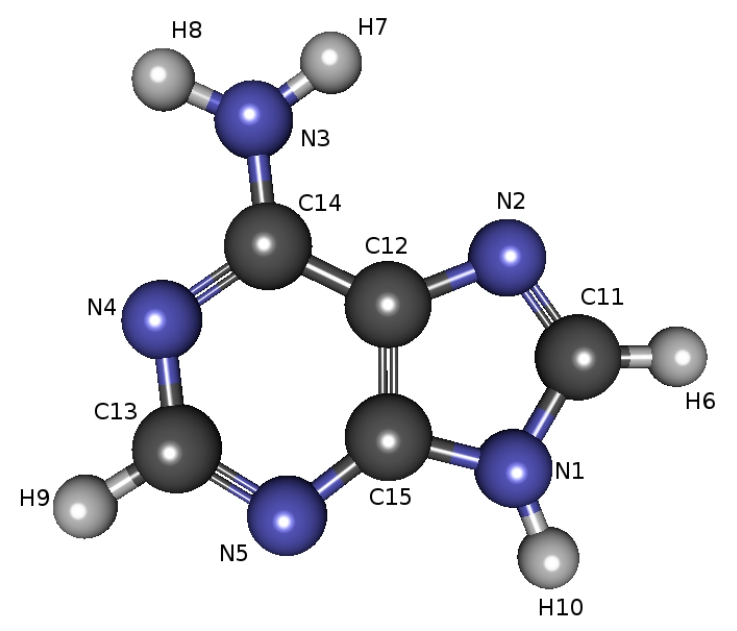

Figura 4.2: Adenina isolada com geometria otimizada pelo CP-PAW.

Tabela 4.1: Distâncias de ligação entre os átomos da molécula adenina isolada e otimizada obtidos no presente trabalho utilizando o código CP-PAW. Apresentamos também os valores experimentais [49] e obtidos utilizando o código Gaussian94 da literatura [43].

\begin{tabular}{cccc}
\hline \hline $\begin{array}{c}\text { Átomos ligantes } \\
\text { (Fig. 1.2) }\end{array}$ & DISTÂNCIAS & INTERATÔMICAS $[\AA]$ & \\
\hline N4 - C13 & 1,346 & Gaussian94 [43] & Experimental [49] \\
C13 - N5 & 1,342 & 1,338 & 1,339 \\
N5 - C15 & 1,341 & 1,331 & 1,331 \\
C15 - C12 & 1,403 & 1,333 & 1,334 \\
C12 - C14 & 1,412 & 1,393 & 1,383 \\
C14 - N3 & 1,357 & 1,405 & 1,406 \\
C15 - N1 & 1,381 & 1,350 & 1,335 \\
C12 - N2 & 1,387 & 1,374 & 1,374 \\
N2 - C11 & 1,318 & 1,382 & 1,388 \\
C11 - N1 & 1,382 & 1,305 & 1,311 \\
N3 - H7(H8) & 1,020 & 1,377 & 1,373 \\
\hline \hline
\end{tabular}




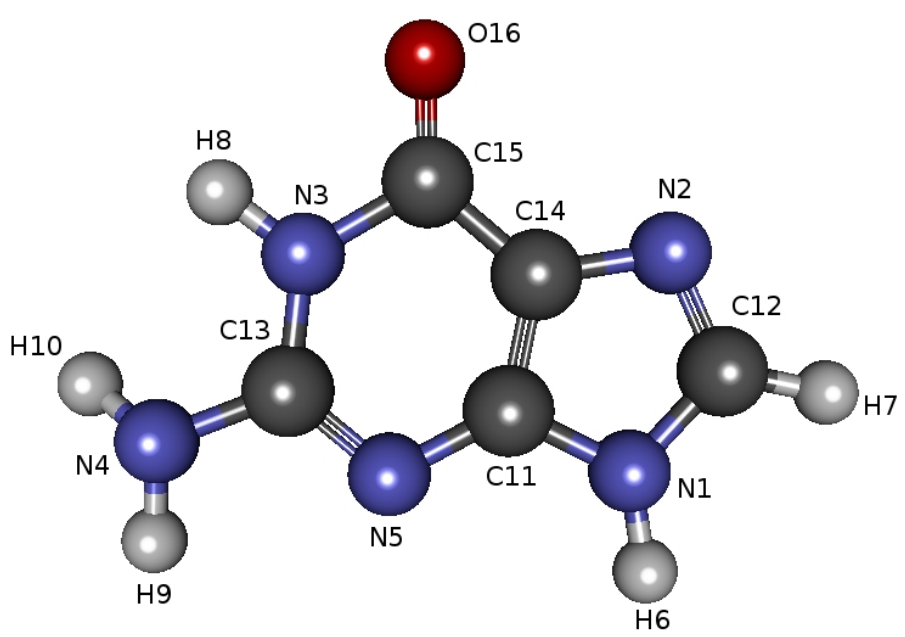

Figura 4.3: Guanina isolada com geometria otimizada pelo CP-PAW.

Tabela 4.2: Distâncias de ligação entre os átomos da molécula guanina isolada e otimizada obtidos no presente trabalho utilizando o código CP-PAW. Apresentamos também os valores experimentais [49] e obtidos utilizando o código Gaussian94 da literatura [43]

\begin{tabular}{cccc}
\hline \hline & DISTANCIAS & INTERATÔMICAS [A] & \\
Átomos ligantes & & & \\
(Fig. 1.3) & CP-PAW & Gaussian94 [43] & Experimental [49] \\
\hline N3 - C13 & 1,372 & 1,366 & 1,373 \\
C13 - N5 & 1,318 & 1,306 & 1,323 \\
N4 - C13 & 1,380 & 1,371 & 1,341 \\
N5 - C11 & 1,358 & 1,353 & 1,350 \\
C11 - C14 & 1,401 & 1,390 & 1,379 \\
C14 - C15 & 1,439 & 1,435 & 1,419 \\
C15 - O16 & 1,224 & 1,212 & 1,237 \\
C11 - N1 & 1,373 & 1,366 & 1,374 \\
C14 - N2 & 1,383 & 1,379 & 1,388 \\
N2 - C12 & 1,314 & 1,301 & 1,305 \\
C12 - N1 & 1,386 & 1,381 & 1,374 \\
\hline \hline
\end{tabular}




\section{Bases Pirimídicas: Citosina e Timina}

Nas tabelas 4.3 e 4.4 apresentamos respectivamente as distâncias de ligação entre os átomos das moléculas isoladas citosina e timina obtidas no presente trabalho utilizando o CP-PAW. A nomenclatura dos átomos é apresentada nas figuras 4.4 (citosina) e 4.5 (timina). Podemos ver que os valores das distâncias de ligação tanto para timina quanto para citosina concordam bastante bem com os valores experimentais [49] e valores teóricos obtidos por outra abordagem da literatura [43] que apresentamos também nas tabelas 4.1 e 4.2. Na tabela 4.3 observamos que a maior diferença encontrada na comparação entre os resultados obtidos com o CP-PAW e medidas de raios-X [49] foi de 5,9\% para a ligação C9-N1. Quando comparamos os resultados obtidos com o CP-PAW e os obtidos com o Gaussian94 [43], vemos que o maior desvio (4,5\%) também foi para ligação C9-N1. A mesma análise para os resultados apresentados na tabela 4.4 mostra que o maior desvio percentual $(2,45 \%)$ encontrada na comparação entre os resultados obtidos com o CP-PAW e medidas de raio-X [49] foi para ligação C11-C12. Quando comparamos os resultados obtidos com o CP-PAW com os resultados obtidos com o Gaussian94 [43], vemos que o maior desvio $(1,7 \%)$ foi para ligação N1-H8. Analisando as tabelas 4.3 e 4.4 verificamos que praticamente todas as distâncias de ligação obtidas com o CP-PAW (com exceção da ligação N2-C9 na citosina e C12-C13 na timina) são maiores que os obtidos pelo gaussian94. No entanto, estas diferenças são bem pequenas (da ordem de três casas decimais após a vírgula) e ocorrem devido aos métodos de DFT utilizados nos dois programas serem diferentes. O CP-PAW utiliza a base de ondas planas e o funcional é o PBE [32]. Os cálculos obtidos com o Gaussian94 [43] são com o funcional híbrido B3LYP e base 6-311+G(2d,2p).

O mais importante a se notar é que os dois métodos teóricos (Gaussian94 e CPPAW) reproduzem muito bem os valores experimentais de cristalografia de raio-X para as distâncias de ligação entre os átomos das moléculas de citosina, timina, 
adenina e guanina.

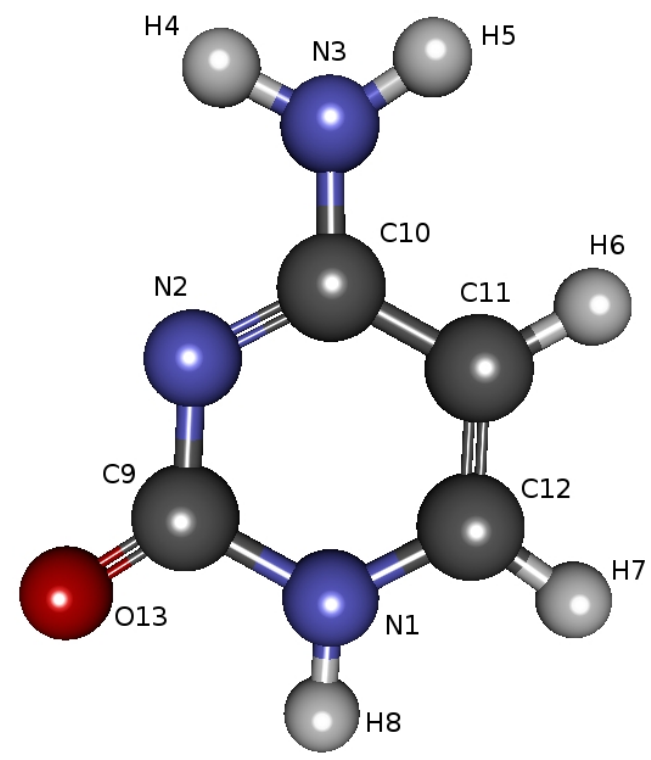

Figura 4.4: Citosina isolada com geometria otimizada pelo CP-PAW.

Tabela 4.3: Distâncias de ligação entre os átomos da molécula citosina isolada e otimizada obtidos no presente trabalho utilizando o código CP-PAW. Apresentamos também os valores experimentais [49] e obtidos utilizando o código Gaussian94 da literatura [43].

\begin{tabular}{cccc}
\hline \hline $\begin{array}{c}\text { Átomos ligantes } \\
\text { (Fig. 1.3) }\end{array}$ & DISTÂNCIAS & INTERATÔMICAS [A] & \\
\hline N2 - C9 & 1,372 & Gaussian94 [43] & Experimental [49] \\
C9 - O13 & 1,227 & 1,413 & 1,397 \\
C9 - N1 & 1,433 & 1,218 & 1,240 \\
N2 - C10 & 1,327 & 1,372 & 1,353 \\
C10 - N3 & 1,363 & 1,313 & 1,335 \\
C10 - C11 & 1,438 & 1,359 & 1,335 \\
C11 - C12 & 1,363 & 1,431 & 1,425 \\
C12 - N1 & 1,356 & 1,355 & 1,339 \\
N1 - H8 & 1,025 & 1,350 & 1,367 \\
C11 - H6 & 1,093 & 1,008 & - \\
N3 - H5(H4) & 1,019 & 1,077 & - \\
\hline \hline
\end{tabular}




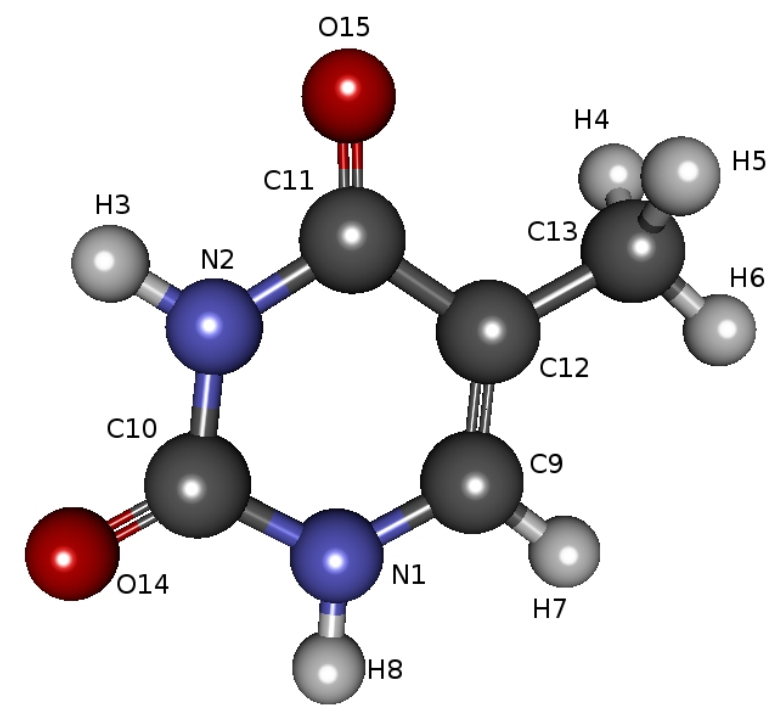

Figura 4.5: Timina isolada com geometria otimizada pelo CP-PAW.

Tabela 4.4: Distâncias de ligação entre os átomos da molécula timina isolada e otimizada obtidos no presente trabalho utilizando o código CP-PAW. Apresentamos também os valores experimentais [49] e obtidos utilizando o código Gaussian94 da literatura [43].

\begin{tabular}{cccc}
\hline \hline & DISTANCIAS & INTERATÔMICAS [A] & \\
Átomos ligantes & & Gaussian94 [43] & Experimental [49] \\
(Fig. 1.3) & CP-PAW & 1,376 & 1,375 \\
\hline N1 - C9 & 1,379 & 1,006 & - \\
N1 - H8 & 1,023 & 1,384 & 1,381 \\
N1 - C10 & 1,394 & 1,212 & 1,219 \\
C10 - O14 & 1,225 & 1,381 & 1,373 \\
C10 - N2 & 1,388 & 1,403 & 1,380 \\
N2 - C11 & 1,412 & 1,215 & 1,232 \\
C11 - O15 & 1,229 & 1,464 & 1,431 \\
C11 - C12 & 1,466 & 1,497 & - \\
C12 - C13 & 1,497 & 1,090 & - \\
C13 - H5(H4,H6) & 1,105 & 1,346 & 1,337 \\
C12 - C9 & 1,357 & & \\
\hline \hline
\end{tabular}




\subsubsection{Cálculos de GCE para as bases nitrogenadas}

Apresentamos os resultados obtidos para as componentes $V_{z z}, V_{y y}$ e $V_{x x}$ para o tensor GCE no sistema de eixos principais, parâmetro de assimetria $\eta$ (eq. 3.14) e frequência qudrupolar $\nu_{q}$ (eq. 3.15) para as bases nitrogenadas isoladas. Nossos resultados são comparados com os obtidos por outros métodos computacionais encontrados na literatura [44, 43] e támbem com medidas obtidas por NMR [42].

\section{Convergência do GCE com Relação ao Corte de Ondas Planas}

As figuras 4.6 a 4.9 apresentam os valores do GCE, obtidos no presente trabalho, para os átomos de nitrogênio $(\mathrm{N})$, oxigênio $(\mathrm{O})$ e hidrogênio $(\mathrm{H})$ em função da energia corte $E_{c u t}$ (eq. 2.24) da base de ondas planas para as moléculas adenina (figura 4.6), guanina (figura 4.7), citosina (figura 4.8) e timina (figura 4.9) respectivamente. Podemos notar que em todos os casos os resultados do GCE encontram-se suficientemente convergidos para $E_{c u t}=80$ Ry sendo que a maior diferença entre a utilização da $E_{c u t}=70$ Ry e $E_{c u t}=80$ Ry ocorre para o caso do átomo N3 da citosina, onde esta diferença é de aproximadamente $0,4 \times 10^{21} \mathrm{~V} / \mathrm{m}^{2}$. Os valores obtidos do GCE para $E_{c u t}=70$ Ry também estão convergidos, no entanto, optamos em usar $E_{c u t}=80$ Ry nos nossos cálculos para assegurar que os valores de GCE vão estar dentro da convergência necessária para os cálculos. Todos os valores obtidos de GCE para as 4 moléculas possuem a mesma ordem de grandeza $\left(10 \times 10^{21} \mathrm{~V} / \mathrm{m}^{2}\right)$. Os maiores valores de GCE obtidos são para os sítios de oxigênio e estão na faixa de $15 \times 10^{21} \mathrm{~V} / \mathrm{m}^{2}$. Os valores obtidos de GCE para os sítios de nitrogênio estão na faixa de $6 \times 10^{21} \mathrm{~V} / \mathrm{m}^{2}$ a $10 \times 10^{21} \mathrm{~V} / \mathrm{m}^{2}$. Os menores valores obtidos de GCE (na faixa de $2 \times 10^{21} \mathrm{~V} / \mathrm{m}^{2}$ a $4 \times 10^{21} \mathrm{~V} / \mathrm{m}^{2}$ ) foi para os sítios de Hidrogênio da citosina. Devido a estes valores de GCE no sítio de hidrogênio serem pequenos, não temos medidas experimentais uma vez que o valor do sítio é menor que a precisão da medida. Portanto, discutiremos neste 
trabalho somente os valores de GCE obtidos nos sítios de nitrogênio e oxigênio das moléculas adenina, guanina, citosina e timina.

Com os resultados de relaxação de estrutura em ótima concordância com as medidas de cristalografia de raio- $\mathrm{X}$ para as quatro bases nitrogenadas e a convergência do GCE em relação ao corte de ondas planas da base nos indicando que $E_{c u t}=80$ Ry é o suficiente, todos os resultados obtidos e apresentados neste trabalho de GCE são realizados com $E_{c u t}=80 \mathrm{Ry}$.

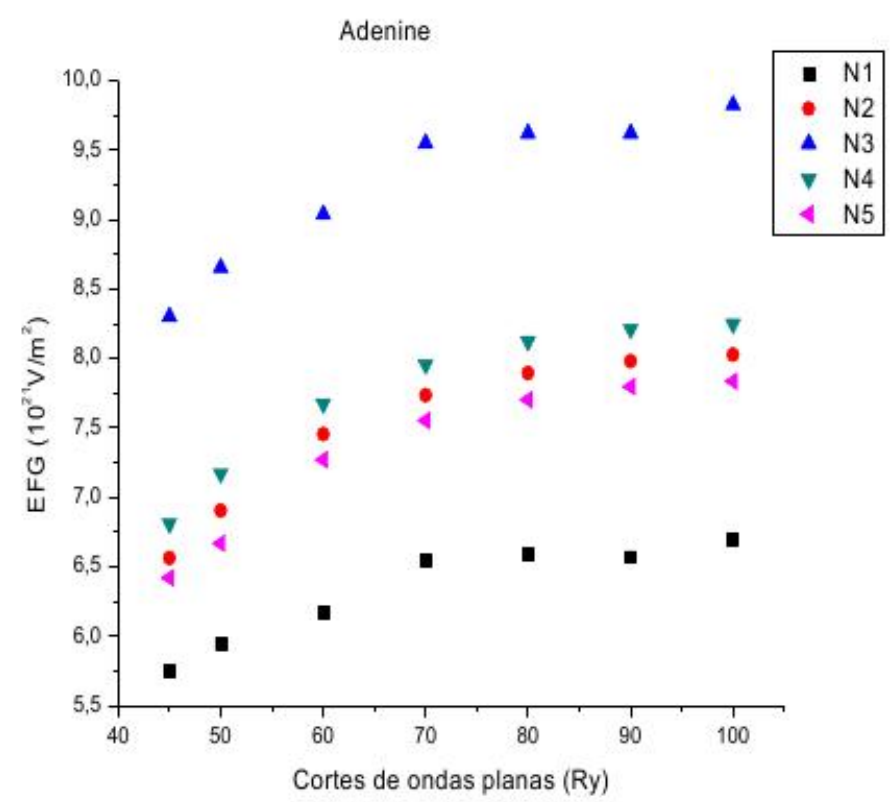

Figura 4.6: Gradiente de Campo Elétrico $V_{z z}$, em módulo, nos sítios de nitrogênio em função da energia de corte da base de ondas planas para a molécula de adenina isolada. 


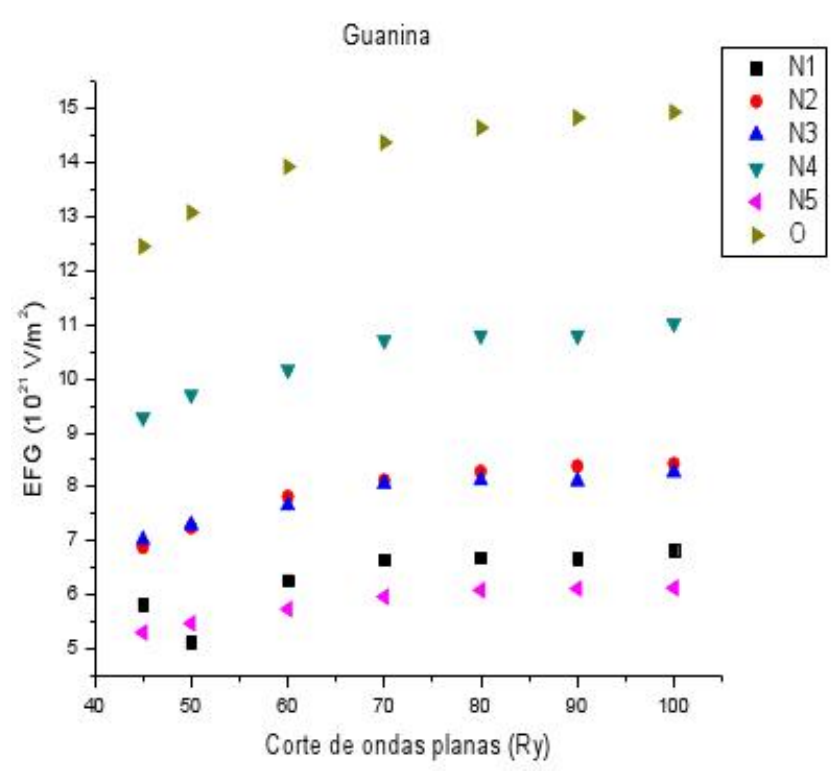

Figura 4.7: Gradiente de Campo Elétrico $V_{z z}$, em módulo, nos sítios de nitrogênio e oxigênio em função da energia de corte da base de ondas planas para a molécula de guanina isolada .

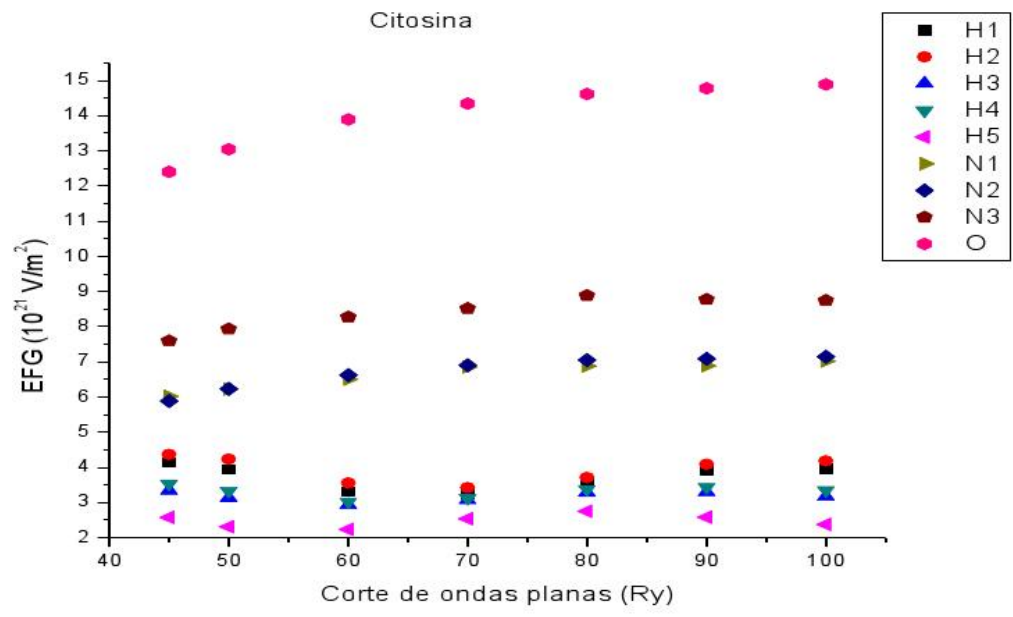

Figura 4.8: Gradiente de Campo Elétrico $V_{z z}$, em módulo, nos sítios de hidrogênio, oxigênio e nitrogênio em função da energia de corte da base de ondas planas para a molécula de citosina isolada. 


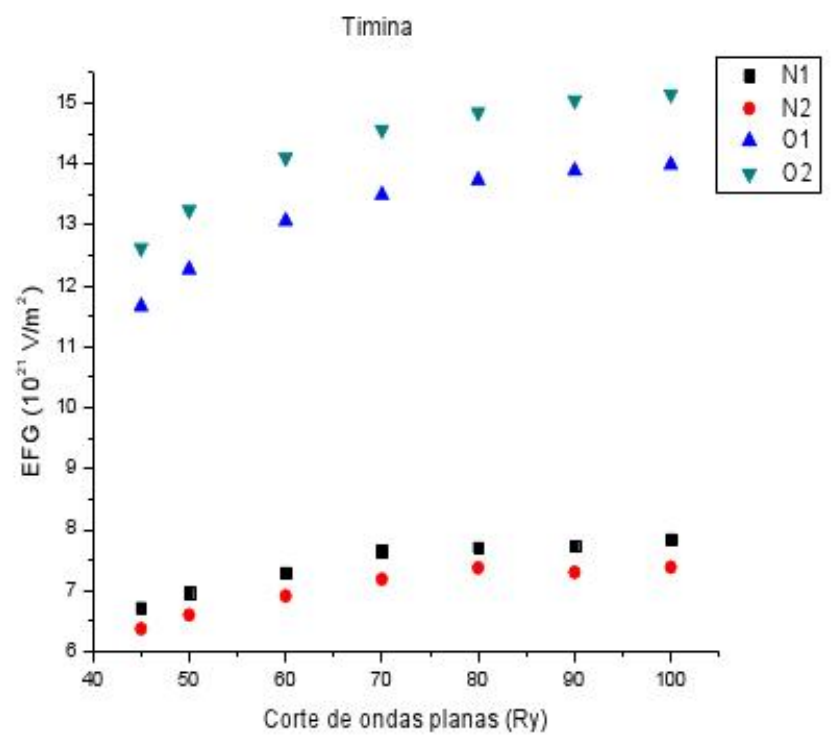

Figura 4.9: Gradiente de Campo Elétrico $V_{z z}$, em módulo, nos sítios de nitrogênio e oxigênio em função da energia de corte da base de ondas planas para a molécula de citosina isolada.

\section{Resultados de GCE para as Bases Púricas}

Os valores obtidos para as componentes do tensor de GCE $V_{z z}, V_{y y}$ e $V_{x x}$ nos átomos de $\mathrm{N}$ da adenina e $\mathrm{N}$ e $\mathrm{O}$ da guanina são mostrados nas figuras $4.10 \mathrm{e}$ 4.11, respectivamente. Note-se que a numeração dos $\mathrm{N}$ não é a mesma para a adenina e guanina sendo que o N3 da adenina é equivalente ao N4 da guanina como podemos verificar pelas figuras 4.2 e 4.3. Analisando as figuras 4.10 e 4.11 verificamos que os valores de $V_{z z}$ obtidos para os correspondentes sítios de $\mathrm{N}$ da adenina e guanina são muito próximos. Isto ocorre devido ao fato de que as duas moléculas possuem estruturas muito semelhantes (anel pirimidínico fundido a um anel imidazólico). Com os valores das componentes $V_{z z}, V_{y y}$ e $V_{x x}$ obtemos os valores de $\eta$ (eq. 3.14) para cada sítio de $\mathrm{N}$ da adenina e $\mathrm{N}$ e $\mathrm{O}$ da guanina. Para comparar com o experimental usaremos os valores de $\nu_{q}$ (eq. 3.16)[45] obtidos de $\mathrm{N}$ e O das moléculas de adenina e guanina. 


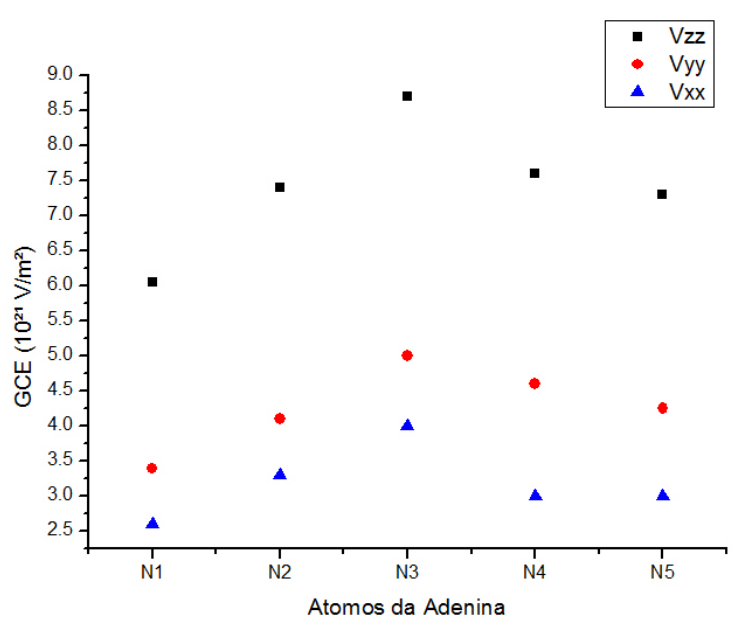

Figura 4.10: Valores de $V_{z z}, V_{y y}$ e $V_{x x}$ dos átomos de nitrogênio da molécula de adenina.

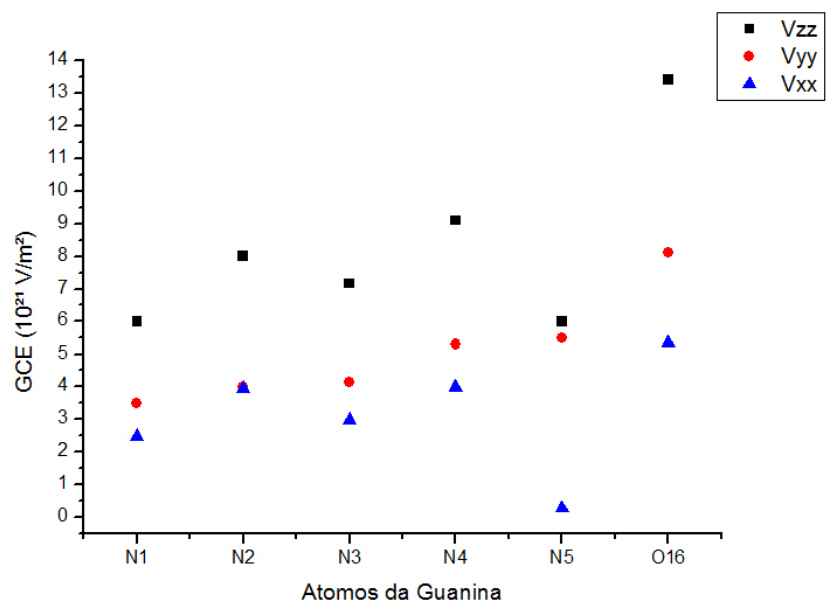

Figura 4.11: Valores de $V_{z z}, V_{y y}$ e $V_{x x}$ dos átomos de nitrogênio e oxigênio da molécula de guanina.

A tabela 4.5 mostra os resultados de $\nu_{q}$ e $\eta$ para os átomos de $\mathrm{N}$ da molécula de adenina e nas tabelas 4.6 e 4.7 mostramos os resultados de $\nu_{q}$ e $\eta$ para a molécula de guanina. Medidas de $\nu_{q}$ e $\eta$ obtidas com NMR para o O16 da guanina são mostrados nas tabelas 4.6 e 4.7 e resultados de GCE obtidos com os métodos com- 
putacionais Gaussian98 [42] e Gaussian03 [44] também são mostrados na tabelas $4.5,4.6$ e 4.7 .

Tabela 4.5: Valores de $\nu_{q}[\mathrm{Mhz}]$ e $\eta$,obtidos com o código CP-PAW, para os sítios de $\mathrm{N}$ da molécula de adenina. Apresentamos também os valores obtidos utilizando o código Gaussian03 da literatura [44].

\begin{tabular}{ccccc}
\hline \hline Átomos & $\begin{array}{c}\nu_{q} \\
\text { CP-PAW }\end{array}$ & $\begin{array}{c}\nu_{q} \\
\text { Gaussian03 }\end{array}$ & $\begin{array}{c}\eta \\
\text { CP-PAW }\end{array}$ & $\begin{array}{c}\eta \\
\text { Gaussian03 }\end{array}$ \\
\hline$N_{1}$ & 3,00 & 3,60 & 0,13 & 0,07 \\
$N_{2}$ & 3,65 & 4,48 & 0,10 & 0,06 \\
$N_{3}$ & 4,31 & 5,03 & 0,01 & 0,23 \\
$N_{4}$ & 3,76 & 4,44 & 0,20 & 0,05 \\
$N_{5}$ & 3,59 & 4,26 & 0,17 & 0,08 \\
\hline \hline
\end{tabular}

Tabela 4.6: Valores de $\nu_{q}[\mathrm{Mhz}]$ obtidos com o código CP-PAW, para os átomos de $\mathrm{N}$ e O da molécula de guanina. Apresentamos também o valor experimental [42] e os valores obtidos utilizando os códigos Gaussian98 (funcional B3LYP e base 6-311G(d,p))[42] e Gaussian03 (Hartree-Fock Roothaan (HF + MP2) com base $6-311 \mathrm{G})[44]$ da literatura.

\begin{tabular}{ccccc}
\hline \hline Átomos & Gaussian98 & Gaussian03 & CP-PAW & $\begin{array}{c}\text { Experimental } \\
\text { (NMR) }\end{array}$ \\
\hline$N_{1}$ & - & 3,41 & 2,97 & - \\
$N_{2}$ & - & 4,89 & 3,94 & - \\
$N_{3}$ & - & 4,21 & 3,53 & - \\
$N_{4}$ & - & 5,19 & 4,51 & - \\
$N_{5}$ & - & 3,35 & 2,85 & - \\
$O_{16}$ & 8,37 & 10,16 & 8,31 & $7,10 \pm 0,05$ \\
\hline \hline
\end{tabular}


Tabela 4.7: Valores de $\eta$ obtidos com o código CP-PAW, para os átomos de $\mathrm{N}$ e O da molécula de guanina. Apresentamos também o valor experimental [42] e os valores obtidos utilizando os códigos Gaussian98 (funcional B3LYP e base 6-311G(d,p))[42] e Gaussian03 (Hartree-Fock Roothaan (HF + MP2) com base 6-311G) [44] da literatura.

\begin{tabular}{ccccc}
\hline \hline Átomos & Gaussian98 & Gaussian03 & CP-PAW & $\begin{array}{c}\text { Experimental } \\
(\mathrm{NMR})\end{array}$ \\
\hline$N_{1}$ & - & 0,11 & 0,16 & - \\
$N_{2}$ & - & 0,18 & 0,01 & - \\
$N_{3}$ & - & 0,28 & 0,16 & - \\
$N_{4}$ & - & 0,18 & 0,17 & - \\
$N_{5}$ & - & 0,34 & 0,90 & - \\
$O_{16}$ & 0,13 & 0,85 & 0,20 & $0,80 \pm 0,05$ \\
\hline \hline
\end{tabular}

Verificamos que os valores de $\nu_{q}$ tanto para os átomos de nitrogênio da adenina (tabela 4.5) quanto para a guanina (tabela 4.6) obtidos no presente trabalho com o código computacional CP-PAW e funcional PBE [32] dentro da DFT concordam, de maneira geral, bastante bem com os valores teóricos da literatura obtidos com o código Gaussian03 na aproximação de Hartree-Fock Roothaan com a teoria de perturbação de Møller-Plesset (HF + MP2). Notamos que a base 6-311G(d,p) é muito usada na literatura para estudos de sistemas biológicos sobretudo pela comunidade de química quântica. Vemos também que os $\nu_{q}$ medidos por NMR para o O16 da guanina estão mais próximos dos valores obtidos com o CP-PAW. Apresentamos nas tabelas 4.6 e 4.7 os valores teóricos obtidos para o O16, também dentro da teoria DFT, porém com o código gaussian98 e funcional B3LYP. Estes valores estão em boa concordância com os nossos resultados. 
Os valores de $\eta$ (tabela 4.5) aqui obtidos para os sítios de $\mathrm{N}$ no caso da adenina, são todos muito pequenos, o que concorda com a literatura [44]. No caso da guanina (tabela 4.7), também observamos uma concordância geral com os valores de $\eta$ da literatura para os sítios de $\mathrm{N}$, com exceção do sítio N5. No caso do sítio de O16, nosso valor de $\eta$ concorda com o valor teórico da literatura obtido com o Gaussian98 (DFT e funcional B3LYP) mas ambos discordam com o valor experimental e com o valor teórico obtido com o Gaussian03 (HF + MP2) da literatura. Uma possível explicação para justificar esta discrepância seria a incorreta descrição da DFT neste único caso. Esta questão deve, no entanto, ser profundamente investigada num futuro trabalho. Note-se também que o $\eta$ é mais sensível que o GCE à ligações intermoleculares que podem estar presentes nas medidas [40].

\section{Resultados de GCE para as Bases Pirimídicas}

Os valores obtidos das componentes $V_{z z}, V_{y y}$ e $V_{x x}$ nos átomos de $\mathrm{N}$ e $\mathrm{O}$ da timina e citosina são mostradas nas figuras 4.12 e 4.13, respectivamente. Devido a semelhança entre as estruturas destas moléculas (ver figuras 4.4 e 4.5), os valores de $V_{z z}$ obtidos para os correspondentes sítios de $\mathrm{N}$ e $\mathrm{O}$ da citosina e timina são bem próximos. Nas tabelas 4.8 e 4.9 mostramos os resultados de $\nu_{q}$ e $\eta$ para os sítios de $\mathrm{N}$ e $\mathrm{O}$ da timina e nas tabelas 4.10 e 4.11 os valores de $\nu_{q}$ e $\eta$ para os sítios de $\mathrm{N}$ e $\mathrm{O}$ da citosina. Verificamos que os valores de $\nu_{q}$ tanto para os átomos de $\mathrm{N}$ e $\mathrm{O}$ da timina (tabela 4.8) quanto para a citosina (tabela 4.10) obtidos no presente trabalho com o código computacional CP-PAW e funcional PBE [32] dentro da DFT concordam, de maneira geral, bastante bem com os valores teóricos da literatura obtidos com o código Gaussian03 na aproximação de Hartree-Fock Roothaan com a teoria de perturbação de Møller-Plesset (HF + MP2). Notamos também que os $\nu_{q}$ medidos por NMR para o O14 e O15 da timina e O da citosina estão mais próximos dos valores obtidos com o CP-PAW e Gaussian98. 
Os valores de $\eta$ (tabela 4.8) aqui obtidos para os sítios de $\mathrm{N}$ e $\mathrm{O}$ no caso da timina, concordam muito bem com a literatura [44, 42]. No caso do O15, o valor obtido de $\eta$ com o CP-PAW coincide com o valor experimental (tabela 4.8). No entanto, para o sítio O14 temos uma diferença significativa em relação ao experimental (desvio percentual de $56 \%$ ), sendo que o valor obtido pelo código CP-PAW está mais próximo dos valores de $\eta$ obtidos com o Gaussian98 $(\eta=$ $0,37)$ e com o Gaussian03( $\eta=0,61)$. No caso da citosina (tabela 4.11), também observamos uma concordância geral com os valores de $\eta$ da literatura para os sítios de $\mathrm{N}$ e O. No entanto, para o sítio de $\mathrm{O}$ da citosina, nenhum dos resultados apresentados na tabela 4.11 estão de acordo com o valor experimental. O nosso valor de $\eta$ para o sítio O14 concorda com os valores teóricos da literatura obtido com o Gaussian98 (DFT e funcional B3LYP) e com o Gaussian03 (HF + MP2). Esta questão deve, no entanto, ser investigada num futuro trabalho para se ter uma explicação destes desvios.

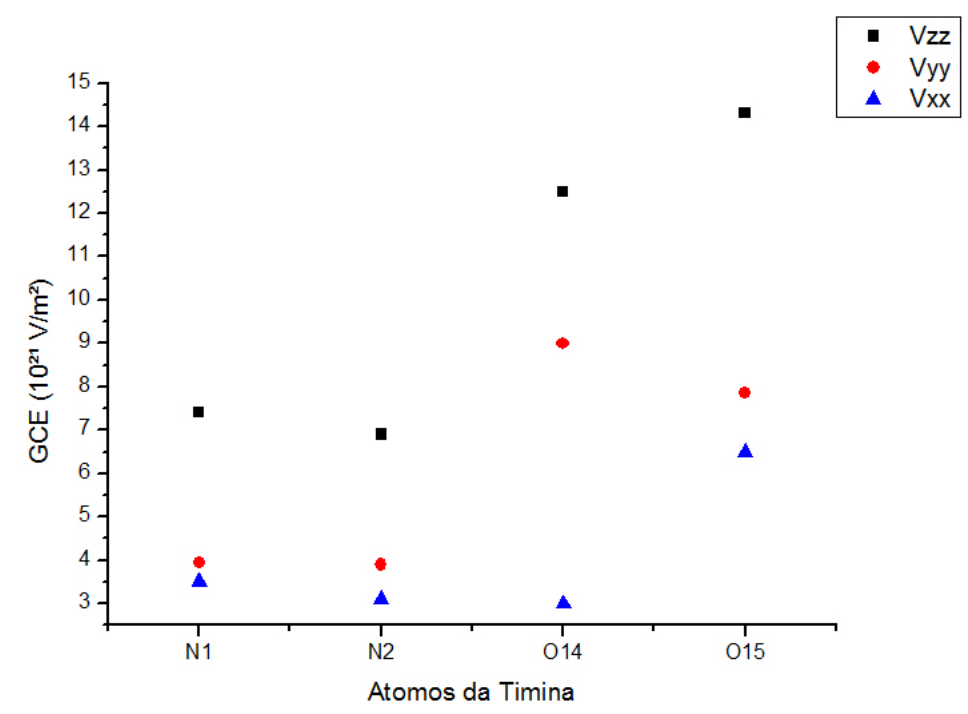

Figura 4.12: Valores de $V_{z z}, V_{y y}$ e $V_{x x}$ dos átomos de nitrogênio da molécula de timina. 


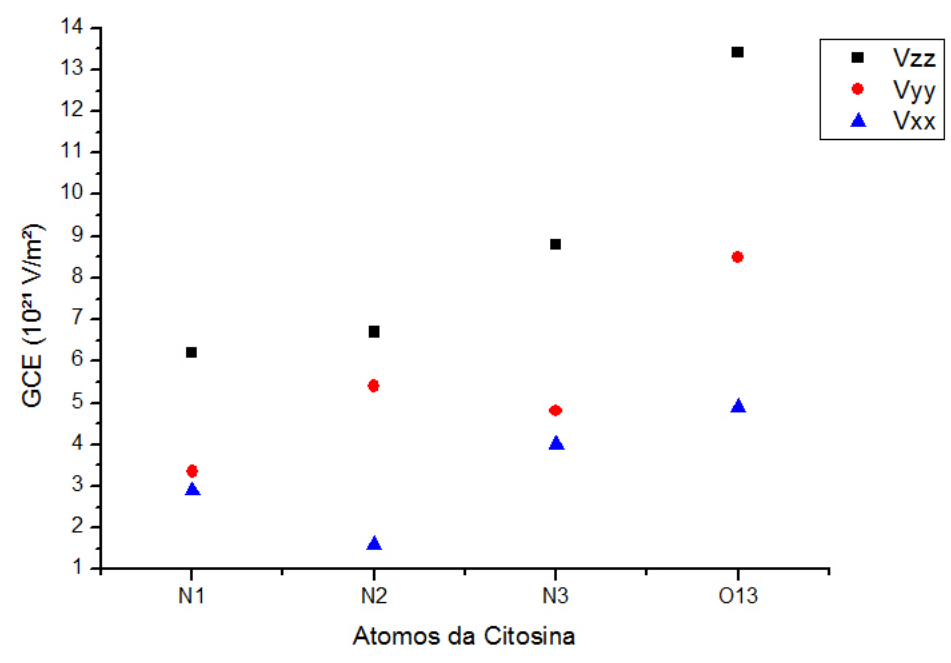

Figura 4.13: Valores de $V_{z z}, V_{y y}$ e $V_{x x}$ dos átomos de nitrogênio e oxigênio da molécula de citosina.

Tabela 4.8: Valores de $\nu_{q}[\mathrm{Mhz}]$ obtidos com o código CP-PAW, para os átomos de $\mathrm{N}$ e $\mathrm{O}$ da molécula de timina. Apresentamos também o valor experimental [42] e os valores obtidos utilizando os códigos Gaussian98 (funcional B3LYP e base 6-311G(d,p))[42] e Gaussian03 (Hartree-Fock Roothaan (HF + MP2) com base 6-311G) [44] da literatura.

\begin{tabular}{ccccc}
\hline \hline Átomos & Gaussian98 & Gaussian03 & CP-PAW & $\begin{array}{c}\text { Experimental } \\
(\mathrm{NMR})\end{array}$ \\
\hline$N_{1}$ & - & 4,69 & 3,68 & - \\
$N_{2}$ & - & 4,29 & 3,42 & - \\
$O_{14}$ & 7,76 & 9,34 & 7,75 & $6,65 \pm 0,05$ \\
$O_{15}$ & 8,93 & 10,72 & 8,87 & $8,40 \pm 0,05$ \\
\hline \hline
\end{tabular}


Tabela 4.9: Valores de $\eta$ obtidos com o código CP-PAW, para os átomos de $\mathrm{N}$ e O da molécula de timina. Apresentamos também o valor experimental [42] e os valores obtidos utilizando os códigos Gaussian98 (funcional B3LYP e base 6-311G(d,p))[42] e Gaussian03 (Hartree-Fock Roothaan (HF + MP2) com base 6-311G) [44] da literatura.

\begin{tabular}{ccccc}
\hline \hline Átomos & Gaussian98 & Gaussian03 & CP-PAW & $\begin{array}{c}\text { Experimental } \\
(\mathrm{NMR})\end{array}$ \\
\hline$N_{1}$ & - & 0,16 & 0,07 & - \\
$N_{2}$ & - & 0,20 & 0,12 & - \\
$O_{14}$ & 0,37 & 0,61 & 0,44 & $1,00 \pm 0,05$ \\
$O_{15}$ & 0,02 & 0,18 & 0,10 & $0,10 \pm 0,05$ \\
\hline \hline
\end{tabular}

Tabela 4.10: Valores de $\nu_{q}[\mathrm{Mhz}]$ obtidos com o código CP-PAW, para os átomos de $\mathrm{N}$ e $\mathrm{O}$ da molécula de citosina. Apresentamos também o valor experimental [42] e os valores obtidos utilizando os códigos Gaussian98 (funcional B3LYP e base 6-311G(d,p))[42] e Gaussian03 (Hartree-Fock Roothaan (HF + MP2) com base 6-311G) [44] da literatura.

\begin{tabular}{ccccc}
\hline \hline Átomos & Gaussian98 & Gaussian03 & CP-PAW & $\begin{array}{c}\text { Experimental } \\
(\mathrm{NMR})\end{array}$ \\
\hline$N_{1}$ & - & 3,94 & 3,07 & - \\
$N_{2}$ & - & 4,00 & 3,44 & - \\
$N_{3}$ & - & 5,00 & 4,33 & - \\
$O$ & 8,30 & 10,00 & 8,23 & $7,20 \pm 0,05$ \\
\hline
\end{tabular}


Tabela 4.11: Valores de $\eta$ obtidos com o código CP-PAW, para os átomos de $\mathrm{N}$ e O da molécula de citosina. Apresentamos também o valor experimental [42] e os valores obtidos utilizando os códigos Gaussian98 (funcional B3LYP e base 6-311G(d,p))[42] e Gaussian03 (Hartree-Fock Roothaan (HF + MP2) com base 6-311G) [44] da literatura.

\begin{tabular}{ccccc}
\hline \hline Átomos & Gaussian98 & Gaussian03 & CP-PAW & $\begin{array}{c}\text { Experimental } \\
(\mathrm{NMR})\end{array}$ \\
\hline$N_{1}$ & - & 0,08 & 0,08 & - \\
$N_{2}$ & - & 0,59 & 0,54 & - \\
$N_{3}$ & - & 0,13 & 0,08 & - \\
$O$ & 0,20 & 0,21 & 0,27 & $0,70 \pm 0,05$ \\
\hline \hline
\end{tabular}




\subsection{Cd ligado a bases nitrogenadas}

Após o estudo de otimização de geometria e GCE das bases nitrogenadas isoladas, inserimos o átomo de Cd no sistema. De acordo com a referência [4], os metais divalentes (possuem estado de carga +2 ) complexam com as bases nitrogenadas e esta interação ocorre em sítios específicos de cada base. Os sítios de ligação para os metais $\left(M^{+2}\right)$ são na adenina N2 e N4, (figura 4.14a) e na guanina é o N2 (figura 4.14b). No caso das bases pirimídicas, os $M^{+2}$ se ligam na citosina ao N2 e na timina ao O15, conforme ilustrado na figura 4.15. Estudamos todos os casos de interação entre o íon $\mathrm{Cd}\left(C d^{+2}\right)$ e os sítios mostrados nas figuras 4.14 e 4.15 das bases nitrogenadas. Novamente, através do código CP-PAW, otimizamos as geometrias destes complexos de Cd utilizando como estrutura inicial as geometrias das bases isoladas obtidas na seção 4.1.1.

Chamamos a atenção para o fato de que apesar de se encontrar na literatura estudos sobre a geometria e os sítios de ligação do Cd com as bases nitrogenadas isoladas $[13,12,10,50]$, não encontramos cálculos de GCE para as interações entre o íon $C d^{2+}$ e as bases nitrogenadas isoladas. 


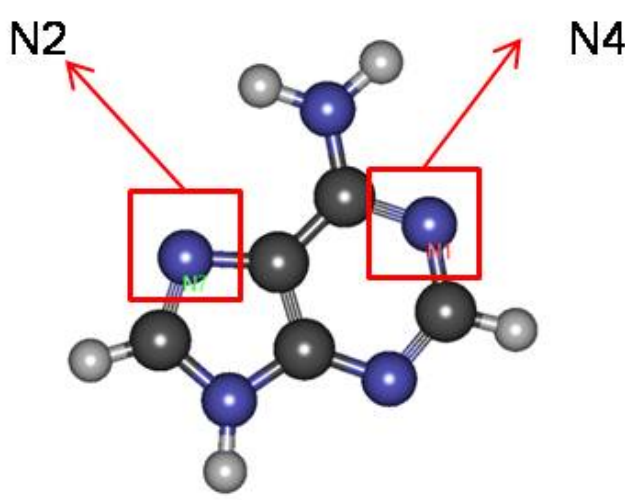

Adenina

(a)

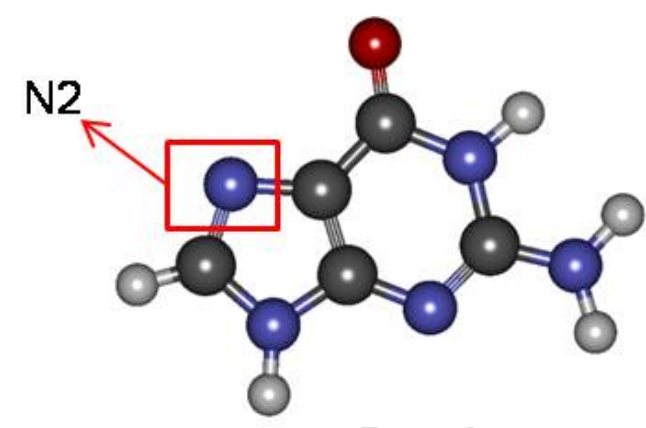

Guanina

Figura 4.14: Sítios de ligação dos metais na molécula: a) adenina;b) guanina, conforme sugerido na referência [4].

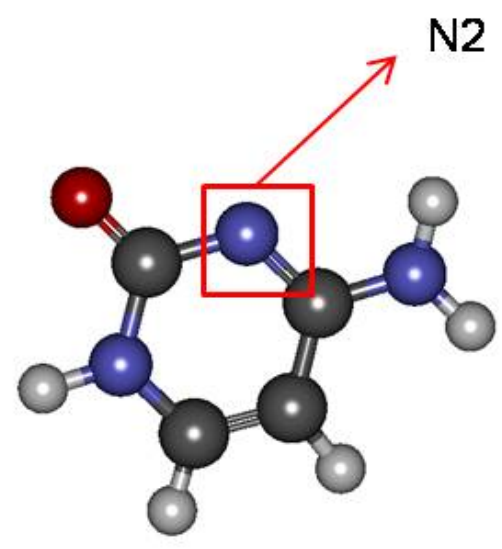

Citosina

(a)

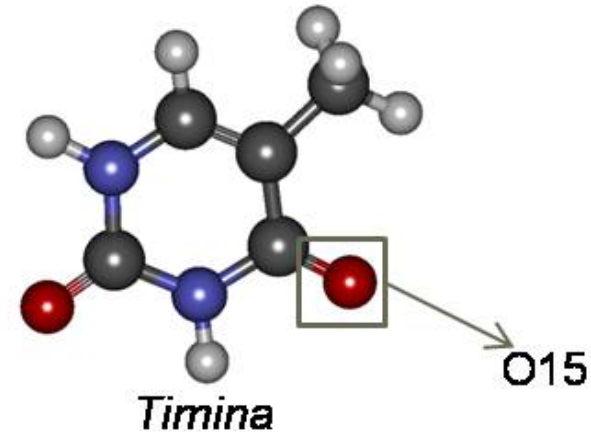

(b)

Figura 4.15: Sítios de ligação dos metais na molécula: a) citosina;b) timina, conforme sugerido na referência [4]. 


\subsubsection{Otimização de Geometria do Cd Ligado as Bases Ni- trogenadas}

Para simular o íon $C d^{2+}$ interagindo com as bases nitrogenadas, retiramos 2 elétrons do sistema "Cd+ Base nitrogenada", em cada caso.

\section{Adenina}

Apresentamos na figura 4.16 os resultados antes e depois da otimização de geometria obtido para a interação do Cd e adenina nos sítios N2 (figuras 4.16a e 4.16b) e N4 (figuras 4.16c e 4.16d). Para distância inicial do Cd aos sítios N2 e N4 da adenina, mostrada na figura 4.16a e 4.16c utilizamos resultados da literatura obtidos teoricamente por Hartree-Fock com a teoria de pertubação de segunda ordem Møller-Plesset (HF + MP2) [10] e DFT com funcional híbrido B3LYP e base $6-311++\mathrm{G}$ (3df, 2pd) [13]. Na tabelas 4.12 e 4.13 comparamos os valores por nós obtidos após a otimização de geometria, no presente trabalho, para a distância de ligação N2-Cd e N4-Cd com os valores obtidos nas referências [10, 13]. Notamos que em ambos os cálculos o Cd se liga ao N2, já que as distâncias de ligação são aproximadamente $2 \AA$. É interessante notar que os nossos resultados indicam que o Cd também se liga ao sítio N4 estando de acordo com a ref. [13], embora a ref. [10] não analise esta possibilidade. Notamos também que em ambos os casos (sítio N2 e sítio N4) o Cd também se liga ao sítio N3, conforme a figura 4.16b e 4.16d. 


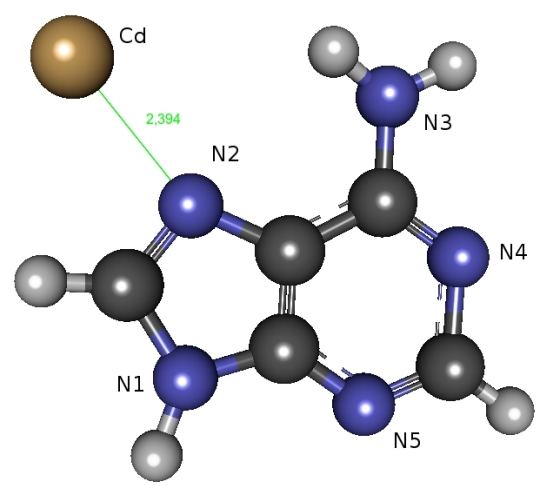

(a)

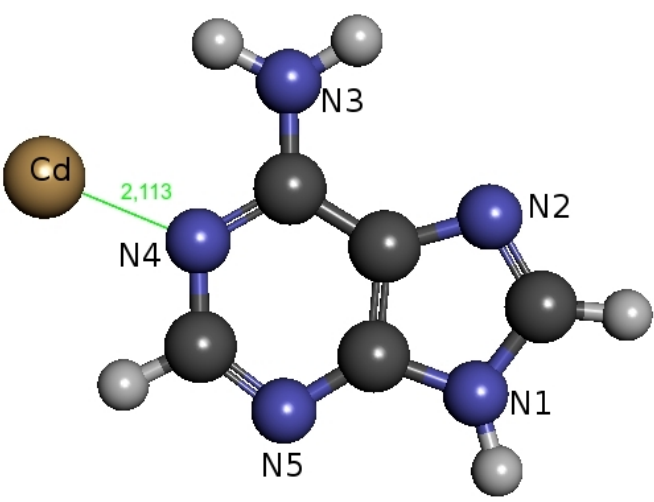

(c)

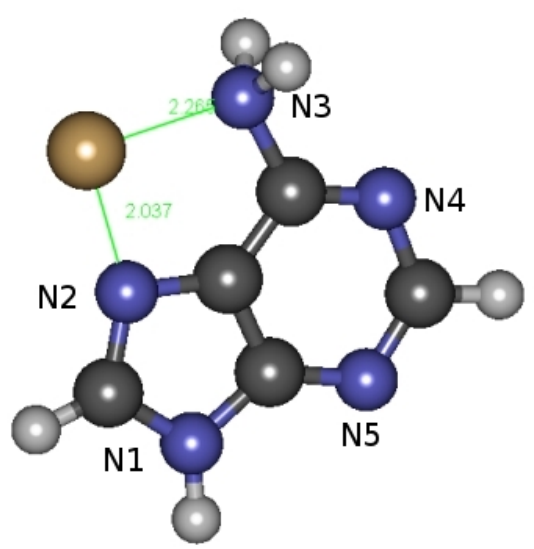

(b)

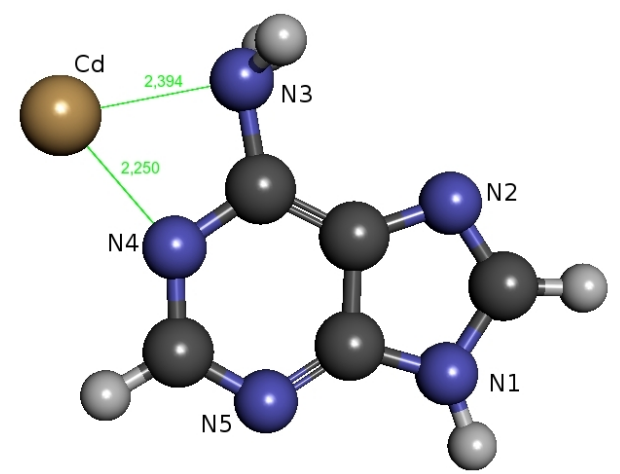

(d)

Figura 4.16: (a) $C d^{+2}$ ligado no sítio N2 da adenina antes da otimização de geometria e em (b) a estrutura após a otimização de geometria. Em (c) o $C d^{+2}$ ligado no sítio N4 da adenina antes da otimização e em (d) geometria obtida após otimização de geometria. As distâncias de ligação Cd-Adenina estão em verde. 
Tabela 4.12: Distância de ligação Cd-N2 e Cd-N3 da adenina [Å] obtido no presente trabalho utilizando o código CP-PAW após relaxação estrutural do sistema. Apresentamos também os valores obtidos utilizando os códigos Gaussian92 (Hartree-Fock + MP2) [10] e Gaussian03 (funcional B3LYP e base 6$311++\mathrm{G}(3 \mathrm{df}, 2 \mathrm{pd}))[13]$ da literatura.

\begin{tabular}{ccc}
\hline \hline $\begin{array}{c}\text { Método } \\
\text { Computacional }\end{array}$ & Distância Cd-N2 Adenina & Distância Cd-N3 Adenina \\
\hline CP-PAW & 2.04 & 2.26 \\
Gaussian92 & 2.12 & - \\
Gaussian03 & 2.16 & 2.28 \\
\hline
\end{tabular}

Tabela 4.13: Distância de ligação Cd-N4 e Cd-N3 da adenina [Å] obtido no presente trabalho utilizando o código CP-PAW após relaxação estrutural do sistema. Apresentamos também os valores obtidos utilizando o código Gaussian03 (funcional B3LYP e base 6-311 $++\mathrm{G}(3 \mathrm{df}, 2 \mathrm{pd}))$ [13] da literatura.

\begin{tabular}{ccc}
\hline \hline $\begin{array}{c}\text { Método } \\
\text { Computacional }\end{array}$ & Distância Cd-N4 Adenina & Distância Cd-N3 Adenina \\
\hline CP-PAW & 2.25 & 2.39 \\
Gaussian03 & 2.20 & 2.35 \\
\end{tabular}




\section{Guanina}

Apresentamos na figura 4.17 os resultados antes e depois da otimização de geometria obtido para a interação do Cd e guanina no sítio N2 (figuras 4.17a e 4.17b). Para distância inicial do Cd ao sítio N2 da guanina, mostrada na figura 4.17a utilizamos resultados da literatura obtidos teoricamente utilizando HartreeFock com a teoria de perturbação de segunda ordem Møller-Plesset (HF + MP2) [10]. Na tabela 4.14 comparamos os valores por nós obtidos após a otimização de geometria no presente trabalho para a distância de ligação Cd-N2 e Cd-O16 com os valores obtidos na referência [10].

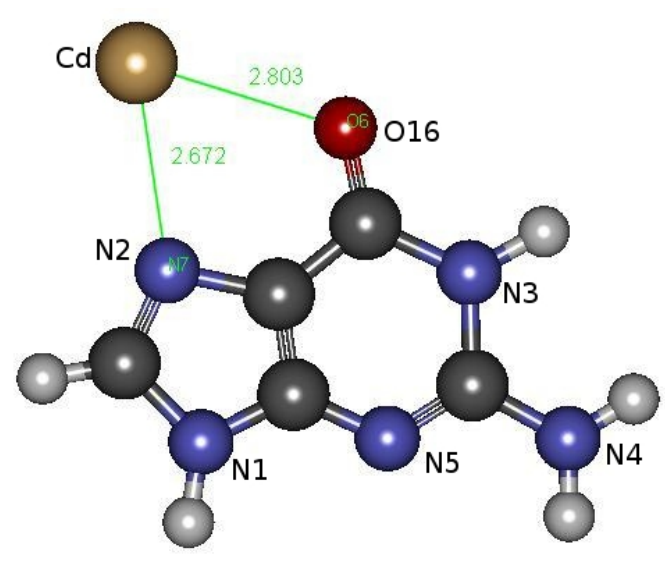

(a)

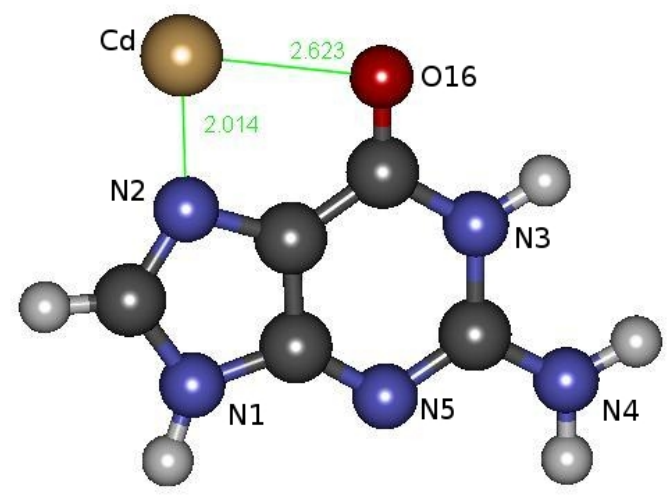

(b)

Figura 4.17: (a) $C d^{+2}$ ligado no sítio N2 da guanina antes da otimização de geometria e em (b) a estrutura após a otimização de geometria. As distâncias de ligação Cd-Guanina estão em verde.

Notamos nos nossos cálculos que o Cd se liga ao N2 e ao O16, já que as distâncias de ligação são aproximadamente $2 \AA$ (tabela 4.14). É interessante notar também que nos cálculos obtidos com o Gaussian92 da literatura (ref. [10]) o Cd também se liga ao N2 e ao O16. No entanto, na geometria otimizada pelo gaussian 92, o Cd está mais centrado entre o N2 e o O16 enquanto que na geometria otimizada pelo CP-PAW o Cd está mais próximo do N2. 
Tabela 4.14: Distância de ligação Cd-N2 e Cd-O16 da guanina [Å] obtido no presente trabalho utilizando o código CP-PAW após relaxação estrutural do sistema. Apresentamos também os valores obtidos utilizando o código Gaussian92 (Hartree-Fock + MP2) [10] da literatura.

\begin{tabular}{ccc}
\hline $\begin{array}{c}\text { Método } \\
\text { Computacional }\end{array}$ & $\begin{array}{c}\text { Distância } \\
\text { Cd-N2 }\end{array}$ & $\begin{array}{c}\text { Distância } \\
\text { Cd-O16 }\end{array}$ \\
\hline CP-PAW & 2.01 & 2.62 \\
Gaussian92 & 2.24 & 2.18 \\
& & \\
\hline \hline
\end{tabular}

\section{Citosina}

Apresentamos na figura 4.18 os resultados antes e depois da otimização de geometria obtido para a interação do Cd e citosina no sítio N2 (figuras 4.18a e 4.18b). Na figura 4.18 mostramos também os valores por nós obtidos após a otimização de geometria no presente trabalho para a distância de ligação Cd-N2 e Cd-O13. Notamos nos nossos cálculos que o Cd se liga ao N2 e ao O13, já que as distâncias de ligação são aproximadamente $2 \AA$ (figura 4.18). Não temos resultados na literatura para comparar os nossos valores obtidos. Analisando a figura 4.18 verificamos que o Cd apresenta preferência de ligação tanto ao N2 quanto ao O13 no caso da citosina. 


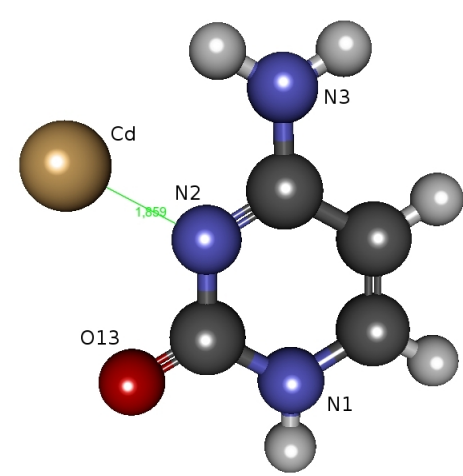

(a)

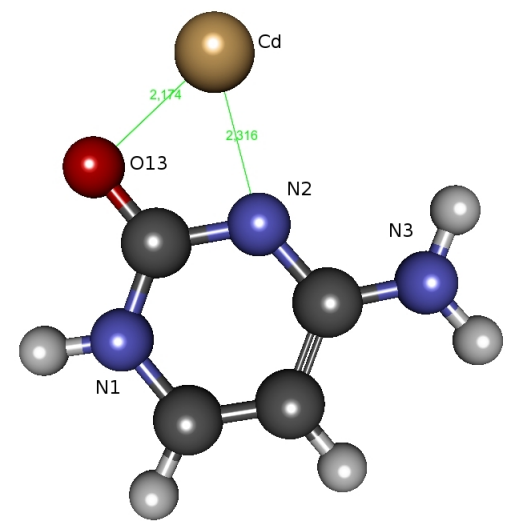

(b)

Figura 4.18: (a) $C d^{+2}$ ligado no sítio N2 da citosina antes da otimização de geometria e em (b) a estrutura após a otimização de geometria. As distâncias de ligação Cd-Citosina estão em verde.

\section{Timina}

Apresentamos na figura 4.19 os resultados antes e depois da otimização de geometria obtido para a interação do Cd e timina no sítio O15 (figuras 4.19a e 4.19b). Na figura 4.19 mostramos também os valores por nós obtidos após a otimização de geometria no presente trabalho para a distância de ligação Cd-O15 e Cd-H4. Notamos nos nossos cálculos que o Cd se liga ao O15, já que as distâncias de ligação são aproximadamente $2 \AA$ (figura 4.19). No entanto, verificamos que o Cd está se distanciando do átomo H4 (figura 4.19b) devido repulsão eletrostática. Na tabela 4.15 comparamos os valores por nós obtidos após a otimização de geometria, no presente trabalho para a distância de ligação Cd-O15 com os valores obtidos na referência [13]. Todos os resultados aqui apresentados confirmam as sugestões de sítios de ligação do Cd nas bases nitrogenadas apresentados nas figuras $4.14 \mathrm{e}$ 4.15 . 


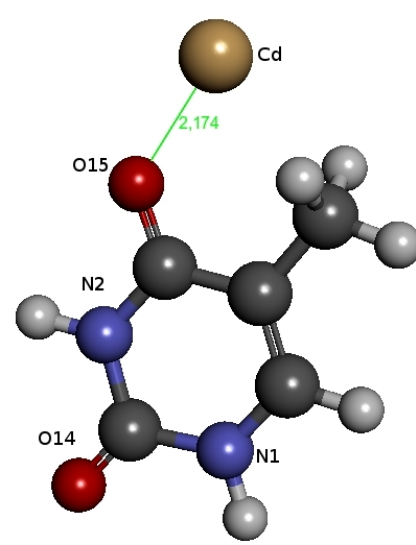

(a)

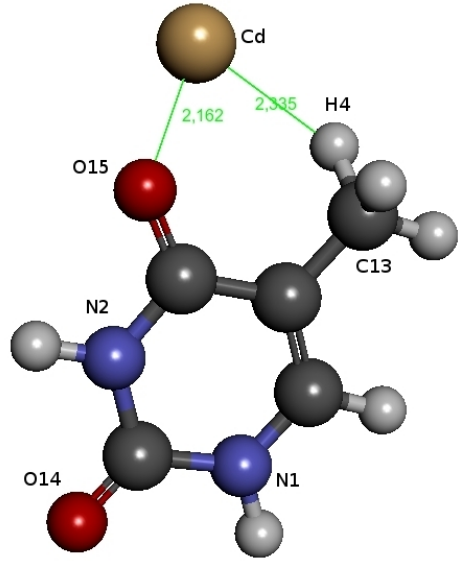

(b)

Figura 4.19: (a) Estrutura Cd com timina antes da otimização de energia. (b) Estrutura otimizada com o CP-PAW.

Tabela 4.15: Distância de ligação Cd-O15 e Cd-H4 da timina [Å] obtido no presente trabalho utilizando o código CP-PAW após relaxação estrutural do sistema. Apresentamos também os valores obtidos utilizando o código Gaussian03 (funcional B3LYP e base 6-311++G(3df,2pd)) [13] da literatura.

\begin{tabular}{ccc}
\hline \hline Método & & \\
Computacional & Distância Cd-O15 Timina & Distância Cd-H4 Timina \\
\hline CP-PAW & 2.16 & 2.33 \\
Gaussian03 & 2.14 & - \\
& & \\
\hline \hline
\end{tabular}

\subsubsection{GCE para o Cd Ligado as Bases Nitrogenadas}

Para os cálculos de $\nu_{q}$ utilizamos os valores de momento de quadrupolo nuclear Q obtidos da referência [45]. Para os sítios de nitrogênio utilizamos $Q^{N}=20,44 \pm$ $0,03 m b\left(1 m b=10^{-31} m^{2}\right)$, para os sítios de oxigênio utilizamos $Q^{O}=25,58 \pm$ $0,22 m b$ e para os sítios de Cd utilizamos $Q^{C d}=780 \pm 90 m b$. 


\section{Adenina}

Na figura 4.20 temos os valores de $V_{z z}, V_{y y}$ e $V_{x x}$ e na tabela 4.16 os correspondentes resultados de $\nu_{q}$ e $\eta$ nos sítios de nitrogênio da adenina e no sítio do $\mathrm{Cd}$ ligado ao N2 (fig. 4.16b). Comparando estes resultados com os apresentados na

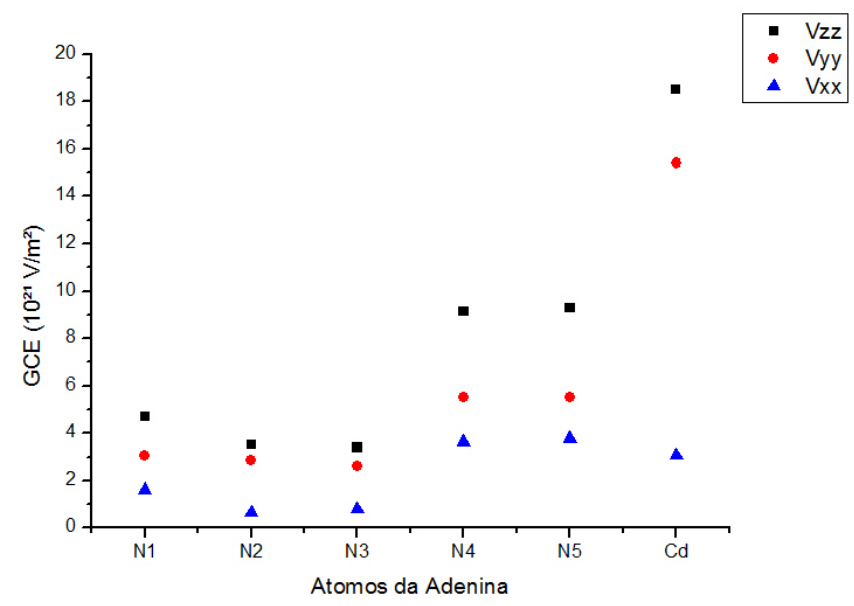

Figura 4.20: $V_{z z}, V_{y y}$ e $V_{x x}$ no Cd ligado ao sítio N2 da adenina.

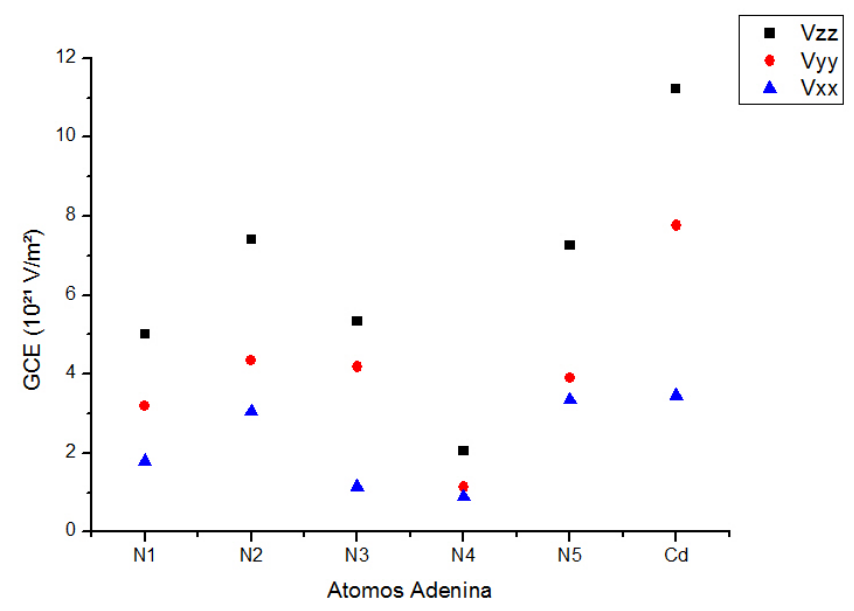

Figura 4.21: $V_{z z}, V_{y y}$ e $V_{x x}$ do Cd ligado no sítio N4 da adenina.

tabela 4.5 vemos que os valores de $V_{z z}$ nos sítios N2 e N3 são os mais afetados com 
a inserção do Cd no sistema conforme esperado. Vemos também na tabela 4.16 que o $\nu_{q}$ no sítio do Cd é bem maior do que o dos sítios de $\mathrm{N}$.

Na figura 4.21 temos os valores de $V_{z z}, V_{y y}$ e $V_{x x}$ e na tabela 4.17 os resultados de $\nu_{q}$ e $\eta$ nos sítios de nitrogênio da adenina e no sítio do Cd ligado ao N4 (fig. $4.16 \mathrm{~d})$. Analogamente ao observado para o N2 notamos que o valor de $V_{z z}$ no sítios N4 é o mais afetado com a inserção do Cd no sistema, conforme esperado. O valor de $V_{z z}$ do Cd, quando este ligado ao sítio N4, diminui $30 \%$ em relação ao Cd ligado ao sítio de ligação N2.

Tabela 4.16: Valores de $\nu_{q}[\mathrm{Mhz}]$ e $\eta$ para os átomos de nitrogênio e átomo de cádmio inserido no sítio_N2 da molécula de adenina.

\begin{tabular}{ccc} 
Átomos & $\eta$ & $\nu_{q}$ \\
\hline$N_{1}$ & 0,3 & $2,317 \pm 0,001$ \\
$N_{2}$ & 0,6 & $1,739 \pm 0,001$ \\
$N_{3}$ & 0,53 & $1,675 \pm 0,001$ \\
$N_{4}$ & 0,2 & $4,529 \pm 0,001$ \\
$N_{5}$ & 0,19 & $4,581 \pm 0,001$ \\
$C d$ & 0,66 & $52,310 \pm 0,090$
\end{tabular}


Tabela 4.17: Valores de $\nu_{q}$ [Mhz] e $\eta$ para os átomos de nitrogênio da molécula de adenina e átomo de cádmio com o Cd ligado ao sítio N4.

\begin{tabular}{ccc} 
Átomos & $\eta$ & $\nu_{q}$ \\
\hline$N_{1}$ & 0,3 & $2,468 \pm 0,001$ \\
$N_{2}$ & 0,2 & $3,653 \pm 0,001$ \\
$N_{3}$ & 0,57 & $2,636 \pm 0,001$ \\
$N_{4}$ & 0,1 & $1,015 \pm 0,001$ \\
$N_{5}$ & 0,08 & $3,587 \pm 0,001$ \\
$C d$ & 0,38 & $31,738 \pm 0,090$
\end{tabular}

\section{Guanina}

Na figura 4.22 temos os valores de $V_{z z}, V_{y y}$ e $V_{x x}$ e na tabela 4.18 os resultados de $\nu_{q}$ e $\eta$ nos sítios de nitrogênio, oxigênio da guanina e no sítio do Cd ligado ao N2 (fig. 4.17 b). Comparando estes resultados com os apresentados na tabela 4.6 que os valores de $\nu_{q}$ nos sítios N2 e O16 são os mais afetados com a inserção do Cd no sistema conforme esperado. O valor de $\nu_{q}$ no sítio do Cd é bem maior do que o dos sítios de N.

Verificamos (através da figura 4.22) que os valores de $V_{z z}, V_{y y}, V_{x x}$ para o nitrogênio N2 são os menores quando comparados aos outros átomos de nitrogênio da molécula. 


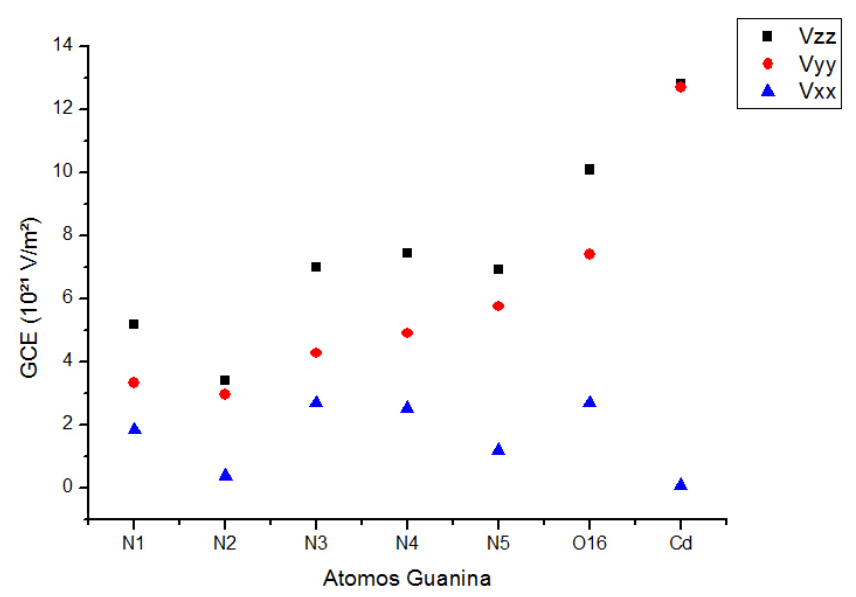

Figura 4.22: Valores de $V_{z z}, V_{y y}$ e $V_{x x}$ do Cd ligado no sítio N2 da guanina.

Tabela 4.18: Valores de $\nu_{q}[\mathrm{Mhz}]$ e $\eta$ para os átomos de nitrogênio e oxigênio da molécula de guanina e átomo de cádmio pelo método CP-PAW.

\begin{tabular}{ccc} 
Átomos & $\eta$ & $\nu_{q}$ \\
\hline$N_{1}$ & 0,3 & $2,570 \pm 0,001$ \\
$N_{2}$ & 0,75 & $1,672 \pm 0,001$ \\
$N_{3}$ & 0,22 & $3,465 \pm 0,001$ \\
$N_{4}$ & 0,32 & $3,677 \pm 0,001$ \\
$N_{5}$ & 0,65 & $3,418 \pm 0,001$ \\
$O_{16}$ & 0,46 & $6,244 \pm 0,022$ \\
$C d$ & 0,98 & $36,200 \pm 0,090$
\end{tabular}




\section{Citosina}

Na figura 4.23 temos os valores de $V_{z z}, V_{y y}$ e $V_{x x}$ e na tabela 4.19 os resultados de $\nu_{q}$ e $\eta$ nos sítios de nitrogênio, oxigênio da citosina e no sítio do Cd ligado ao $\mathrm{N} 2$ (fig. 4.18 b). Comparando os resultados apresentados na figura 4.23 temos que o valor de $V_{z z}$ no sítio de O13 é maior do que o $V_{z z}$ no sítio do Cd. No entanto, o valor de $\nu_{q}$ no sítio do Cd é maior que o $\nu_{q}$ no sítio do O13 devido ao fato de que os valores de $\mathrm{Q}$ nos dois núcleos são muito diferentes, sendo o $Q^{C d}$ uma ordem de grandeza maior que o $Q^{O}$.

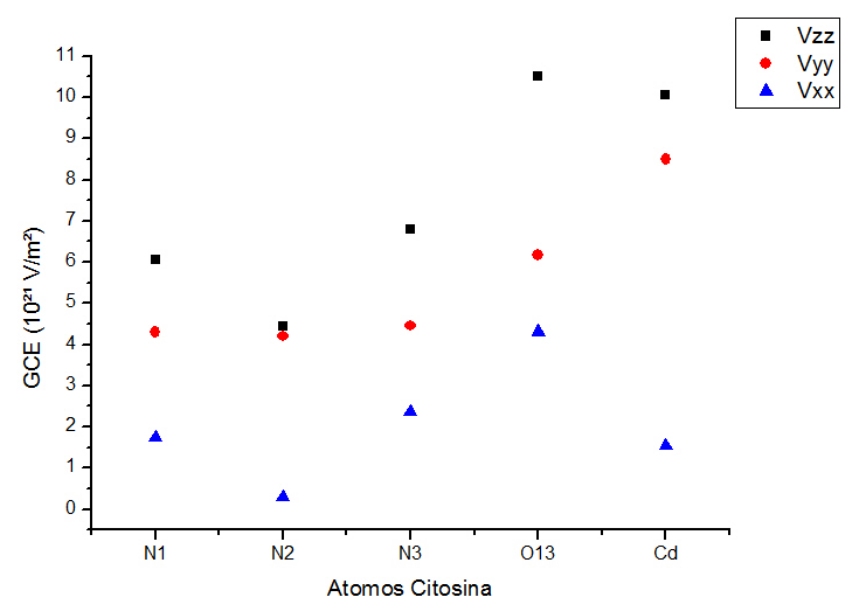

Figura 4.23: Valores de $V_{z z}, V_{y y}$ e $V_{x x}$ do Cd ligado no sítio N2 da citosina. 
Tabela 4.19: Valores de $\nu_{q}$ [Mhz] e $\eta$ para os sítios de nitrogênio e oxigênio da molécula de citosina e sítio de Cd.

\begin{tabular}{ccc} 
Átomos & $\eta$ & $\nu_{q}$ \\
\hline$N_{1}$ & 0,42 & $3,000 \pm 0,001$ \\
$N_{2}$ & 0,88 & $2,200 \pm 0,001$ \\
$N_{3}$ & 0,30 & $3,365 \pm 0,001$ \\
$O_{13}$ & 0,18 & $6,500 \pm 0,022$ \\
$C d$ & 0,70 & $28,423 \pm 0,090$ \\
\hline \hline
\end{tabular}

\section{Timina}

Na figura 4.24 temos os valores de $V_{z z}, V_{y y}$ e $V_{x x}$ e na tabela 4.20 os resultados de $\nu_{q}$ e $\eta$ nos sítios de nitrogênio, oxigênio da citosina e no sítio do Cd ligado ao O15 (fig. 4.19b).

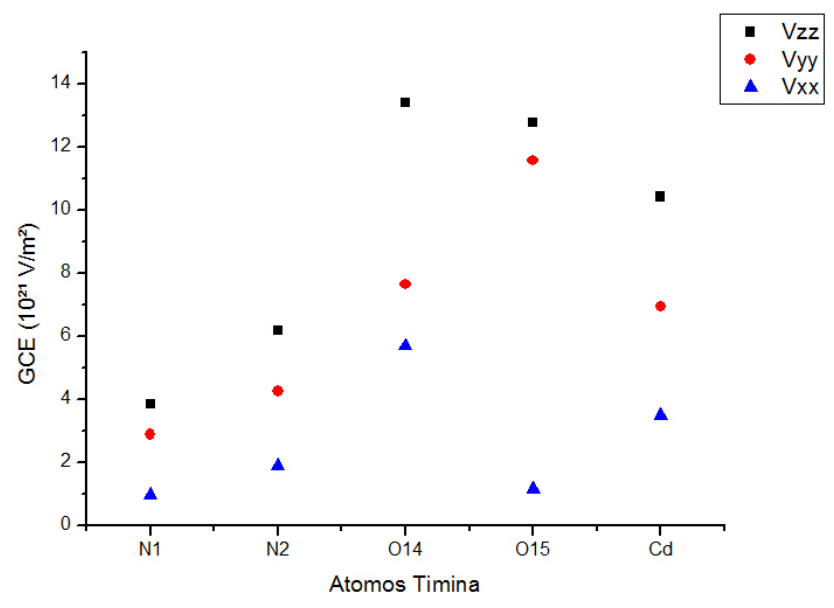

Figura 4.24: Valores de $V_{z z}, V_{y y}$ e $V_{x x}$ do Cd ligado no sítio O15 da timina. 
Tabela 4.20: Valores de $\nu_{q}[\mathrm{Mhz}]$ e $\eta$ para os átomos de nitrogênio e oxigênio da molécula de timina e átomo de Cd.

\begin{tabular}{ccc} 
Átomos & $\eta$ & $\nu_{q}$ \\
\hline$N_{1}$ & 0,5 & $1,910 \pm 0,001$ \\
$N_{2}$ & 0,34 & $3,058 \pm 0,001$ \\
$O_{14}$ & 0,15 & $8,281 \pm 0,022$ \\
$O_{15}$ & 0,82 & $7,898 \pm 0,022$ \\
$C d$ & 0,33 & $29,487 \pm 0,090$ \\
\hline \hline
\end{tabular}

Os valores de $V_{z z}$ do Cd para as moléculas de timina e citosina estão muito próximos, indicando que a interação do Cd nos sítios N2 da citosina e O15 da timina ocorrem de forma semelhante. No entanto, o valor de $\eta$ obtido da interação do Cd com a timina $(\eta=0,33)$ é aproximadamente a metade do valor obtido do Cd interagindo com a citosina $(\eta=0,70)$ e desta forma podemos diferenciá-los.

\subsection{Inserindo Moléculas de Água no Sistema}

Medidas utilizando a técnica TDPAC obtidas com o decaimento ${ }^{111} \mathrm{In} \rightarrow{ }^{111} \mathrm{Cd}$, foram realizadas em meio aquoso (ácido nítrico, hidróxido de sódio e água) com Cd metálico para investigar a interação do Cd com as bases nitrogenadas do DNA [51]. Sendo assim, para comparar, entender e interpretar os resultados obtidos pelo grupo do professor A. Carbonari do IPEN utilizando TDPAC, inserimos moléculas de água nos sistemas estudados na seção precedente. Notamos que o valor de $Q=830 \pm 14 m b$ para o Cd [52] foi utilizado para obter os valores de $V_{z z}$ nas medidas TDPAC. O primeiro passo para simular de forma adequada o ambiente químico no 
qual o Cd ligado a uma dada base nitrogenada está inserido, foi estudar a química de coordenação do $\mathrm{Cd}$ nestes casos. Encontramos diversas vezes na literatura o Cd coordenando com seis ligantes e com estrutura octaédrica quando ligado a uma base nitrogenada $[53,54,50]$. Entretanto, neste trabalho, testamos também outras coordenações para o $\mathrm{Cd}$, além da mais comum na literatura. Todas as medidas TDPAC apresentadas neste trabalho ainda não foram publicadas [51] e, foram feitas à temperatura $77 \mathrm{~K}$ e são aqui comparadas com simulações computacionais feitas a zero Kelvin utilizando o CP-PAW.

Para efeito de notação nos complexos com Cd e moléculas de água, nos referiremos às bases nitrogenadas nas fórmulas moleculares: $C_{5} H_{5} N_{5}$ para a adenina, $\mathrm{C}_{5} \mathrm{H}_{5} \mathrm{~N}_{5} \mathrm{O}$ para a guanina, $\mathrm{C}_{4} \mathrm{H}_{5} \mathrm{~N}_{3} \mathrm{O}$ para a citosina e $\mathrm{C}_{5} \mathrm{H}_{6} \mathrm{~N}_{2} \mathrm{O}_{2}$ para a timina, nas discussões a seguir. Utilizaremos nas tabelas 4.24, 4.25, 4.26 e 4.27 a notação $\left(B A^{a g u a}\right)$, onde $B$ são os átomos da base nitrogenada e $A^{\text {agua }}$ são os átomos das moléculas de água que fazem coordenação com o Cd.

\subsubsection{Otimização de Geometria dos Sistemas Estudados}

Adenina: Otimização das Geometrias dos Complexos $\left[\mathrm{Cd}\left(\mathrm{C}_{5} \mathrm{H}_{5} \mathrm{~N}_{5}\right)\left(\mathrm{H}_{2} \mathrm{O}\right)_{n}\right]^{2+}$

Consideramos as coordenações 5 e 6 no caso da molécula de adenina ligada ao Cd. Não fizemos as simulações com o Cd ligado ao sítio N4 devido ao fato de ocorrer um impedimento estérico das moléculas de água ao se ligarem ao $\mathrm{Cd}$ quando este está ligado ao sitio N4. Isto ocorre devido o sítio N4 estar geralmente localizado na alça menor do DNA e fazer ligação de hidrogênio com a timina, dificultando a interação do Cd com moléculas de água neste sítio. No entanto, não descartamos a possibilidade de termos o caso de o Cd, sozinho, estar ligado ao sítio N4.

A geometria otimizada para o $\left[\mathrm{Cd}\left(\mathrm{C}_{5} \mathrm{H}_{5} \mathrm{~N}_{5}\right)\left(\mathrm{H}_{2} \mathrm{O}\right)_{3}\right]^{2+}$ é mostrada na figura 
4.25a e, para o $\left[\mathrm{Cd}\left(\mathrm{C}_{5} \mathrm{H}_{5} \mathrm{~N}_{5}\right)\left(\mathrm{H}_{2} \mathrm{O}\right)_{5}\right]^{2+}$ na figura 4.25b. Apresentamos na tabela 4.21 as distâncias de ligação entre o $\mathrm{Cd}$ e a adenina para os complexos da figura 4.25. Vemos que o Cd permanece estável em ambas configurações apresentadas: coordenação 5 e 6.

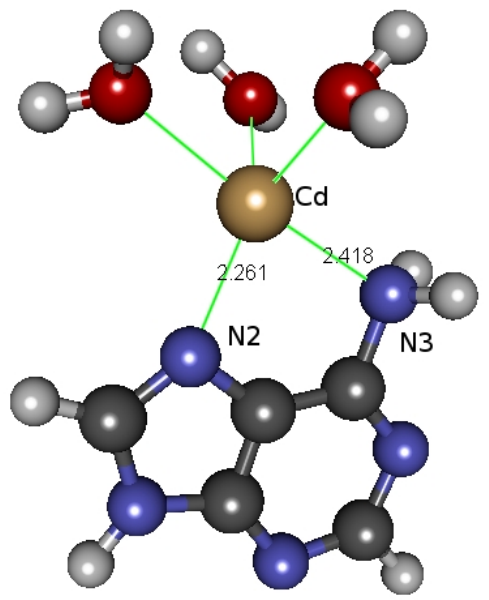

(a)

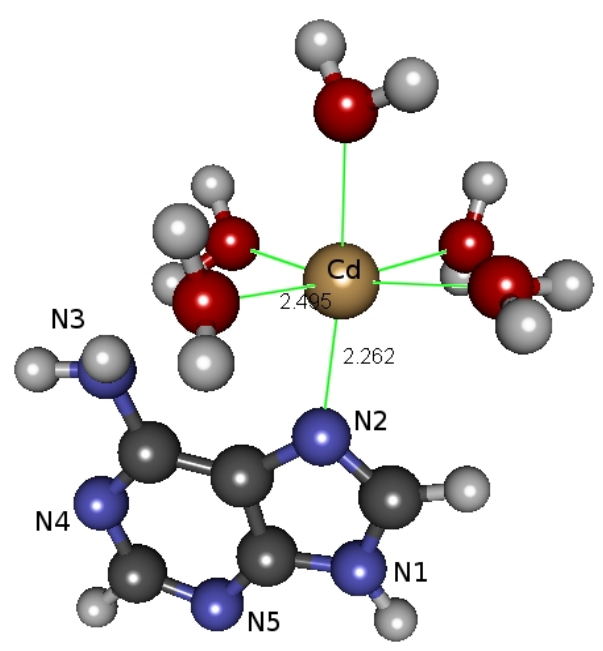

(b)

Figura 4.25: Estruturas otimizadas dos complexos com o Cd ligado ao sítio N2 da $\mathrm{C}_{5} \mathrm{H}_{5} \mathrm{~N}_{5}$ em: a) pentacoordenado, $\left[\mathrm{Cd}\left(\mathrm{C}_{5} \mathrm{H}_{5} \mathrm{~N}_{5}\right)\left(\mathrm{H}_{2} \mathrm{O}\right)_{3}\right]^{2+}$; b) hexacoordenado $\left[\mathrm{Cd}\left(\mathrm{C}_{5} \mathrm{H}_{5} \mathrm{~N}_{5}\right)\left(\mathrm{H}_{2} \mathrm{O}\right)_{5}\right]^{2+}$.

Tabela 4.21: Distância de ligação Cd-N2 e Cd-N3 $[\AA]$ dos complexos pentacoordenado $\left[\mathrm{Cd}\left(\mathrm{C}_{5} \mathrm{H}_{5} \mathrm{~N}_{5}\right)\left(\mathrm{H}_{2} \mathrm{O}\right)_{3}\right]^{2+}$ e hexacoordenado $\left[\mathrm{Cd}\left(\mathrm{C}_{5} \mathrm{H}_{5} \mathrm{~N}_{5}\right)\left(\mathrm{H}_{2} \mathrm{O}\right)_{5}\right]^{2+}$ obtido no presente trabalho utilizando o código CP-PAW após relaxação estrutural do sistema.

\begin{tabular}{ccc}
\hline \hline Complexo & $\begin{array}{c}\text { Distância de } \\
\text { ligação Cd-N2 }\end{array}$ & $\begin{array}{c}\text { Distância de } \\
\text { ligação Cd-N3 }\end{array}$ \\
\hline$\left[\mathrm{Cd}\left(\mathrm{C}_{5} \mathrm{H}_{5} \mathrm{~N}_{5}\right)\left(\mathrm{H}_{2} \mathrm{O}\right)_{3}\right]^{2+}$ & 2,261 & 2,418 \\
{$\left[\mathrm{Cd}\left(\mathrm{C}_{5} \mathrm{H}_{5} \mathrm{~N}_{5}\right)\left(\mathrm{H}_{2} \mathrm{O}\right)_{5}\right]^{2+}$} & 2,262 & - \\
& & \\
\hline \hline
\end{tabular}


Guanina: Otimização das Geometrias dos Complexos $\left[\mathrm{Cd}\left(\mathrm{C}_{5} \mathrm{H}_{5} \mathrm{~N}_{5} \mathrm{O}\right)\left(\mathrm{H}_{2} \mathrm{O}\right)_{n}\right]^{2+}$

Estudamos três sistemas que simulam a guanina ligada ao $\mathrm{Cd}$ em meio aquoso: $\left[\mathrm{Cd}\left(\mathrm{C}_{5} \mathrm{H}_{5} \mathrm{~N}_{5} \mathrm{O}\right)\left(\mathrm{H}_{2} \mathrm{O}\right)_{3}\right]^{2+},\left[\mathrm{Cd}\left(\mathrm{C}_{5} \mathrm{H}_{5} \mathrm{~N}_{5} \mathrm{O}\right)\left(\mathrm{H}_{2} \mathrm{O}\right)_{5}\right]^{2+}$ e $\left[\mathrm{Cd}\left(\mathrm{C}_{5} \mathrm{H}_{5} \mathrm{~N}_{5} \mathrm{O}\right)\left(\mathrm{H}_{2} \mathrm{O}\right)_{4}\right]^{2+}$, com o Cd ligado ao O16 e N2 da guanina. As geometrias otimizadas obtidas com o CP-PAW para estes 3 sistemas são apresentadas na figura 4.26 e as respectivas distâncias de ligação entre o Cd e a guanina são apresentadas na tabela 4.22. Novamente verificamos que o Cd permanece estável em todas configurações apresentadas: coordenação 4 e 6 .

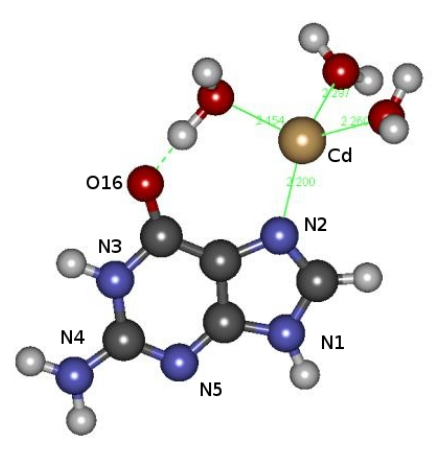

(a)

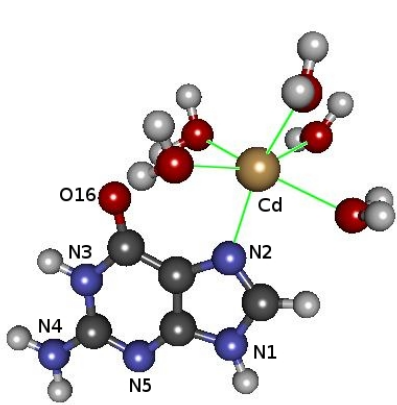

(b)

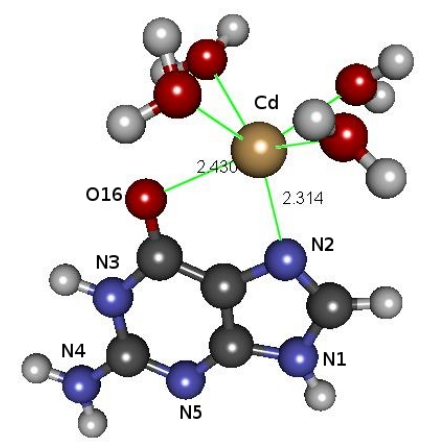

(c)

Figura 4.26: Estruturas otimizadas dos complexos com o $\mathrm{Cd}$ ligado ao sítio $\mathrm{N} 2$ e $\mathrm{O} 16$ da $\mathrm{C}_{5} \mathrm{H}_{5} \mathrm{~N}_{5} \mathrm{O}$ em: a) tetracoordenado, $\left[\mathrm{Cd}\left(\mathrm{C}_{5} \mathrm{H}_{5} \mathrm{~N}_{5} \mathrm{O}\right)\left(\mathrm{H}_{2} \mathrm{O}\right)_{3}\right]^{2+}$; b) hexacoordenado $\left[\mathrm{Cd}\left(\mathrm{C}_{5} \mathrm{H}_{5} \mathrm{~N}_{5} \mathrm{O}\right)\left(\mathrm{H}_{2} \mathrm{O}\right)_{5}\right]^{2+}$; c) hexacoordenado $\left[\mathrm{Cd}\left(\mathrm{C}_{5} \mathrm{H}_{5} \mathrm{~N}_{5} \mathrm{O}\right)\left(\mathrm{H}_{2} \mathrm{O}\right)_{4}\right]^{2+}$. 
Tabela 4.22: Distância de ligação Cd-N2 e Cd-N3 [A] dos complexos tetracoordenado $\left[\mathrm{Cd}\left(\mathrm{C}_{5} \mathrm{H}_{5} \mathrm{~N}_{5} \mathrm{O}\right)\left(\mathrm{H}_{2} \mathrm{O}\right)_{3}\right]^{2+}$ e complexos hexacoordenados $\left[\mathrm{Cd}\left(\mathrm{C}_{5} \mathrm{H}_{5} \mathrm{~N}_{5} \mathrm{O}\right)\left(\mathrm{H}_{2} \mathrm{O}\right)_{5}\right]^{2+}$ e $\left[\mathrm{Cd}\left(\mathrm{C}_{5} \mathrm{H}_{5} \mathrm{~N}_{5} \mathrm{O}\right)\left(\mathrm{H}_{2} \mathrm{O}\right)_{4}\right]^{2+}$ obtidos no presente trabalho utilizando o código CP-PAW após relaxação estrutural do sistema.

\begin{tabular}{ccc}
\hline \hline Complexo & $\begin{array}{c}\text { Distância de } \\
\text { ligação Cd-N2 }\end{array}$ & $\begin{array}{c}\text { Distância de } \\
\text { ligação Cd-O16 }\end{array}$ \\
\hline$\left[\mathrm{Cd}\left(\mathrm{C}_{5} \mathrm{H}_{5} \mathrm{~N}_{5} \mathrm{O}\right)\left(\mathrm{H}_{2} \mathrm{O}\right)_{3}\right]^{2+}$ & 2,20 & - \\
{$\left[\mathrm{Cd}\left(\mathrm{C}_{5} \mathrm{H}_{5} \mathrm{~N}_{5} \mathrm{O}\right)\left(\mathrm{H}_{2} \mathrm{O}\right)_{5}\right]^{2+}$} & 2,30 & - \\
{$\left[\mathrm{Cd}\left(\mathrm{C}_{5} \mathrm{H}_{5} \mathrm{~N}_{5} \mathrm{O}\right)\left(\mathrm{H}_{2} \mathrm{O}\right)_{4}\right]^{2+}$} & 2,31 & 2,43 \\
\hline
\end{tabular}

Timina: Otimização da Geometria do Complexo $\left[\mathrm{Cd}\left(\mathrm{C}_{5} \mathrm{H}_{6} \mathrm{~N}_{2} \mathrm{O}_{2}\right)\left(\mathrm{H}_{2} \mathrm{O}\right)_{5}\right]^{2+}$

Simulamos a interação do Cd com a molécula de timina em meio aquoso. Num futuro trabalho pretendemos estudar outras geometrias para o complexo $\left[\mathrm{Cd}\left(\mathrm{C}_{5} \mathrm{H}_{6} \mathrm{~N}_{2} \mathrm{O}_{2}\right)\left(\mathrm{H}_{2} \mathrm{O}\right)_{n}\right]^{2+}$. Optamos pela geometria da figura 4.27 por termos a coordenação do Cd mais utilizada na literatura (coordenação 6) e por ser o sítio O15 com maior probabilidade de interação com o $\mathrm{Cd}$ na timina. A geometria otimizada para o complexo $\left[\mathrm{Cd}\left(\mathrm{C}_{5} \mathrm{H}_{6} \mathrm{~N}_{2} \mathrm{O}_{2}\right)\left(\mathrm{H}_{2} \mathrm{O}\right)_{5}\right]^{2+}$ é mostrada na figura 4.27. A distância de ligação do Cd com o sítio O15 da timima é 2,18 A, como mostrado na figura 4.27. Vemos que o Cd permanece estável com esta configuração de coordenação 6 e ele não se liga ao hidrogênio do N2 devido repulsão eletrostática. 


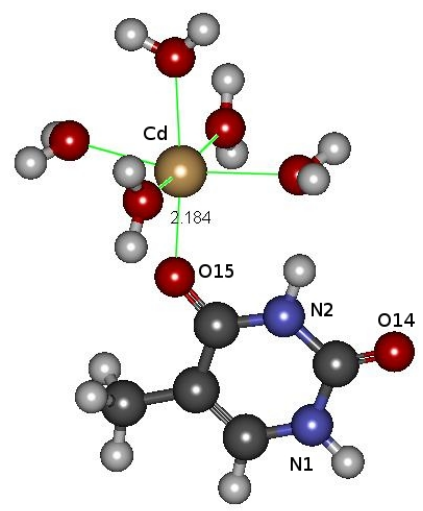

(a)

Figura 4.27: Estrutura otimizada do complexo com o $\mathrm{Cd}$ hexacoordenado $\left[\mathrm{Cd}\left(\mathrm{C}_{5} \mathrm{H}_{6} \mathrm{~N}_{2} \mathrm{O}_{2}\right)\left(\mathrm{H}_{2} \mathrm{O}\right)_{5}\right]^{2+}$ ligado ao sítio $\mathrm{O} 15$ da $\mathrm{C}_{5} \mathrm{H}_{6} \mathrm{~N}_{2} \mathrm{O}_{2}$.

Citosina: Otimização das Geometrias dos Complexos $\left[\mathrm{Cd}\left(\mathrm{C}_{4} \mathrm{H}_{5} \mathrm{~N}_{3} \mathrm{O}\right)\left(\mathrm{H}_{2} \mathrm{O}\right)_{n}\right]^{2+}$

Apresentamos na figura 4.28 as geometrias otimizadas para os dois sistemas que simulamos para o Cd ligado à citosina em meio aquoso. A figura 4.28a mostra a estrutura otimizada do complexo $\left[\mathrm{Cd}\left(\mathrm{C}_{4} \mathrm{H}_{5} \mathrm{~N}_{3} \mathrm{O}\right)\left(\mathrm{H}_{2} \mathrm{O}\right)_{5}\right]^{2+}$ e em $4.28 \mathrm{~b}$ a estrutura otimizada do complexo $\left[\mathrm{Cd}\left(\mathrm{C}_{4} \mathrm{H}_{5} \mathrm{~N}_{3} \mathrm{O}\right)\left(\mathrm{H}_{2} \mathrm{O}\right)_{4}\right]^{2+}$ com o Cd ligado ao N2 e O13 da citosina. As distâncias de ligação entre o Cd e a citosina nestes casos são mostradas na tabela 4.23 .

Tabela 4.23: Distância de ligação Cd-N2 e Cd-O13 [A] dos complexos hexacoordenados $\left[\mathrm{Cd}\left(\mathrm{C}_{4} \mathrm{H}_{5} \mathrm{~N}_{3} \mathrm{O}\right)\left(\mathrm{H}_{2} \mathrm{O}\right)_{5}\right]^{2+}$ e $\left[\mathrm{Cd}\left(\mathrm{C}_{4} \mathrm{H}_{5} \mathrm{~N}_{3} \mathrm{O}\right)\left(\mathrm{H}_{2} \mathrm{O}\right)_{4}\right]^{2+}$ obtidos no presente trabalho utilizando o código CP-PAW após relaxação estrutural do sistema.

\begin{tabular}{ccc}
\hline \hline Complexo & $\begin{array}{c}\text { Distância de } \\
\text { ligação Cd-N2 }\end{array}$ & $\begin{array}{c}\text { Distância de } \\
\text { ligação Cd-O13 }\end{array}$ \\
\hline$\left[\mathrm{Cd}\left(\mathrm{C}_{4} \mathrm{H}_{5} \mathrm{~N}_{3} \mathrm{O}\right)\left(\mathrm{H}_{2} \mathrm{O}\right)_{5}\right]^{2+}$ & 2,37 & - \\
{$\left[\mathrm{Cd}\left(\mathrm{C}_{4} \mathrm{H}_{5} \mathrm{~N}_{3} \mathrm{O}\right)\left(\mathrm{H}_{2} \mathrm{O}\right)_{4}\right]^{2+}$} & 2,40 & 2,33 \\
& & \\
\hline
\end{tabular}




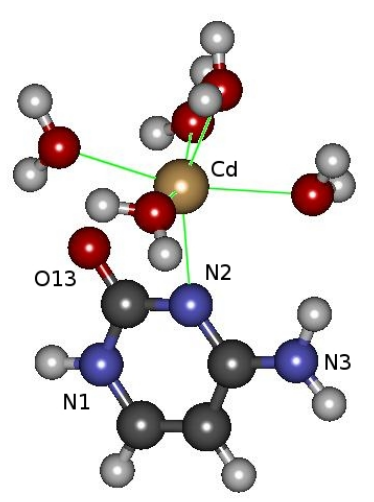

(a)

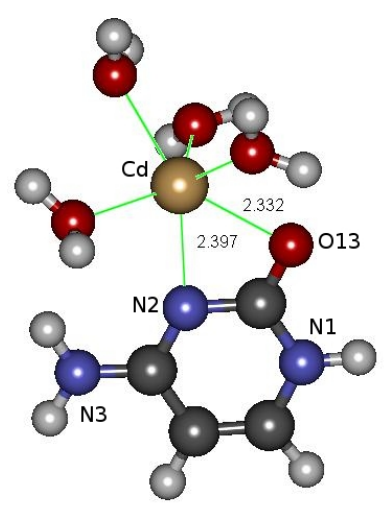

(b)

Figura 4.28: Estruturas otimizadas dos complexos com o Cd ligado ao sítio N2 e O13 da $\mathrm{C}_{4} \mathrm{H}_{5} \mathrm{~N}_{3} \mathrm{O}$ em: a) hexacoordenado, $\left[\mathrm{Cd}\left(\mathrm{C}_{4} \mathrm{H}_{5} \mathrm{~N}_{3} \mathrm{O}\right)\left(\mathrm{H}_{2} \mathrm{O}\right)_{5}\right]^{2+}$; b) hexacoordenado, $\left[\mathrm{Cd}\left(\mathrm{C}_{4} \mathrm{H}_{5} \mathrm{~N}_{3} \mathrm{O}\right)\left(\mathrm{H}_{2} \mathrm{O}\right)_{4}\right]^{2+}$.

Vemos que o Cd permanece estável em ambas configurações apresentadas de coordenação 6 e notamos que na estrutura otimizada do complexo $\left[\mathrm{Cd}\left(\mathrm{C}_{4} \mathrm{H}_{5} \mathrm{~N}_{3} \mathrm{O}\right)\left(\mathrm{H}_{2} \mathrm{O}\right)_{5}\right]^{2+}$ não temos a interação do Cd com o O13 (figura 4.28a) devido ao impedimento das moléculas de água em torno do $\mathrm{Cd}$, o que não ocorre no caso da otimização de geometria da estrutura $\left[\mathrm{Cd}\left(\mathrm{C}_{4} \mathrm{H}_{5} \mathrm{~N}_{3} \mathrm{O}\right)\left(\mathrm{H}_{2} \mathrm{O}\right)_{4}\right]^{2+}$ (figura 4.28b). Isto nos indica que o $\mathrm{Cd}$, nestes sistemas, tem a preferência de estar com a coordenação 6 . 


\subsubsection{Cálculos de GCE para os sistemas estudados}

Nas tabelas 4.24 (adenina), 4.25 (guanina), 4.26 (timina) e 4.27 (citosina) apresentamos os resultados de $V_{z z}$ e $\eta$ para os diferentes sítios de ligação do Cd nas bases nitrogenadas analisados no presente trabalho, juntamente com os resultados experimentais preliminares das interações entre as bases nitrogenadas e o isótopo ${ }^{111} \mathrm{Cd}$ inferidos a partir de medidas TDPAC [51].

No caso da adenina, tabela 4.24, vemos que o valor de $V_{z z}$ obtido experimentalmente para o decaimento ${ }^{111} \mathrm{In} \rightarrow{ }^{111} \mathrm{Cd}$ está mais próximo do $V_{z z}$ calculado para a situação $N O_{5}^{a g u a}$, descrito pela figura 4.25b. Notamos, entretanto, que o valor de $\eta$ medido se assemelha mais ao valor de $\eta$ calculado para a situação $N_{2} O_{3}^{a g u a}$, descrito ela figura 4.25a.

Tabela 4.24: Valores de $V_{z z}\left[10^{21} \mathrm{~V} / \mathrm{m}^{2}\right]$, e $\eta$ obtidos com o código CP-PAW, para os complexos $\left[\mathrm{Cd}\left(\mathrm{C}_{5} \mathrm{H}_{5} \mathrm{~N}_{5}\right)\left(\mathrm{H}_{2} \mathrm{O}\right)_{3}\right]^{2+}$ e $\left[\mathrm{Cd}\left(\mathrm{C}_{5} \mathrm{H}_{5} \mathrm{~N}_{5}\right)\left(\mathrm{H}_{2} \mathrm{O}\right)_{5}\right]^{2+}$. Apresentamos também os valores experimentais [51] obtidos com TDPAC.

\begin{tabular}{ccc}
\hline \hline $\begin{array}{c}\text { Coordenação } \\
\text { do Cd (CP-PAW) }\end{array}$ & $V_{z z}$ & $\eta$ \\
\hline$N_{2} O_{3}^{\text {agua }}$ & 9,56 & 0,48 \\
$N_{5}^{\text {agua }}$ & 7,14 & 0,94 \\
\hline $\begin{array}{c}\text { Experimental } \\
(\text { TDPAC) }\end{array}$ & & \\
${ }^{111} \mathrm{In} \rightarrow{ }^{111} \mathrm{Cd}$ & $7,13 \pm 0,12$ & $0,52 \pm 0,02$ \\
\hline \hline
\end{tabular}


No caso da guanina, tabela 4.25 , vemos que o valor de $V_{z z}$ obtido experimentalmente para o decaimento ${ }^{111} \mathrm{In} \rightarrow{ }^{111} \mathrm{Cd}$ está mais próximo do $V_{z z}$ calculado para a situação $\mathrm{NOO}_{4}^{\text {agua }}$, descrito pela figura 4.26c. Notamos, entretanto, que o valor de $\eta$ medido se assemelha mais ao valor de $\eta$ calculado para a situação $\mathrm{NO}_{3}^{\text {agua }}$, descrito ela figura 4.26a.

Tabela 4.25: Valores de $V_{z z}\left[10^{21} V / m^{2}\right]$ e $\eta$ obtidos com o código CP-PAW, para o Cd dos complexos $\left[\mathrm{Cd}\left(\mathrm{C}_{5} \mathrm{H}_{5} \mathrm{~N}_{5} \mathrm{O}\right)\left(\mathrm{H}_{2} \mathrm{O}\right)_{3}\right]^{2+},\left[\mathrm{Cd}\left(\mathrm{C}_{5} \mathrm{H}_{5} \mathrm{~N}_{5} \mathrm{O}\right)\left(\mathrm{H}_{2} \mathrm{O}\right)_{5}\right]^{2+} \mathrm{e}$ $\left[\mathrm{Cd}\left(\mathrm{C}_{5} \mathrm{H}_{5} \mathrm{~N}_{5} \mathrm{O}\right)\left(\mathrm{H}_{2} \mathrm{O}\right)_{4}\right]^{2+}$. Apresentamos também os valores experimentais [51] obtidos com TDPAC.

\begin{tabular}{ccc}
\hline \hline $\begin{array}{c}\text { Coordenação } \\
\text { do Cd (CP-PAW) }\end{array}$ & $V_{z z}$ & $\eta$ \\
\hline$N O_{3}^{\text {agua }}$ & 11,74 & 0,61 \\
$N O_{5}^{\text {agua }}$ & 4,83 & 0,52 \\
$N O O_{4}^{\text {agua }}$ & 5,80 & 0,90 \\
\hline $\begin{array}{c}\text { Experimental } \\
(\text { TDPAC) }\end{array}$ & \\
${ }^{111} \mathrm{In} \rightarrow{ }^{111} \mathrm{Cd}$ & $7,47 \pm 0,13$ & $0,58 \pm 0,03$ \\
\hline \hline
\end{tabular}

No caso da timina, tabela 4.26, vemos que o valor de $V_{z z}$ obtido experimentalmente para o decaimento ${ }^{111} \mathrm{In} \rightarrow{ }^{111} \mathrm{Cd}$ está bem próximo do $V_{z z}$ calculado para a situação $O O_{5}^{\text {agua }}$, descrito pela figura 4.27. Notamos, entretanto, que o valor de $\eta$ medido é exatamente o dobro do valor de $\eta$ calculado para a situação $O O_{5}^{\text {agua }}$. No caso da citosina, tabela 4.27, vemos que o valor de $V_{z z}$ obtido experimentalmente para o decaimento ${ }^{111} \mathrm{In} \rightarrow{ }^{111} \mathrm{Cd}$ está mais próximo do $V_{z z}$ calculado para a situação $N_{4} O_{4}^{a g u a}$, descrito pela figura 4.28b. Neste caso, o valor de $\eta$ medido também se assemelha mais ao valor de $\eta$ calculado para a situação $N O O_{4}^{a g u a}$. 
Tabela 4.26: Valores de $V_{z z}\left[10^{21} \mathrm{~V} / \mathrm{m}^{2}\right]$ e $\eta$ obtidos com o código CP-PAW, para o Cd do complexo $\left[\mathrm{Cd}\left(\mathrm{C}_{5} \mathrm{H}_{6} \mathrm{~N}_{2} \mathrm{O}_{2}\right)\left(\mathrm{H}_{2} \mathrm{O}\right)_{n}\right]^{2+}$. Apresentamos também os valores experimentais [51] obtidos com TDPAC.

\begin{tabular}{ccc}
\hline \hline $\begin{array}{c}\text { Coordenação } \\
\text { do Cd (CP-PAW) }\end{array}$ & $V_{z z}$ & $\eta$ \\
\hline$O O_{5}^{\text {agua }}$ & 7,08 & 0,30 \\
\hline $\begin{array}{c}\text { Experimental } \\
(\mathrm{TDPAC})\end{array}$ & & \\
${ }^{111} \mathrm{In} \rightarrow{ }^{111} \mathrm{Cd}$ & $6,94 \pm 0,12$ & $0,58 \pm 0,01$ \\
\hline \hline
\end{tabular}

Tabela 4.27: Valores de $V_{z z}\left[10^{21} V / m^{2}\right]$ e $\eta$ obtidos com o código CP-PAW, para o Cd dos complexos $\left[\mathrm{Cd}\left(\mathrm{C}_{4} \mathrm{H}_{5} \mathrm{~N}_{3} \mathrm{O}\right)\left(\mathrm{H}_{2} \mathrm{O}\right)_{5}\right]^{2+}$ e $\left[\mathrm{Cd}\left(\mathrm{C}_{4} \mathrm{H}_{5} \mathrm{~N}_{3} \mathrm{O}\right)\left(\mathrm{H}_{2} \mathrm{O}\right)_{4}\right]^{2+}$. Apresentamos também os valores experimentais [51] obtidos com TDPAC.

\begin{tabular}{|c|c|c|}
\hline $\begin{array}{c}\text { Coordenação } \\
\text { do Cd (CP-PAW) }\end{array}$ & $V_{z z}$ & $\eta$ \\
\hline$N O_{5}^{a g u a}$ & 5,22 & 0,14 \\
\hline $\begin{array}{c}\mathrm{NOO}_{4}^{\text {agua }} \\
\text { (ligado ao O13) }\end{array}$ & 8,33 & 0,50 \\
\hline $\begin{array}{l}\text { Experimental } \\
\text { (TDPAC) }\end{array}$ & & \\
\hline${ }^{111} \mathrm{In} \rightarrow{ }^{111} \mathrm{Cd}$ & $7,31 \pm 0,12$ & $0,51 \pm 0,02$ \\
\hline
\end{tabular}

\subsection{Estudo do $\mathrm{Cd}^{+2}$ Ligado a Pares de Bases Ni- trogenadas}

Como última etapa deste trabalho, investigamos a interação do Cd com os pares de bases nitrogenadas. Estudamos duas configurações possíveis para as interações entre o $\mathrm{Cd}$ com o par timina-adenina e três configurações para o par guanina-citosina. Até o presente momento, não existem medidas TDPAC para estes sistemas e ,desta forma, apresentaremos somente os resultados teóricos obti- 
dos com o CP-PAW. No entanto, existem medidas preliminares realizadas utilizando a técnica TDPAC [51] para os DNAs das famílias de camundongos A/J, C57BL/6, B6AF1, BXA1 e BXA2 conforme nomenclatura utilizada na referência [18]. As famílias de camundongos A/J, C57BL/6 e B6AF1 são de uma linhagem direta de camundongos infectados com T. Cruzi e as famílias BXA1 e BXA2 são de 20 gerações da linhagem infectada com T. Cruzi [18]. Os valores experimentais disponíveis no momento [51] de $V_{z z}$ e $\eta$ destas famílias são apresentados nas figuras 4.31 e 4.32 .

\subsubsection{Adenina-Timina}

Estudamos dois possíveis sítios de ligação do $\mathrm{Cd}$ ao par adenina-timina. Na figura 4.29a apresentamos a geometria obtida utilizando o CP-PAW quando inserimos o Cd entre o par adenina-timina. Podemos perceber, pela figura 4.29a, que o Cd não se mantêm estável nesta conformação, saindo do meio das bases. Isto ocorre devido a uma repulsão entre o $C d^{+2}$ e os átomos de $\mathrm{H}$ das bases vizinhos. Na tabela 4.28 temos os valores de $V_{z z}$ e $\eta$ no sítio do Cd para os dois sistemas mostrados na figura 4.29 .

O valor de $V_{z z}$ no sítio do Cd quando colocado inicialmente entre as bases é maior que o $V_{z z}$ obtido nos outros sistemas que aqui estudamos. Na figura 4.29b temos que, ao adicionarmos a base complementar da adenina (timina) ao sistema, este se mantêm estável e não observamos uma variação significativa do $V_{z z}$ no sítio de Cd quando comparado com o complexo $\left[\mathrm{Cd}\left(\mathrm{C}_{5} \mathrm{H}_{5} \mathrm{~N}_{5}\right)\left(\mathrm{H}_{2} \mathrm{O}\right)_{n}\right]^{2+}$ apresentado na seção 4.3.2. 


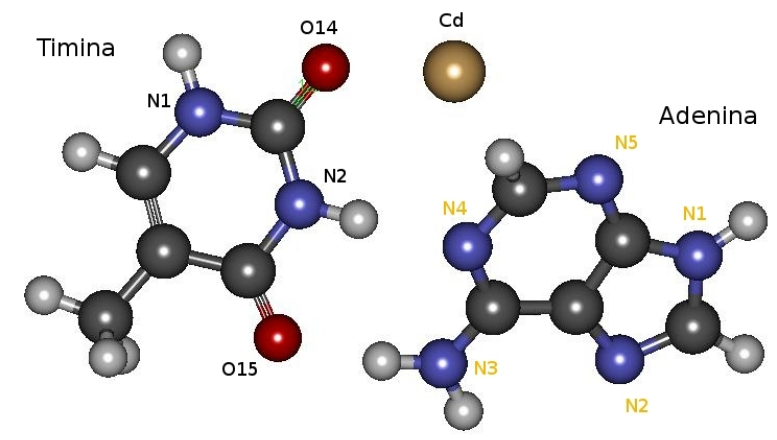

(a)

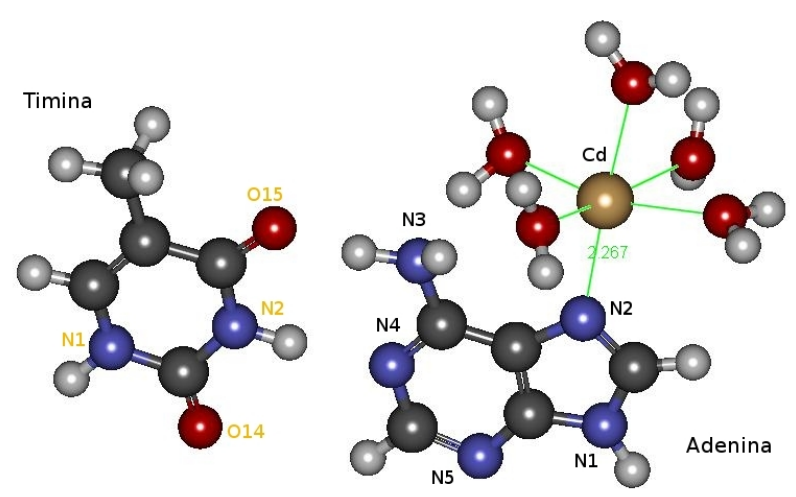

(b)

Figura 4.29: Estrutura otimizada do Cd ligado ao par de base adenina-timina: a) Cd entre as bases; b) Cd ligado ao sítio N2 da adenina.

Tabela 4.28: Valores de $V_{z z}\left[10^{21} \mathrm{~V} / \mathrm{m}^{2}\right]$ e $\eta$ obtidos com o código CP-PAW, no sítio de Cd coordenado com o $\mathrm{H} 4$ da adenina e O14 da timina e $N^{\text {adenina }} O_{5}^{\text {agua }}$ conforme figura 4.29 .

\begin{tabular}{ccc}
\hline \hline $\begin{array}{c}\text { Coordenação } \\
\text { do Cd (CP-PAW) }\end{array}$ & $V_{z z}$ & $\eta$ \\
\hline (4.29a)H4 e O14 & 16,80 & 0,5 \\
& & \\
$(4.29 b) N^{\text {adenina }} O_{5}^{\text {agua }}$ & 7,16 & 0,98 \\
\hline
\end{tabular}




\subsubsection{Guanina-Citosina}

No caso da guanina-citosina (GC) interagindo com o $\mathrm{Cd}^{2+}$ consideramos três possíveis geometrias iniciais: a) Cd está inserido entre o par GC (figura 4.30a); o Cd está próximo ao sítio do N2 da guanina (figura 4.30c); e por fim, o Cd está próximo ao $\mathrm{N} 2$ e $\mathrm{O}$ da guanina (figura 4.30b). Embora não seja possível ver na figura 4.30a, o Cd não se mantêm estável nesta conformação saindo do meio das bases. Na tabela 4.29 temos os valores de $V_{z z}$ e $\eta$ no sítio do Cd para os sistemas mostrados na figura 4.30 .

$\mathrm{O}$ valor de $V_{z z}$ no sítio do $\mathrm{Cd}$ quando colocado inicialmente entre as bases é bem maior $\left(V_{z z}=66,8010^{21} \mathrm{~V} / \mathrm{m}^{2}\right)$ que o $V_{z z}$ obtido nos outros sistemas que aqui estudamos. Nas figuras $4.30 \mathrm{~b}$ e $4.30 \mathrm{c}$ temos que, ao adicionarmos a base complementar da guanina (citosina) nestes sistemas, estes se mantêm estáveis e não observamos uma variação significativa do $V_{z z}$ no sítio de Cd quando comparado com os complexos $\left[\mathrm{Cd}\left(\mathrm{C}_{5} \mathrm{H}_{5} \mathrm{~N}_{5} \mathrm{O}\right)\left(\mathrm{H}_{2} \mathrm{O}\right)_{5}\right]^{2+}$ e $\left[\mathrm{Cd}\left(\mathrm{C}_{5} \mathrm{H}_{5} \mathrm{~N}_{5} \mathrm{O}\right)\left(\mathrm{H}_{2} \mathrm{O}\right)_{4}\right]^{2+}$ apresentado na seção 4.3.2.

Tabela 4.29: Valores de $V_{z z}\left[10^{21} \mathrm{~V} / \mathrm{m}^{2}\right]$ e $\eta$ obtidos com o código CP-PAW, no sítio de Cd coordenado com $H^{\text {guanina }}[N O]^{\text {citosina }},[N O]^{\text {guanina }} O_{4}^{\text {agua }}$ e $[N]^{\text {guanina }} O_{5}^{\text {agua }}$ o $\mathrm{H} 4$ da adenina e $\mathrm{O} 14$ da timina e $N^{\text {adenina }} O_{5}^{\text {agua }}$ conforme figura 4.30.

\begin{tabular}{ccc}
\hline \hline $\begin{array}{c}\text { Coordenação } \\
\text { do Cd (CP-PAW) }\end{array}$ & $V_{z z}$ & $\eta$ \\
\hline$(4.30 \mathrm{a}) H^{\text {guanina }}[N O]^{\text {citosina }}$ & 66,80 & 0,02 \\
$(4.30 \mathrm{~b})[N O]^{\text {guanina }} O_{4}^{\text {agua }}$ & 7,57 & 0,85 \\
$(4.30 \mathrm{c})[N]^{\text {guanina }} O_{5}^{\text {agua }}$ & 8,40 & 0,35
\end{tabular}




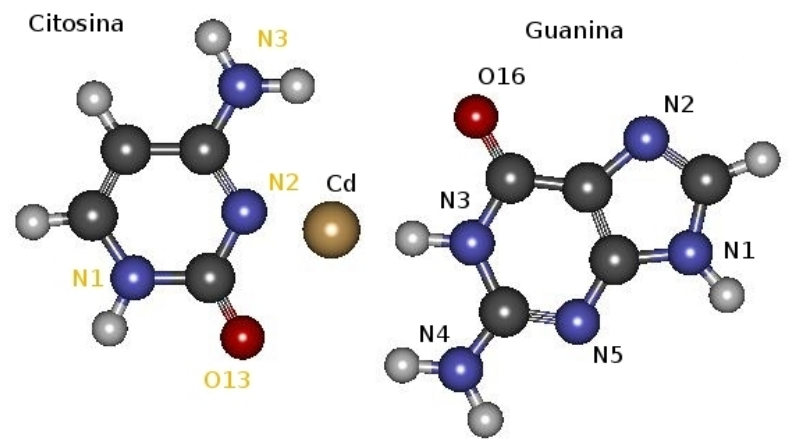

(a)

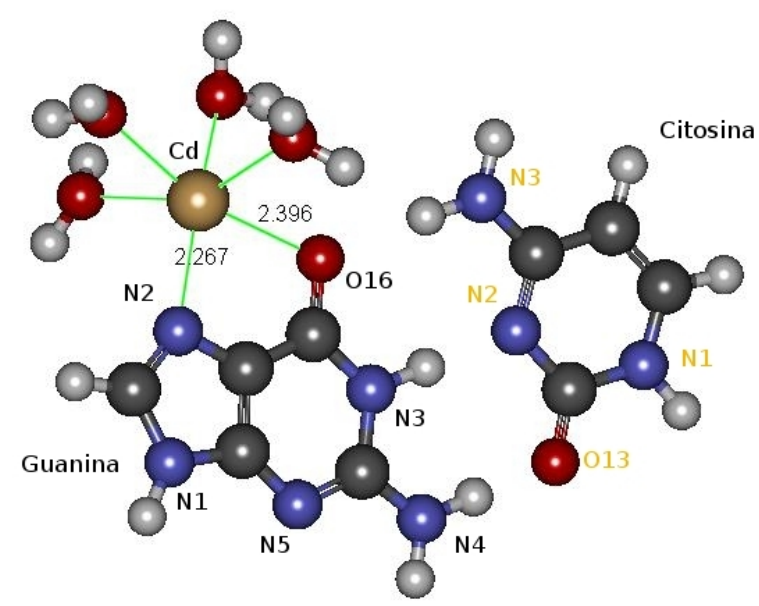

(b)

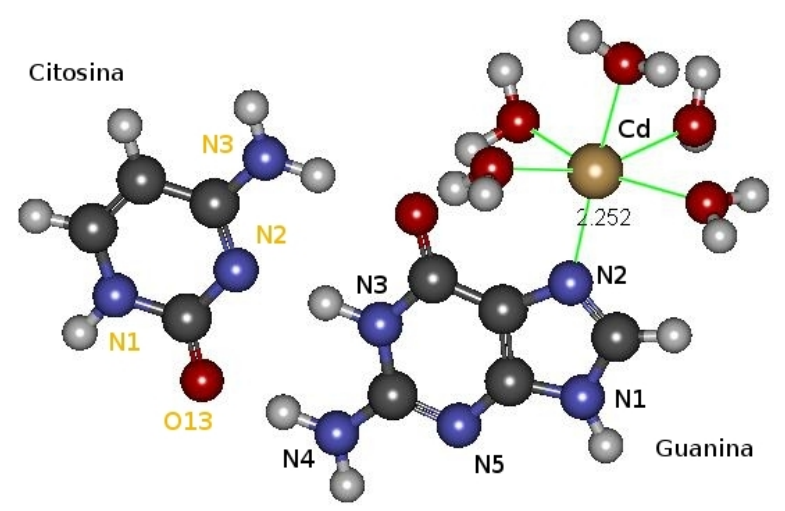

(c)

Figura 4.30: Estrutura otimizada do Cd ligado ao par guanina-citosina: a) Cd entre as bases; b) Cd ligado ao sítio N2 e O da guanina; c) Cd ligado somente ao sítio N2 da guanina. 


\subsubsection{Discussão dos Resultados de GCE}

Na tabela 4.30 apresentamos uma compilação dos resultados de $V_{z z}$ e $\eta$ obtidos nos sítios de Cd em todos os sistemas estudados neste trabalho. Para melhor visualização, estes resultados são apresentados nas figuras $4.31\left(V_{z z}\right)$ e $4.32(\eta)$ onde incluímos também os resultados preliminares [51] obtidos com TDPAC para diferentes linhagens de camundongos infectados com a T. Cruzi.

Nas figuras 4.31 e 4.32 retiramos os nossos resultados mais discrepantes em relação aos valores medidos por TDPAC e podemos verificar que os valores de $V_{z z}$, tanto teóricos quanto experimentais, estão na mesma faixa de valores (entre $5 \times 10^{21} V / m^{2}$ e $12 \times 10^{21} V / m^{2}$ )conforme mostrado na figura 4.31. As exceções ocorrem nas situações em que o Cd está ligado entre as bases $\mathrm{AT}$ ( $V_{z z}=$ $\left.16,80 \mathrm{X} 10^{21} \mathrm{~V} / \mathrm{m}^{2}\right)$ e $\mathrm{GC}\left(V_{z z}=66,80 \mathrm{X} 10^{21} \mathrm{~V} / \mathrm{m}^{2}\right)$ onde o $\mathrm{Cd}$ não permanece ligado aos pares de bases. Na maioria dos nossos resultados de $V_{z z}$ que estão na mesma faixa dos medidos por TDPAC, temos o Cd com coordenação 6, mostrando uma tendência da coordenação 6 do Cd na interação com as bases nitrogenadas e pares de bases conforme indicado pela literatura. No entanto, temos os casos das coordenações 4 ( $\mathrm{NO}_{3}^{\text {agua }}$ na guanina) e $5\left(\mathrm{~N}_{2} \mathrm{O}_{3}^{\text {agua }}\right.$ na adenina) do Cd que também possuem valores de $V_{z z}$ dentro desta faixa $\left(V_{z z}=11,74 \mathrm{X} 10^{21} \mathrm{~V} / \mathrm{m}^{2} \mathrm{e}\right.$ $V_{z z}=9,56 \times 10^{21} \mathrm{~V} / \mathrm{m}^{2}$ respectivamente). Notamos também que as medidas de $V_{z z}$ das famílias de 20 gerações da linhagem infectada com a T. cruzi (BXA1 e BXA2) estão mais de acordo com os valores de $V_{z z}$ destas coordenações de $\mathrm{Cd}$ menos usuais.

Analisando a figura 4.32, no primeiro momento, não temos nenhuma correlação entre o $\eta$ teórico e o experimental. Não conseguimos ver uma sistemática uma vez que o $\eta$ é um parâmetro muito sensível a interações intermoleculares de longo alcance [55] pois depende da simetria da molécula. Estudos futuros devem ser realizados para ajustar o $\eta$ em sistemas moleculares [55]. 


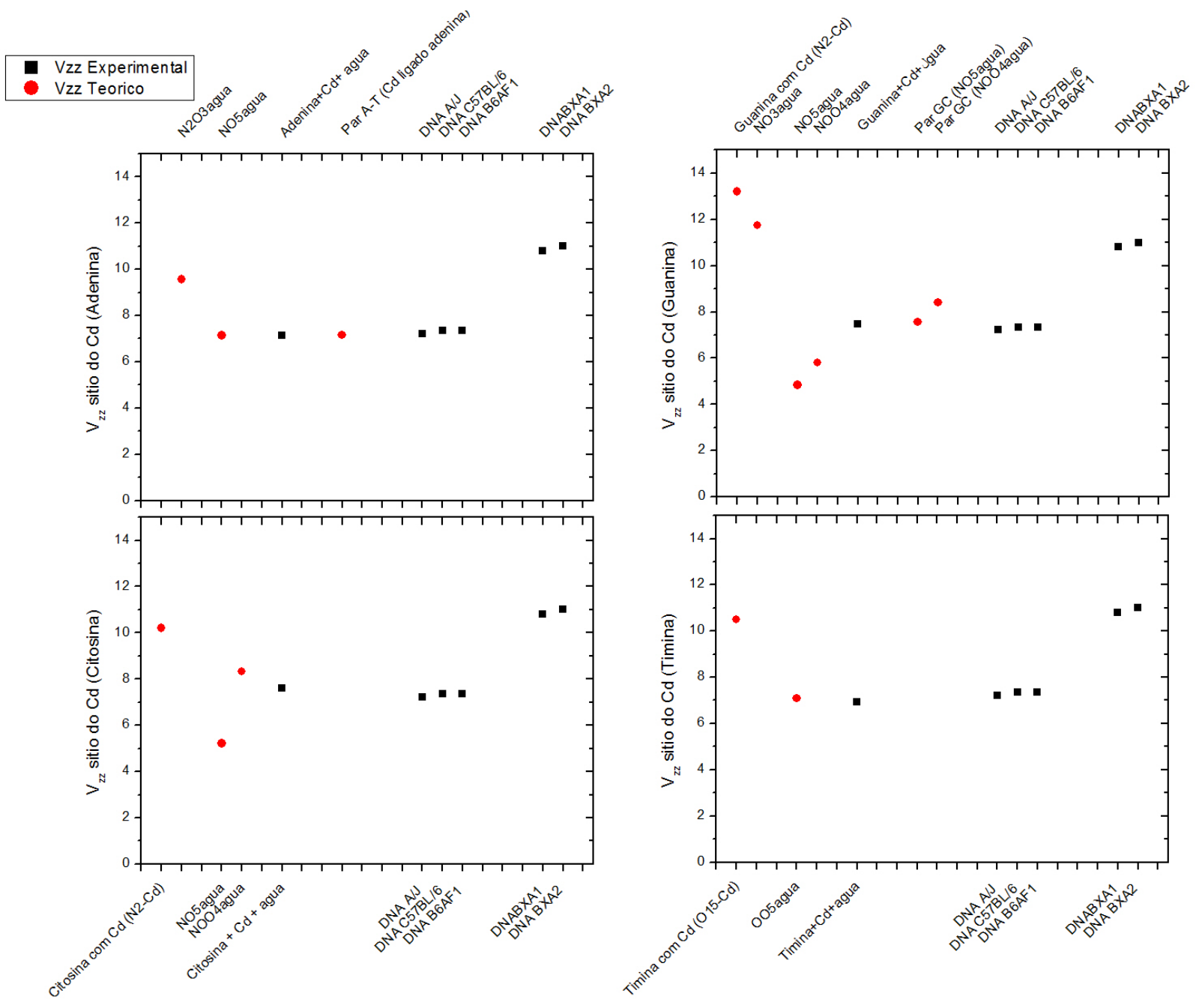

Figura 4.31: Valores de $V_{z z}\left[X 10^{21} \mathrm{~V} / \mathrm{m}^{2}\right]$ obtidos através de cálculos ab initio de estrutura eletrônica (CP-PAW) nos sítios de Cd em todos os sistemas estudados neste trabalho. Apresentamos também os valores experimentais obtidos por TDPAC para as bases nitrogenadas e famílias de camundongos infectados com a $\mathrm{T}$. Cruzi [18]. 


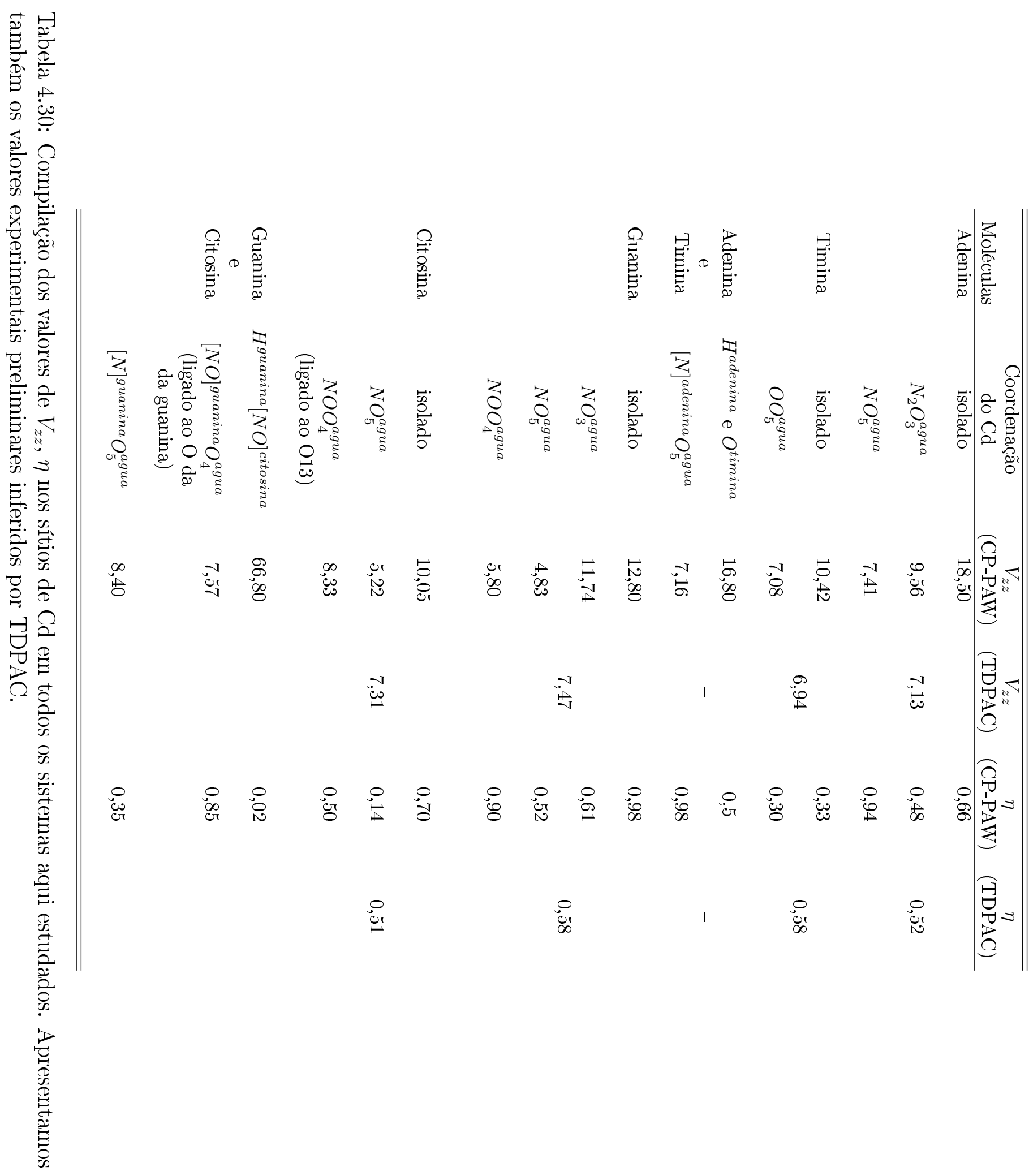




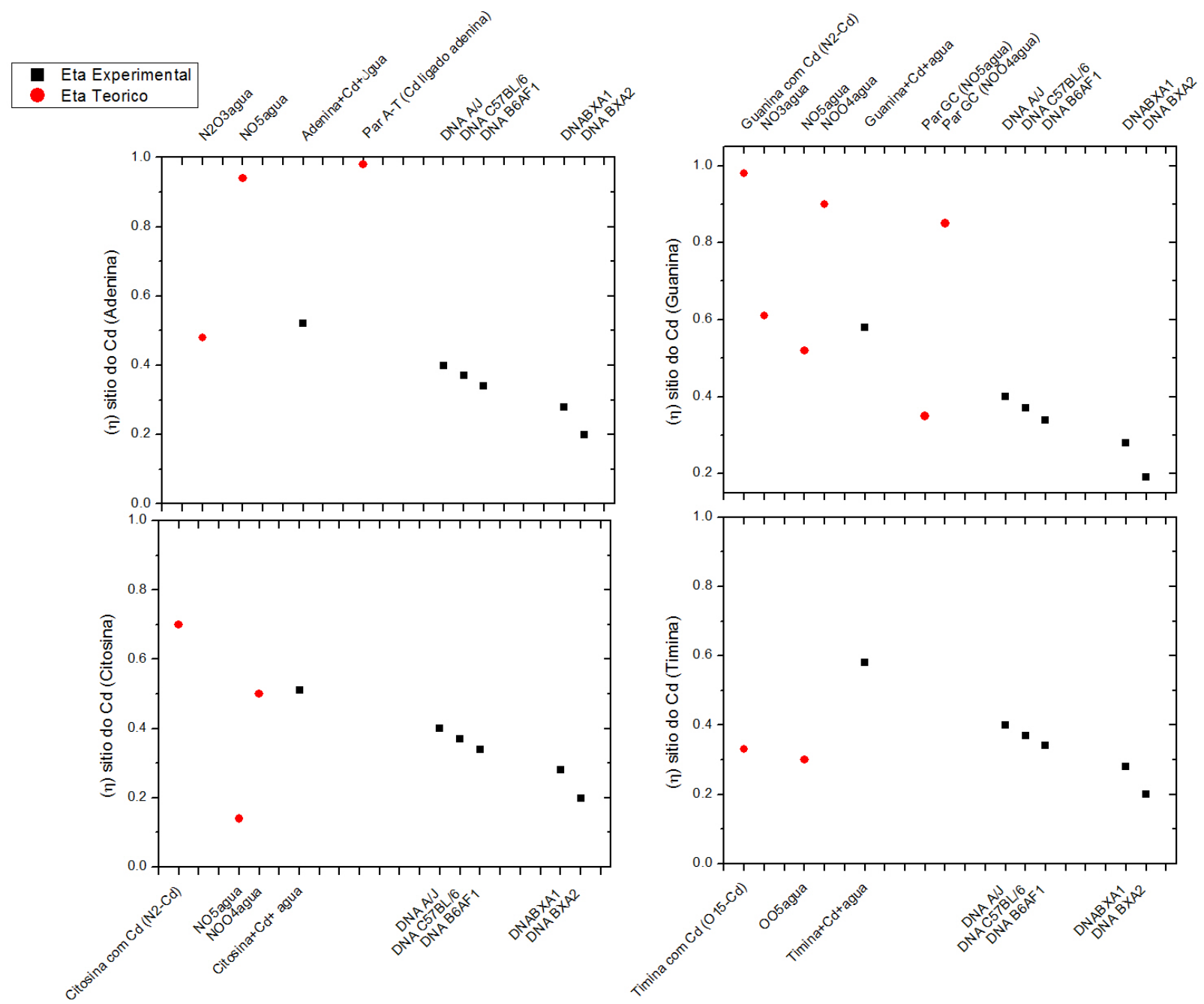

Figura 4.32: Valores de $\eta$ obtidos através de cálculos ab initio de estrutura eletrônica (CP-PAW) nos sítios de Cd em todos os sistemas estudados neste trabalho. Apresentamos também os valores experimentais obtidos por TDPAC para as bases nitrogenadas e famílias de camundongos infectados com a T. Cruzi [18]. 


\subsection{Densidade de Estados (DOS) e Orbitais Mole- culares}

Finalizando os estudos das interações do $\mathrm{Cd}$ com as bases nitrogenadas do DNA, analisamos as densidades de estados eletrônicos (DOS) e orbitais de KohnSham $[27,28]$ obtidos com o código CP-PAW. Cometeremos, daqui para frente, um abuso de linguagem usual na literatura e chamaremos os "orbitais de KohnSham" apenas de "orbitais moleculares". Analisamos somente as DOS e os orbitais moleculares obtidos nos sistemas com Cd e moléculas de água apresentados nas seções 4.3 e 4.4. Nas figuras 4.33, 4.36, 4.39, 4.41 e 4.48 explicitamos a DOS total e projetada no sítio de Cd e nos sítios dos ligantes dos sistemas estudados. Em todas estas figuras assinalamos as energias do último orbital molecular ocupado (HOMO) e do primeiro orbital molecular desocupado (LUMO) e os níveis de energia moleculares mostrados nestas figuras receberam um pequeno alargamento para uma melhor visualização.

\subsubsection{Adenina e Timina}

Na figura 4.33a apresentamos o cálculo da DOS para os sistemas com o Cd ligado a cinco moléculas de água e ligado no sítio N2 da adenina (figura 4.25b) e na figura 4.33b o mesmo sistema, quando adicionamos a base timina (figura 4.29b). Podemos notar que a diferença em energia entre o HOMO e LUMO (gap)diminui, após a inserção da timina no sistema. Isto se deve ao fato de ter novos níveis de energia no sistema com a inserção da timina, indicando que a timina perturbou o sistema Cd ligado a cinco moléculas de água e ligado no sítio N2 da adenina. Notamos também uma maior contribuição dos ligantes do Cd no orbital LUMO com a adição da timina. Os orbitais moleculares HOMO-1, HOMO, LUMO e LUMO +1 obtidos para o sistema adenina com o Cd ligado ao N2 da adenina e 
cinco moléculas de água são apresentadas na figura 4.34 e na figura 4.35 para o mesmo sistema quando inserimos a timina.

a)

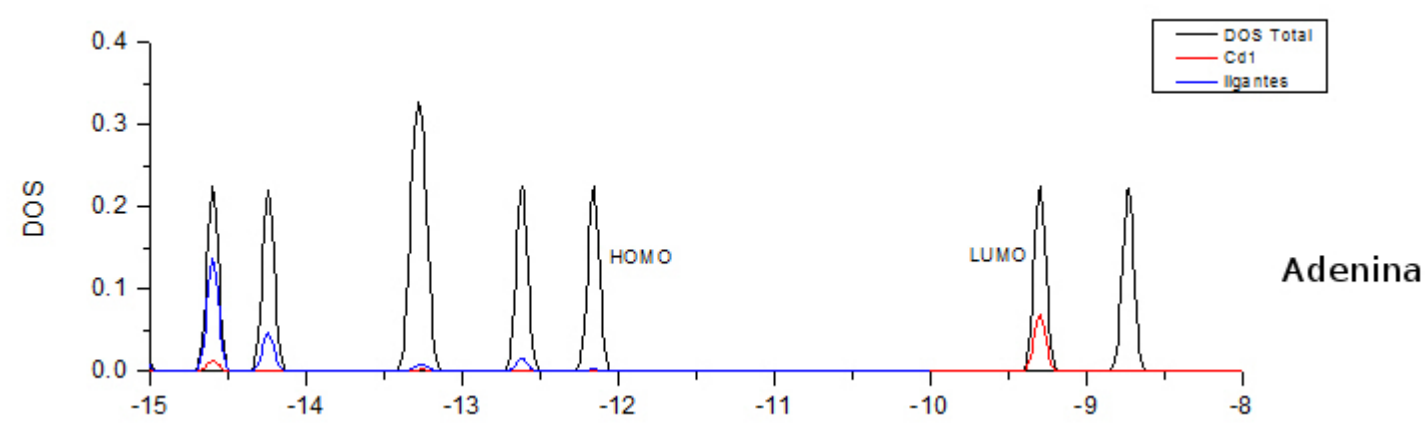

b)

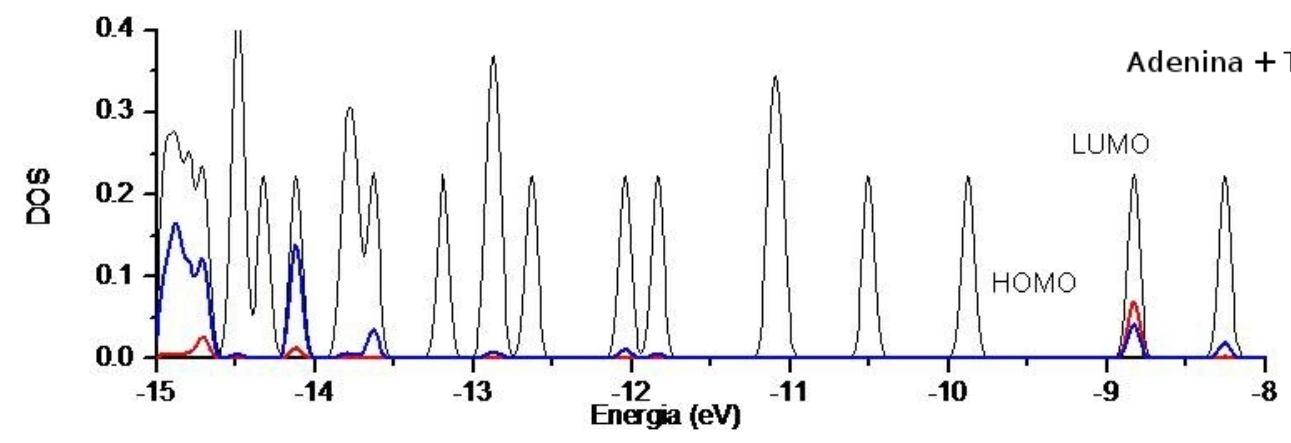

Figura 4.33: DOS total e projetada nos sítios de Cd e sítios dos ligantes do Cd para: a) adenina com o Cd ligado ao sítio N2 e coordenação seis (figura 4.25b); b) adenina com o Cd ligado ao sítio N2 e coordenação seis e timina (figura 4.29b). 


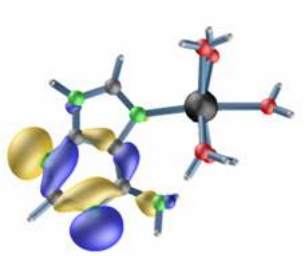

(a) $\mathrm{HOMO}$

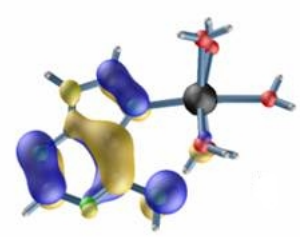

(c) HOMO -1

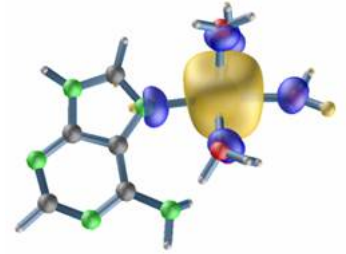

(b) LUMO

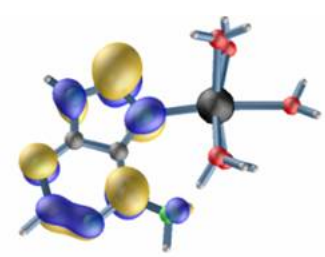

(d) $\mathrm{LUMO}+1$

Figura 4.34: Orbitais moleculares para a adenina com Cd ligado ao N2 e cinco moléculas de água: a) $H O M O$; b) $L U M O$; c) $H O M O-1$; d) $L U M O+1$. Os átomos de nitrogênio estão em verde, carbono em cinza, oxigênio em vermelho e o $\mathrm{Cd}$ em preto.

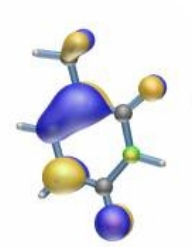

(a) $\mathrm{HOMO}$

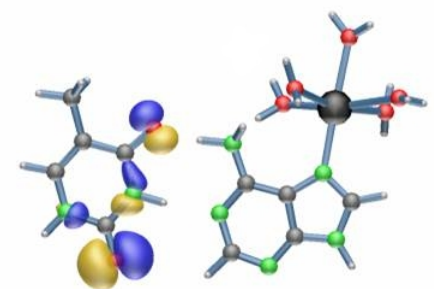

(c) HOMO -1
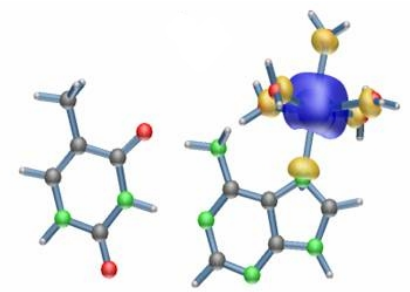

(b) LUMO

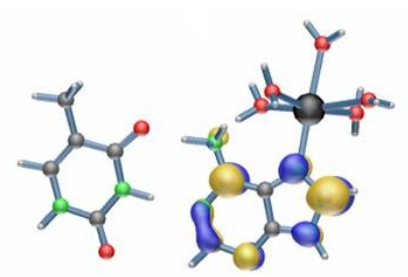

(d) $\mathrm{LUMO}+1$

Figura 4.35: Orbitais moleculares para o par A-T com Cd ligado ao N2 e cinco moléculas de água: a) $H O M O$; b) $L U M O$; c) $H O M O$ - 1; d) $L U M O+1$. Os átomos de nitrogênio estão em verde, carbono em cinza, oxigênio em vermelho e o $\mathrm{Cd}$ em preto. 
$\mathrm{Na}$ figura 4.36a apresentamos o cálculo da DOS para os sistemas com o Cd ligado a cinco moléculas de água e ligado no sítio O15 da timina (figura 4.27) e na figura 4.36b o mesmo sistema, quando adicionamos a base adenina (figura 4.29a). Notamos que este é o caso em que o Cd não se mantêm estabilizado entre as bases AT conforme explicado na seção 4.4. Isto nos mostra que a configuração de mínimo de energia não é obtida quando inserimos a adenina no sistema. Verificamos na figura $4.36 \mathrm{~b}$ e nos orbitais apresentados na figura 4.38 que este "desligamento" do Cd é mostrada pela grande contribuição do Cd na região do HOMO, isto é, o HOMO está localizado no sítio do Cd. Este comportamento não esperado foi mostrado pelo valor de $V_{z z}=16.80 X 10^{21} \mathrm{~V} / \mathrm{m}^{2}$ para este sistema.

a)

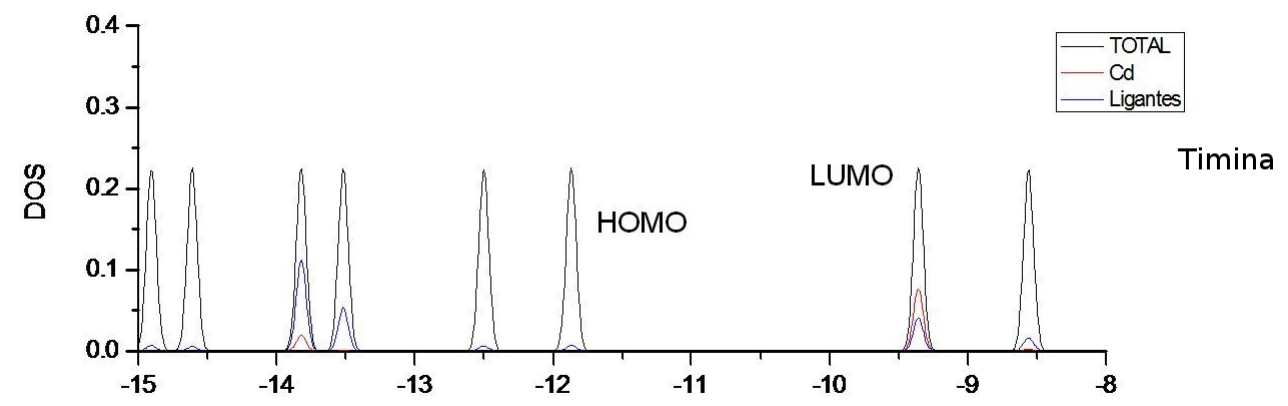

b)

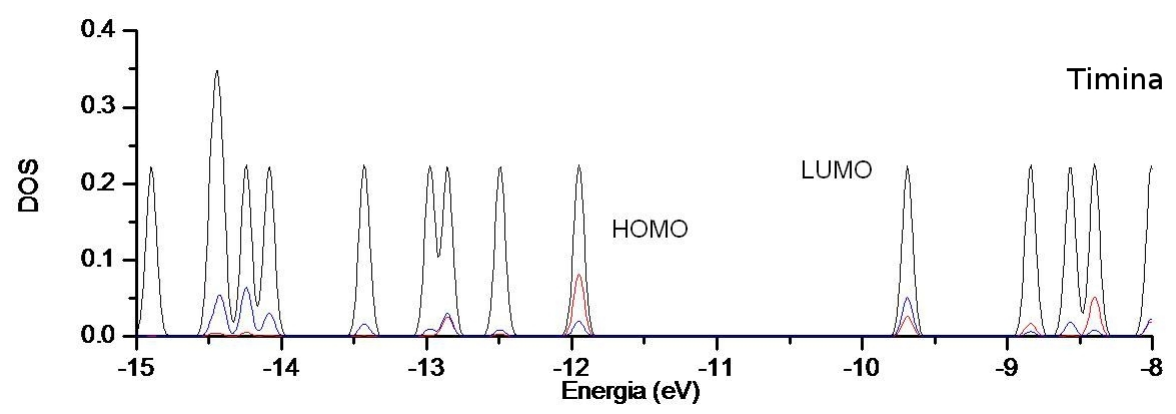

Figura 4.36: DOS total e projetada nos sítios de $\mathrm{Cd}$ e sítios dos ligantes do $\mathrm{Cd}$ para: a) timina com o Cd ligado ao sítio O15 e coordenação seis (figura 4.27); b) timina com o Cd ligado ao sítio O15 e coordenação seis e adenina (figura 4.29a). 
$\mathrm{Na}$ figura 4.37 apresentamos os orbitais moleculares para a timina com $\mathrm{Cd}$ ligado ao O15 com coordenação seis.

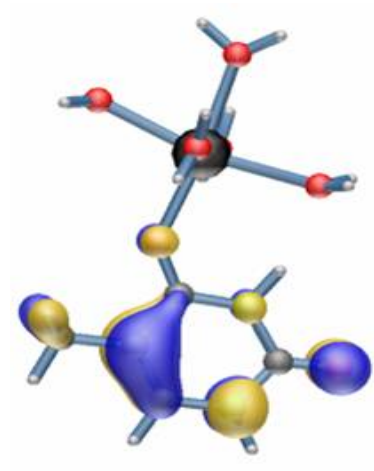

(a) HOMO

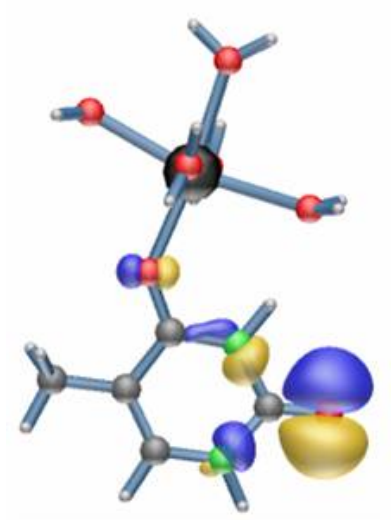

(c) HOMO -1

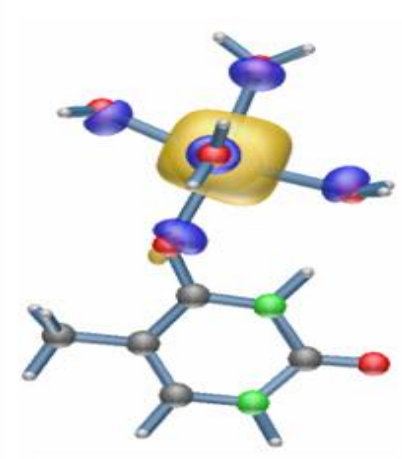

(b) LUMO

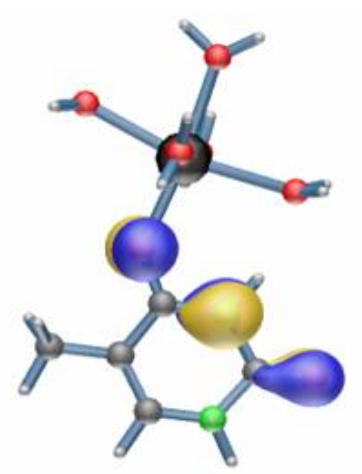

(d) HOMO-2

Figura 4.37: Orbitais moleculares para a timina com Cd ligado ao O15 e 5 moléculas de água: a) $H O M O$; b) $L U M O$; c) $H O M O$-1; d) $H O M O$-2. Os átomos de nitrogênio estão em verde, carbono em cinza, oxigênio em vermelho e o $\mathrm{Cd}$ em preto. 


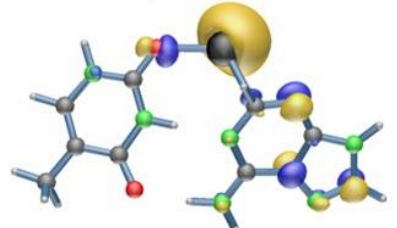

(a) HOMO

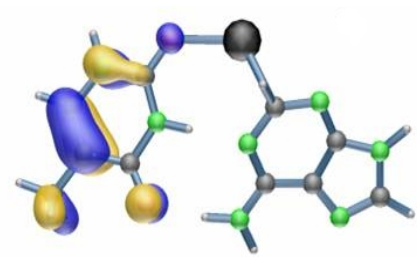

(c) HOMO -1

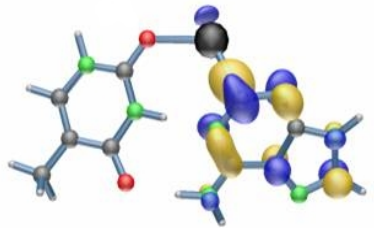

(b) LUMO

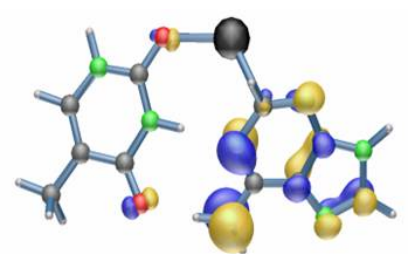

(d) HOMO -2

Figura 4.38: Orbitais moleculares para o par T-A com Cd ligado ao O14 e H4: a) HOMO ; b) LUMO; c) HOMO -1; d) HOMO -2. Os átomos de nitrogênio estão em verde, carbono em cinza, oxigênio em vermelho e o $\mathrm{Cd}$ em preto.

\subsubsection{Guanina e Citosina}

Na figura 4.39a apresentamos o cálculo da DOS para os sistemas com o Cd ligado a quatro moléculas de água e ligado no sítio N2 e O15 da guanina (figura $4.26 \mathrm{c}$ ) e na figura 4.39b o mesmo sistema, quando adicionamos a base citosina (figura 4.30b). Notamos que a diferença em energia entre o HOMO e LUMO (gap) diminui, após a inserção da citosina no sistema. Novamente, devemos este fato de se ter novos níveis de energia no sistema com a inserção da citosina, indicando que a citosina perturbou o sistema Cd ligado a quatro moléculas de água e ligado no sítio N2 e O15 da guanina. O mesmo fato ocorre também quando inserimos a citosina no sistema Cd ligado a cinco moléculas de água e ligado no sítio N2 da guanina conforme mostrado na figura 4.41 .

Na figura 4.48a apresentamos o cálculo da DOS para os sistemas com o Cd ligado a quatro moléculas de água e ligado no sítio N2 e O da citosina (figura $4.28 \mathrm{~b})$ e na figura $4.48 \mathrm{~b}$ apresentamos o cálculo da DOS para os sistemas com o Cd ligado a quatro moléculas de água e ligado no sítio N2 da citosina (figura 
4.28a). Apresentamos também na figura 4.48c o cálculo da DOS para os sistemas com o Cd entre as bases GC (figura 4.30a). Novamente, vemos que este é o caso em que o Cd não se mantêm estabilizado entre as bases GC conforme explicado na seção 4.4. Isto nos mostra que a configuração de mínimo de energia não é obtida quando temos o Cd entre as bases GC. Verificamos na figura 4.48c e nos orbitais apresentados na figura 4.47 que este "desligamento" do Cd é mostrada pela grande contribuição do $\mathrm{Cd}$ na região do HOMO, isto é, o HOMO está localizado no sítio do Cd. Este comportamento não esperado foi mostrado pelo grande valor de $V_{z z}=66.80 X 10^{21} \mathrm{~V} / \mathrm{m}^{2}$ para este sistema.

a)
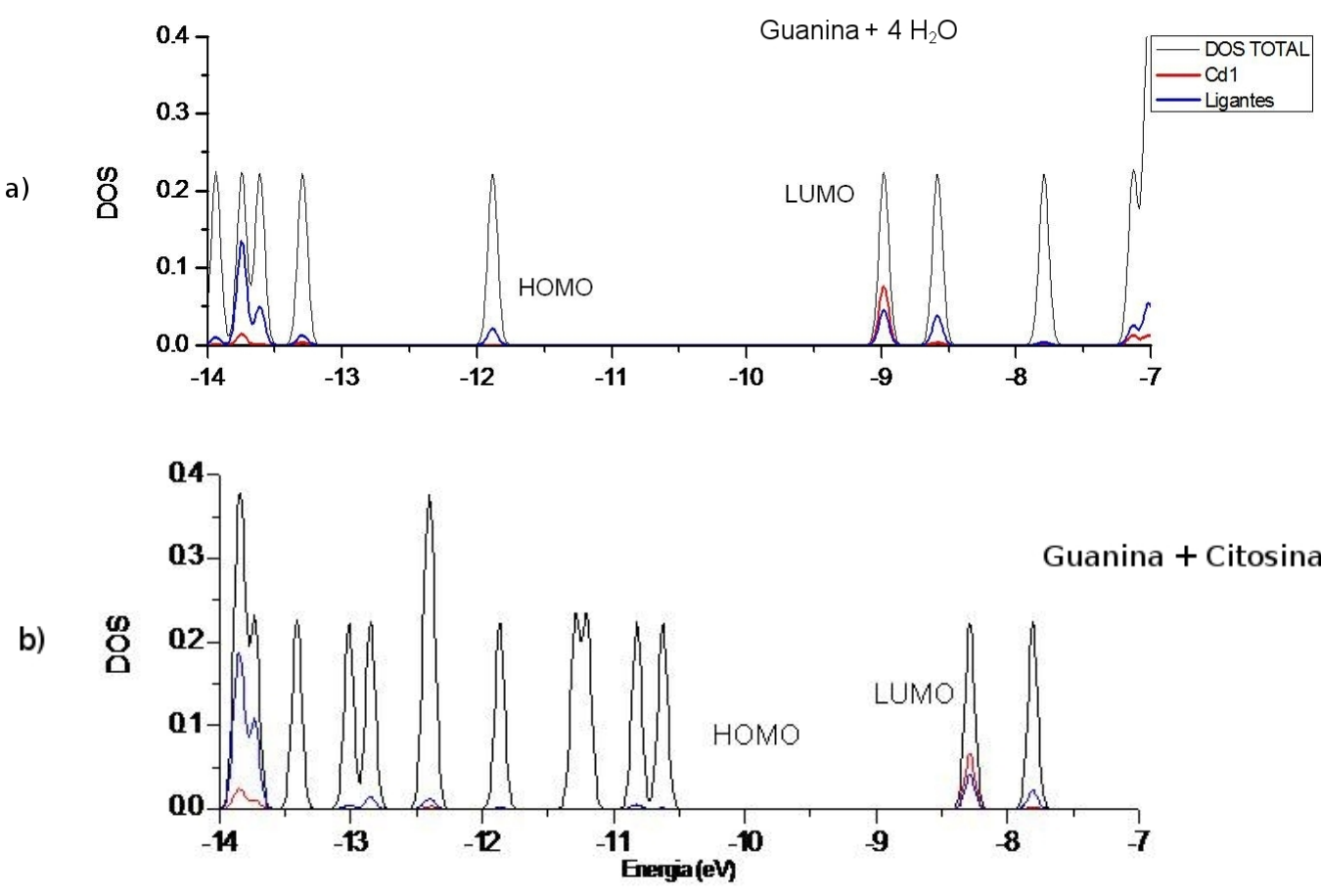

Figura 4.39: DOS total e projetada nos sítios de $\mathrm{Cd}$ e sítios dos ligantes do $\mathrm{Cd}$ para: a) guanina com o Cd ligado ao sítio N2 e O e coordenação seis (figura 4.26c); b) guanina com o Cd ligado ao sítio N2 e O e coordenação seis e citosina (figura $4.30 \mathrm{~b})$. 


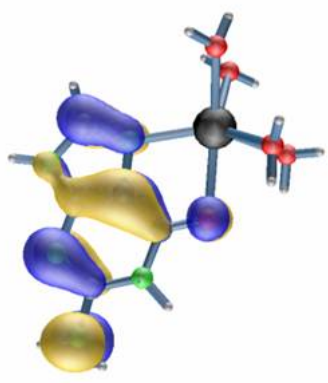

(a) $\mathrm{HOMO}$

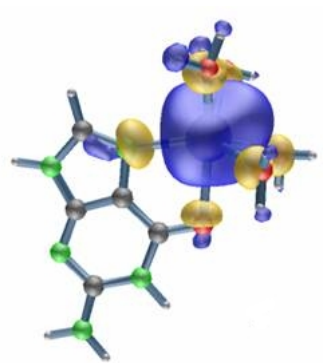

(b) LUMO

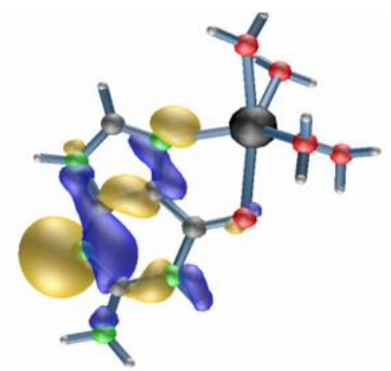

(c) HOMO -1

Figura 4.40: Orbitais moleculares para a guanina com Cd ligado ao N2 e O16 e 4 moléculas de água: a) $H O M O$; b) $L U M O$; c) $H O M O$-1. Os átomos de nitrogênio estão em verde, carbono em cinza, oxigênio em vermelho e o $\mathrm{Cd}$ em preto.

a)
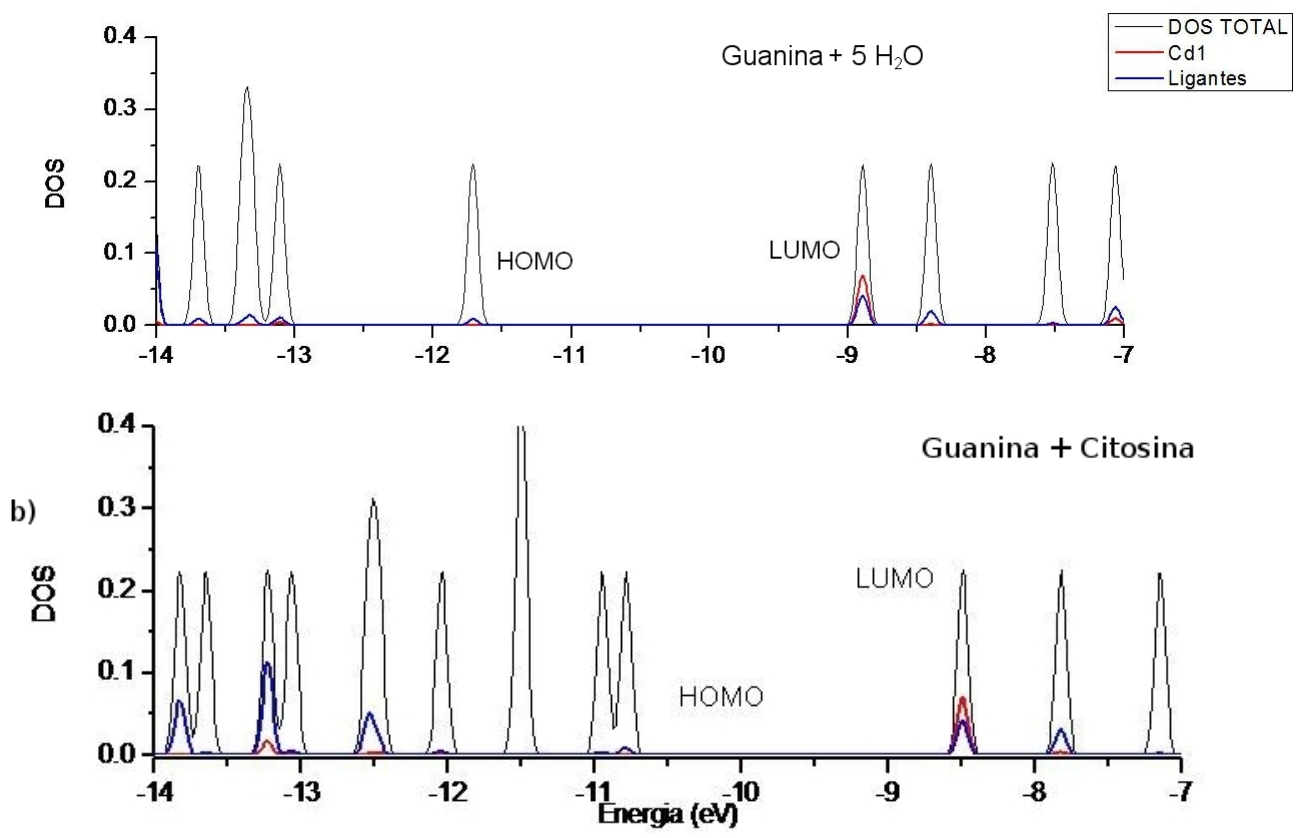

Figura 4.41: DOS total e projetada nos sítios de Cd e sítios dos ligantes do Cd para: a) guanina com o Cd ligado ao sítio N2 e coordenação seis (figura 4.26b); b) guanina com o Cd ligado ao sítio N2 e coordenação seis e citosina (figura 4.30c). 


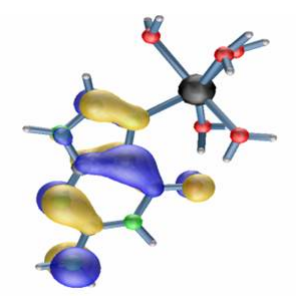

(a) $\mathrm{HOMO}$

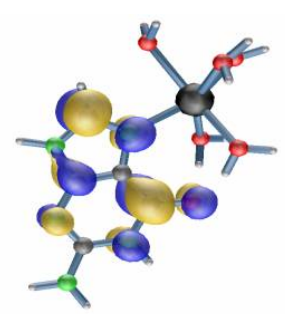

(c) $\mathrm{HOMO}-1$

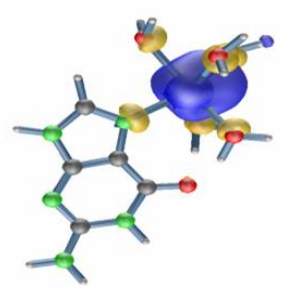

(b) LUMO

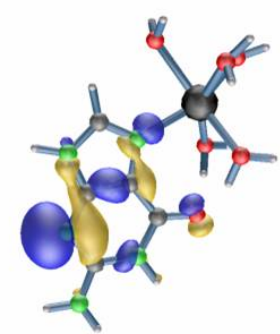

(d) $\mathrm{HOMO}-2$

Figura 4.42: Orbitais moleculares para a guanina com Cd ligado ao N2 e 5 moléculas de água: a) $H O M O$; b) $L U M O$; c) $H O M O$-1; d) $H O M O$-2. Os átomos de nitrogênio estão em verde, carbono em cinza, oxigênio em vermelho e o $\mathrm{Cd}$ em preto.

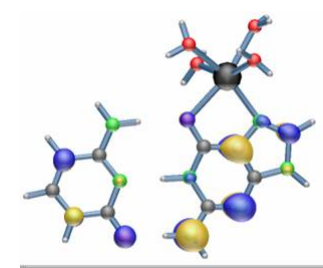

(a) HOMO

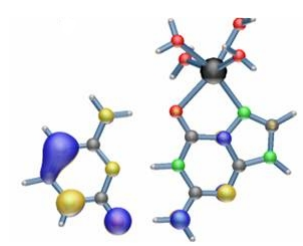

(c) $\mathrm{HOMO}-1$

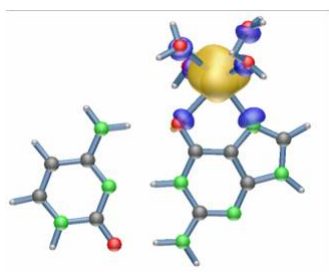

(b) LUMO

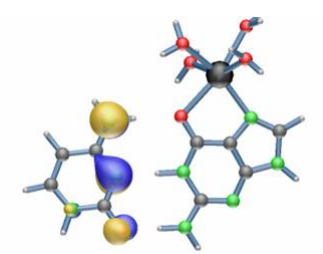

(d) $\mathrm{HOMO}-2$

Figura 4.43: Orbitais moleculares para o par G-C com Cd ligado ao N2 e O15 e 4 moléculas de água: a) $H O M O$; b) $L U M O$; c) $H O M O$-1; d) HOMO -2. Os átomos de nitrogênio estão em verde, carbono em cinza, oxigênio em vermelho e o $\mathrm{Cd}$ em preto. 


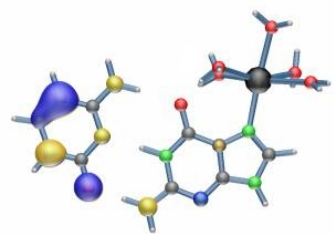

(a) HOMO

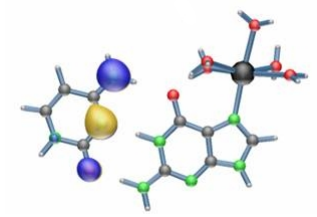

(c) HOMO -1

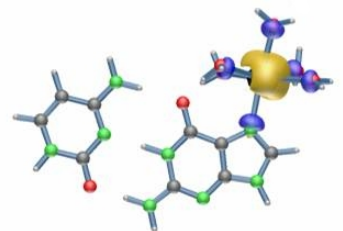

(b) LUMO

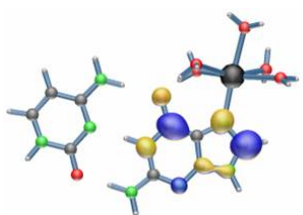

(d) $\mathrm{LUMO}+1$

Figura 4.44: Orbitais moleculares para o par G-C com Cd ligado ao N2 e 5 moléculas de água: a) $H O M O$; b) $L U M O$; c) $H O M O-1$; d) $L U M O+1$. Os átomos de nitrogênio estão em verde, carbono em cinza, oxigênio em vermelho e o $\mathrm{Cd}$ em preto.

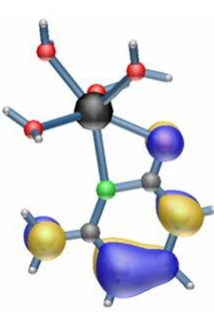

(a) HOMO

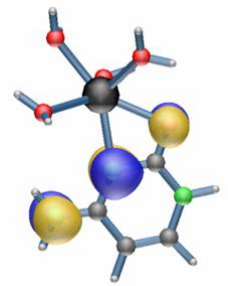

(c) HOMO -1

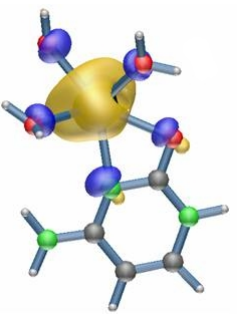

(b) LUMO

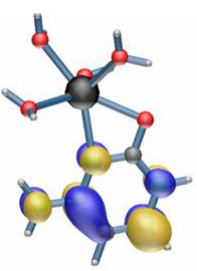

(d) $\mathrm{LUMO}+1$

Figura 4.45: Orbitais moleculares para a citosina com Cd ligado ao N2 e O e 4 moléculas de água: a) $H O M O$; b) $L U M O$; c) $H O M O$ - 1; d) $L U M O+1$. Os átomos de nitrogênio estão em verde, carbono em cinza, oxigênio em vermelho e o $\mathrm{Cd}$ em preto. 


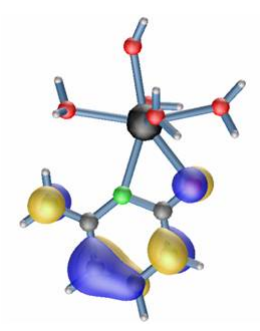

(a) HOMO

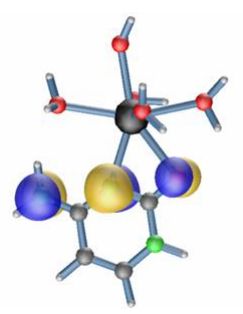

(c) HOMO -1

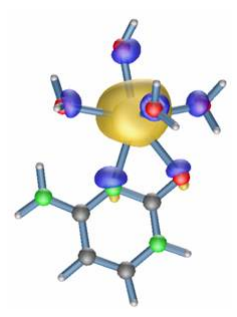

(b) LUMO

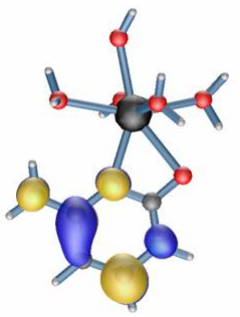

(d) $\mathrm{LUMO}+1$

Figura 4.46: Orbitais moleculares para a citosina com Cd ligado ao N2 e 5 moléculas de água: a) $H O M O$; b) $L U M O$; c) $H O M O ~-1$; d) $L U M O+1$. Os átomos de nitrogênio estão em verde, carbono em cinza, oxigênio em vermelho e o $\mathrm{Cd}$ em preto.

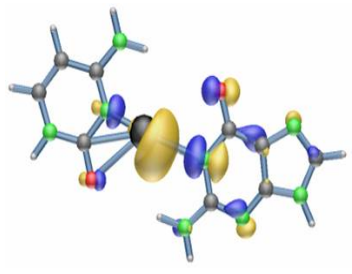

(a) HOMO

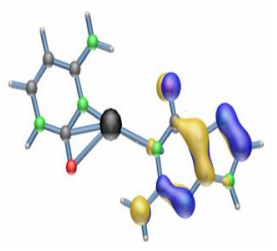

(b) LUMO

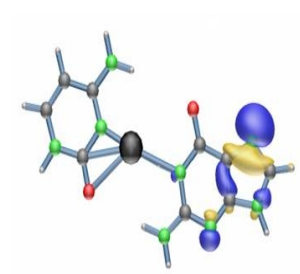

(c) HOMO -1

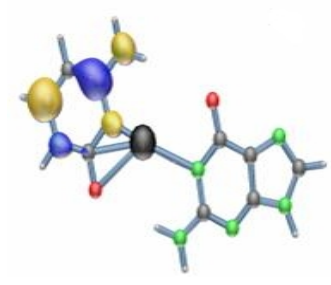

(d) $\mathrm{LUMO}+1$

Figura 4.47: Orbitais moleculares para o par C-G com Cd ligado entre as bases: a) $H O M O$; b) $L U M O$; c) $H O M O$-1; d) $L U M O+1$. Os átomos de nitrogênio estão em verde, carbono em cinza, oxigênio em vermelho e o $\mathrm{Cd}$ em preto. 


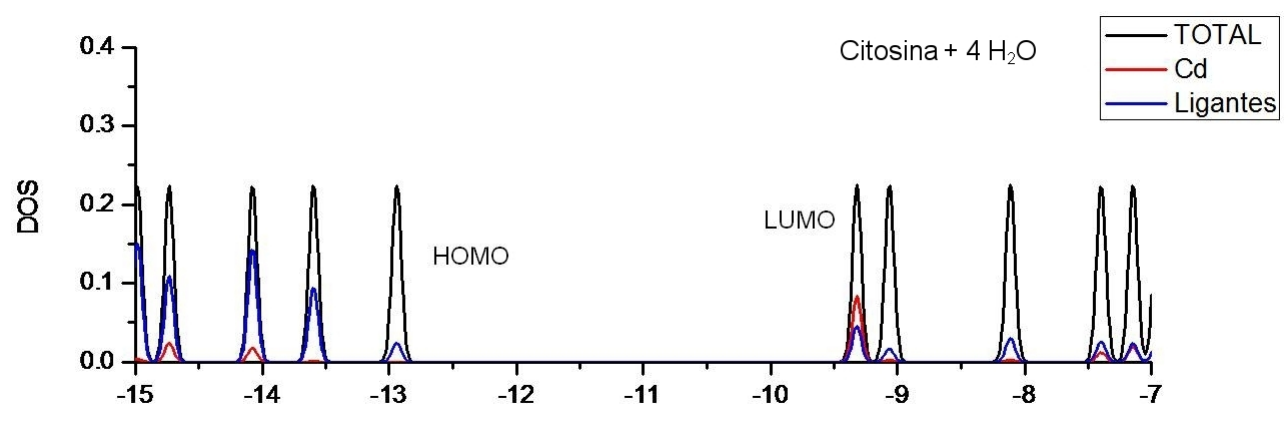

b)
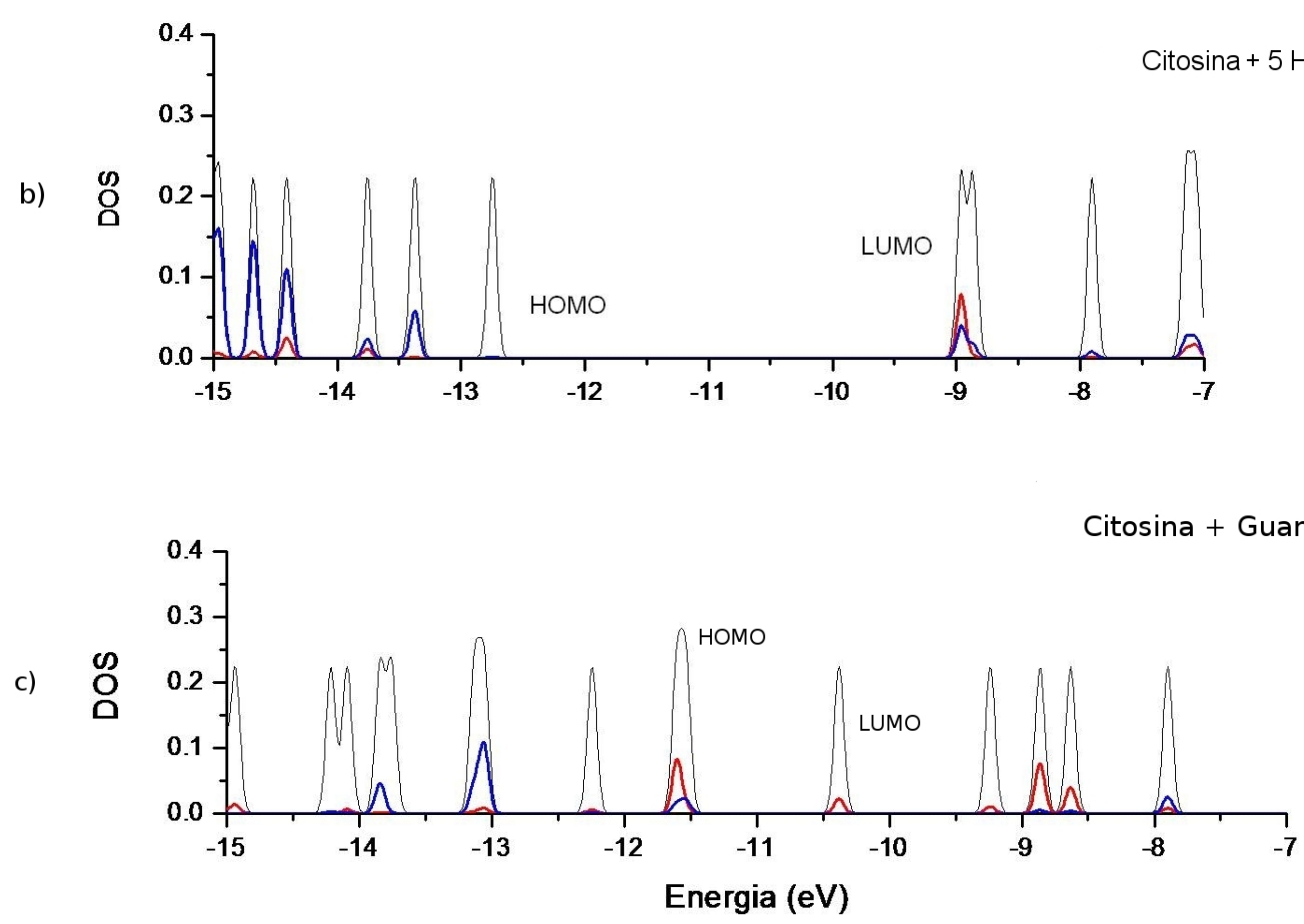

Figura 4.48: DOS total e projetada nos sítios de Cd e sítios dos ligantes do Cd para: a) citosina com o Cd ligado ao sítio N2 e O e coordenação seis (figura 4.28a); b) citosina com o Cd ligado ao sítio N2 e coordenação seis (figura 4.28b); c) Cd ligado entre o par de base C-G (figura 4.30a).

Notamos que, em todos os sistemas aqui estudados que possuem o valor de $V_{z z}$ na faixa de 5 a $12 \times 10^{21} \mathrm{~V} / \mathrm{m}^{2}$, verificamos uma grande contribuição do Cd e dos ligantes do Cd na região de LUMO, mostrando a estabilidade destes sistemas conforme esperado e sendo compatível com o caráter catiônico do sítio do $\mathrm{Cd}$. 


\section{Capítulo 5}

\section{Conclusões}

Neste trabalho realizamos cálculos ab initio de estrutura eletrônica e GCE em bases nitrogenadas, Cd coordenado a bases nitrogenadas, Cd coordenado a moléculas de água e nucleobases e Cd coordenado com pares de bases. Nossos resultados teóricos foram comparados com medidas experimentais, disponíveis na literatura, de NMR nos sítios de O e TDPAC utilizando a sonda proveniente do decaímento ${ }^{111} \mathrm{In} \rightarrow{ }^{111} \mathrm{Cd}$. Este estudo foi, inicialmente, motivado pela possibilidade de utilizar as informações obtidas pela técnica TDPAC para investigar o comportamento do DNA em camundongos infectados pela T. cruzi. Após a comparação entre as medidas obtidas por TDPAC e os nossos resultados de GCE obtidos com o código CP-PAW podemos inferir que o Cd pode estar efetivamente ligado ao DNA.

Notamos que os valores de GCE medidos por TDPAC estão na mesma ordem de grandeza que os nossos resultados de GCE obtidos com o CP-PAW para os sistemas aqui estudados. Nossos resultados mostram que o GCE varia significativamente com o número de coordenação do Cd, podendo ser utilizado como ferramenta para a identificação de diferentes sítios de ligação e as diferentes coordenações que o $\mathrm{Cd}$ pode possuir. Apesar de que os resultados de GCE obtidos para o sítio de Cd com coordenação 6 estão bem próximos dos medidos por TDPAC, observamos situações 
onde a concordância teórico-experimental ocorre quando o Cd tem coordenação 4 ou 5. Desta forma, podemos também considerar a possibilidade de o $\mathrm{Cd}$, na interação com as bases nitrogenadas, ter outras coordenações como 4 ou 5 e não somente 6 .

No entanto, após o presente estudo, não podemos ainda afirmar o exato local da ligação do Cd ao DNA, visto que os valores de GCE no núcleo do Cd obtidos para as situações aqui estudados estão próximos. Entretanto, nos casos em que o Cd foi inserido entre os pares de bases AT e GC, obtivemos valores de GCE fora da faixa que vai de $5 \times 10^{21} \mathrm{~V} / \mathrm{m}^{2}$ a $12 \times 10^{21} \mathrm{~V} / \mathrm{m}^{2}$, o que demonstra que o $\mathrm{Cd}$ não se coordena com os pares de bases nestas situações. Isto mostra que o GCE permite dizer se o Cd está ou não ligado ao DNA.

Em relação ao parâmetro $\eta$, vemos que este é muito sensível a sutis diferenças geométricas nestas biomoléculas, o que não nos permitiu o estabelecimento de tendências gerais claras e conclusivas sobre os diferentes sítios de Cd. No entanto, de forma bastante interessante, pudemos verificar que para uma mesma dada coordenação de $\mathrm{Cd}$ em sistemas distintos e com valores de $V_{z z}$ muito próximos os valores de $\eta$ podem ser bem diferentes, dependendo do tipo de oxigênio que se coordena ao $\mathrm{Cd}$ : se é oxigênio das moléculas de água ou se é oxigênio das bases nitrogenadas.

Pela análise das estruturas eletrônicas aqui obtidas verificamos que, na maioria dos sistemas estudados, o LUMO está concentrado no sítio onde o Cd está inserido, o que está de acordo com o caráter catiônico esperado para o metal nas situações aqui estudadas. As únicas exceções foram para o Cd inserido entre as bases timinaadenina e guanina-citosina. Os grandes valores de $V_{z z}$ obtidos nestas situações sinaliza esta instabilidade estrutural, isto é, a configuração do Cd neste sítio não corresponde a configuração de mais baixa energia deste sistema o que explica o comportamento diferente do caráter do orbital LUMO nestes casos. 
O estudo teórico realizado no presente trabalho se constitui numa primeira e inédita etapa na obtenção de respostas para o intrincado problema da utilização de técnicas experimentais como TDPAC para elucidar problemas biológicos como o comportamento de DNAs de camundongos de diferentes linhagens $(\mathrm{A} / \mathrm{J}$, C57BL/6, B6AF1, BXA1 e BXA2) quando infectados com a cepa Y da T. cruzi. Determinamos algumas situações onde o Cd possivelmente se liga ao DNA nas medidas realizadas por TDPAC. No entanto, para conseguir determinar à exata localização do núcleo de prova Cd ligado ao DNA dos camundongos infectados pela T. cruzi, outras etapas dentro de um estudo multi-escala, assim como outras medidas utilizando outras sondas TDPAC devem ser realizados. Por exemplo, utilizando dinâmica molecular que permite a inclusão de fragmentos maiores de DNA seria interessante. Por outro lado, devemos ter em mente também que as medidas TDPAC foram realizadas com a sonda obtida do decaímento ${ }^{111} \mathrm{In} \rightarrow{ }^{111} \mathrm{Cd}$ e, portanto, seria interessante a realização futura de medidas com a sonda proveniente do decaímento metaestável ${ }^{111 m} \mathrm{Cd} \rightarrow \rightarrow^{111} \mathrm{Cd}$ para comparação com os resultados teóricos aqui obtido no sítio do Cd. 


\section{Apêndice A}

\section{Técnica TDPAC}

A técnica TDPAC é muito utilizada para medidas de interações hiperfinas. Esta técnica nos dá informações sobre a geometria de coordenação do núcleo de prova, isto é, informações sobre o tipo e número de coordenação e a o arranjo geométrico dos átomos que coordenam com o núcleo de prova [15]. No entanto, não conseguimos obter informações da estrutura completa da geometria de coordenação do sistema devido à informação da estrutura obtida pelo TDPAC estar limitado a um raio de 3 a $5 \AA$ a partir do sítio onde está inserido o núcleo de prova.

A essência da espectroscopia PAC está na correlação angular entre raios gama $(\gamma)$ emitidos num decaimento nuclear. Dois raios $\gamma$ são emitidos $\left(\gamma_{1}\right.$ e $\left.\gamma_{2}\right)$ sucessivamente e a correlação angular entre eles é perturbada pela Interação de Quadrupolo Elétrica Nuclear (NQI) do núcleo radioativo durante o tempo entre a emissão de $\gamma_{1}$ e $\gamma_{2}$, isto é, enquanto o núcleo estiver no seu estado intermediário [15]. Porém, a probabilidade de detectar o efeito de NQI durante o tempo de emissão do $\gamma_{1}$ e $\gamma_{2}$ varia periodicamente com o tempo. A função usada para descrever este comportamento é chamada de função de perturbação e na maioria dos casos, é uma função dada pela combinação linear de funções cosseno. A correlação angular $\gamma-\gamma$ 
não perturbada tem a função de correlação dada pela relação [14]

$$
W(\theta)=\sum_{k p a r}^{k_{\max }} A_{k k} P_{k}(\cos \theta),
$$

onde $\theta$ é o angulo entre as direções dos fótons $\mathbf{k}_{1}$ e $\mathbf{k}_{2}$ emitidos por $\gamma_{1}$ e $\gamma_{2}$ respectivamente. $P_{k}(\cos \theta)$ é o k-ésimo polinômio de Legandre e $A_{k k}$ são os coeficientes da correlação angular $\gamma-\gamma$.

A função de correlação angular $\gamma-\gamma$ perturbada é dada por

$$
W(\theta, t)=\sum_{k p a r}^{k_{\max }} G_{k k}(t) A_{k k} P_{k}(\cos \theta),
$$

onde o termo $G_{k k}(t)$ é o fator de perturbação que depende da interação ser elétrica ou magnética [56]. As frequências (wi) dadas pela função de perturbação correspondem as transições energéticas dos subníveis de energia do núcleo. Desta forma, podemos medir a diferença de energia destas transições. Na química inorgânica e bioinorgânica a aplicação mais utilizada da espectroscopia PAC é na obtenção da distribuição eletrônica e estrutura molecular através da inserção de um núcleo de prova radioativo no sítio específico da molécula estudada [57, 58, 59]. O isótopo ${ }^{111} \mathrm{Cd}$ é comumente utilizado como núcleo de prova PAC. Este isótopo pode ser obtido do decaímento ${ }^{111} \mathrm{In} \rightarrow{ }^{111} \mathrm{Cd}$ ou pelo decaímento metaestável ${ }^{111 m} \mathrm{Cd} \rightarrow{ }^{111} \mathrm{Cd}$. Na figura A.1 apresentamos um esquema ilustrativo dos decaimentos ${ }^{111} \mathrm{In} \rightarrow{ }^{111} \mathrm{Cd}$ e ${ }^{111 m} \mathrm{Cd} \rightarrow{ }^{111} \mathrm{Cd}$. 


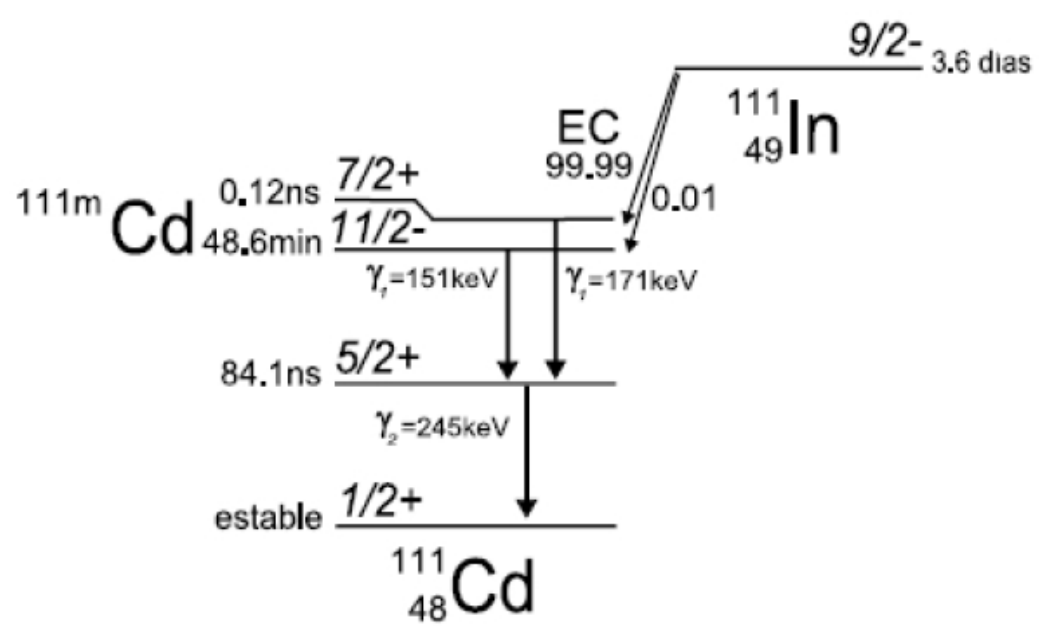

(a)

Figura A.1: Esquema ilustrativo dos decaimentos ${ }^{111} \mathrm{In} \rightarrow{ }^{111} \mathrm{Cd} \mathrm{e}{ }^{111 m} \mathrm{Cd} \rightarrow{ }^{111} \mathrm{Cd}$. Figura extraída da ref. [60]. 


\section{Lista de Tabelas}

4.1 Distâncias de ligação entre os átomos da molécula adenina isolada e otimizada obtidos no presente trabalho utilizando o código CPPAW. Apresentamos também os valores experimentais [49] e obtidos utilizando o código Gaussian94 da literatura [43]. . . . . . . . . . 40

4.2 Distâncias de ligação entre os átomos da molécula guanina isolada e otimizada obtidos no presente trabalho utilizando o código CPPAW. Apresentamos também os valores experimentais [49] e obtidos utilizando o código Gaussian94 da literatura [43] . . . . . . . . 41

4.3 Distâncias de ligação entre os átomos da molécula citosina isolada e otimizada obtidos no presente trabalho utilizando o código CPPAW. Apresentamos também os valores experimentais [49] e obtidos utilizando o código Gaussian94 da literatura [43]. . . . . . . . . . 43

4.4 Distâncias de ligação entre os átomos da molécula timina isolada e otimizada obtidos no presente trabalho utilizando o código CPPAW. Apresentamos também os valores experimentais [49] e obtidos utilizando o código Gaussian94 da literatura [43]. . . . . . . . . . 44

4.5 Valores de $\nu_{q}[\mathrm{Mhz}]$ e $\eta$,obtidos com o código CP-PAW, para os sítios de $\mathrm{N}$ da molécula de adenina. Apresentamos também os valores obtidos utilizando o código Gaussian03 da literatura [44]. . . 50 
4.6 Valores de $\nu_{q}[\mathrm{Mhz}]$ obtidos com o código CP-PAW, para os átomos de $\mathrm{N}$ e $\mathrm{O}$ da molécula de guanina. Apresentamos também o valor experimental [42] e os valores obtidos utilizando os códigos Gaussian98 (funcional B3LYP e base 6-311G(d,p))[42] e Gaussian03 (Hartree-Fock Roothaan (HF + MP2) com base 6-311G) [44] da lit-

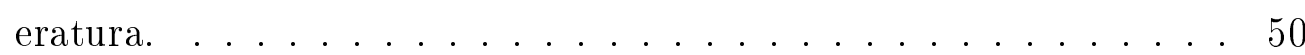

4.7 Valores de $\eta$ obtidos com o código CP-PAW, para os átomos de $\mathrm{N}$ e O da molécula de guanina. Apresentamos também o valor experimental [42] e os valores obtidos utilizando os códigos Gaussian98 (funcional B3LYP e base 6-311G(d,p))[42] e Gaussian03 (HartreeFock Roothaan (HF + MP2) com base 6-311G) [44] da literatura. . 51

4.8 Valores de $\nu_{q}[\mathrm{Mhz}]$ obtidos com o código CP-PAW, para os átomos de $\mathrm{N}$ e $\mathrm{O}$ da molécula de timina. Apresentamos também o valor experimental [42] e os valores obtidos utilizando os códigos Gaussian98 (funcional B3LYP e base 6-311G(d,p))[42] e Gaussian03 (HartreeFock Roothaan (HF + MP2) com base 6-311G) [44] da literatura. . 54

4.9 Valores de $\eta$ obtidos com o código CP-PAW, para os átomos de $\mathrm{N}$ e O da molécula de timina. Apresentamos também o valor experimental [42] e os valores obtidos utilizando os códigos Gaussian98 (funcional B3LYP e base 6-311G(d,p))[42] e Gaussian03 (HartreeFock Roothaan (HF + MP2) com base 6-311G) [44] da literatura. . 55

4.10 Valores de $\nu_{q}[\mathrm{Mhz}]$ obtidos com o código CP-PAW, para os átomos de $\mathrm{N}$ e $\mathrm{O}$ da molécula de citosina. Apresentamos também o valor experimental [42] e os valores obtidos utilizando os códigos Gaussian98 (funcional B3LYP e base 6-311G(d,p))[42] e Gaussian03 (Hartree-Fock Roothaan (HF + MP2) com base 6-311G) [44] da lit-

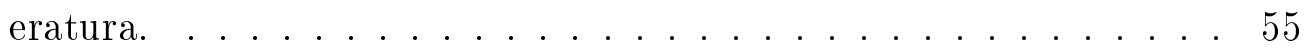


4.11 Valores de $\eta$ obtidos com o código CP-PAW, para os átomos de N e O da molécula de citosina. Apresentamos também o valor experimental [42] e os valores obtidos utilizando os códigos Gaussian98 (funcional B3LYP e base 6-311G(d,p))[42] e Gaussian03 (HartreeFock Roothaan (HF + MP2) com base 6-311G) [44] da literatura. . 56

4.12 Distância de ligação Cd-N2 e Cd-N3 da adenina [A] obtido no presente trabalho utilizando o código CP-PAW após relaxação estrutural do sistema. Apresentamos também os valores obtidos utilizando os códigos Gaussian92 (Hartree-Fock + MP2) [10] e Gaussian03 (funcional B3LYP e base 6-311++G(3df,2pd)) [13] da literatura. . . 61

4.13 Distância de ligação Cd-N4 e Cd-N3 da adenina $[\AA]$ obtido no presente trabalho utilizando o código CP-PAW após relaxação estrutural do sistema. Apresentamos também os valores obtidos utilizando o código Gaussian03 (funcional B3LYP e base 6-311++G(3df,2pd)) [13] da literatura. . . . . . . . . . . . . . . . 61

4.14 Distância de ligação Cd-N2 e Cd-O16 da guanina $[\AA]$ obtido no presente trabalho utilizando o código CP-PAW após relaxação estrutural do sistema. Apresentamos também os valores obtidos utilizando o código Gaussian92 (Hartree-Fock + MP2) [10] da literatura. . . . 63

4.15 Distância de ligação Cd-O15 e Cd-H4 da timina $[\AA]$ obtido no presente trabalho utilizando o código CP-PAW após relaxação estrutural do sistema. Apresentamos também os valores obtidos utilizando o código Gaussian03 (funcional B3LYP e base 6-311++G(3df,2pd)) [13] da literatura. . . . . . . . . . . . . . . . 65

4.16 Valores de $\nu_{q}[\mathrm{Mhz}]$ e $\eta$ para os átomos de nitrogênio e átomo de cádmio inserido no sítio N2 da molécula de adenina. . . . . . . . 67 
4.17 Valores de $\nu_{q}[\mathrm{Mhz}]$ e $\eta$ para os átomos de nitrogênio da molécula de adenina e átomo de cádmio com o Cd ligado ao sítio N4. . . . 68

4.18 Valores de $\nu_{q}[\mathrm{Mhz}]$ e $\eta$ para os átomos de nitrogênio e oxigênio da molécula de guanina e átomo de cádmio pelo método CP-PAW. . 69

4.19 Valores de $\nu_{q}[\mathrm{Mhz}]$ e $\eta$ para os sítios de nitrogênio e oxigênio da molécula de citosina e sítio de Cd. . . . . . . . . . . . 71

4.20 Valores de $\nu_{q}[\mathrm{Mhz}]$ e $\eta$ para os átomos de nitrogênio e oxigênio da molécula de timina e átomo de Cd. . . . . . . . . . . . . 72

4.21 Distância de ligação Cd-N2 e Cd-N3 [A] dos complexos pentacoordenado $\left[\mathrm{Cd}\left(\mathrm{C}_{5} \mathrm{H}_{5} \mathrm{~N}_{5}\right)\left(\mathrm{H}_{2} \mathrm{O}\right)_{3}\right]^{2+}$ e hexacoordenado $\left[\mathrm{Cd}\left(\mathrm{C}_{5} \mathrm{H}_{5} \mathrm{~N}_{5}\right)\left(\mathrm{H}_{2} \mathrm{O}\right)_{5}\right]^{2+}$ obtido no presente trabalho utilizando o código CP-PAW após relaxação estrutural do sistema. . . . . . . . . . . . . . . . . 74

4.22 Distância de ligação Cd-N2 e Cd-N3 [A] dos complexos tetracoordenado $\left[\mathrm{Cd}\left(\mathrm{C}_{5} \mathrm{H}_{5} \mathrm{~N}_{5} \mathrm{O}\right)\left(\mathrm{H}_{2} \mathrm{O}\right)_{3}\right]^{2+}$ e complexos hexacoordenados $\left[\mathrm{Cd}\left(\mathrm{C}_{5} \mathrm{H}_{5} \mathrm{~N}_{5} \mathrm{O}\right)\left(\mathrm{H}_{2} \mathrm{O}\right)_{5}\right]^{2+}$ e $\left[\mathrm{Cd}\left(\mathrm{C}_{5} \mathrm{H}_{5} \mathrm{~N}_{5} \mathrm{O}\right)\left(\mathrm{H}_{2} \mathrm{O}\right)_{4}\right]^{2+}$ obtidos no presente trabalho utilizando o código CP-PAW após relaxação estrutural do sistema. . . . . . . . . . . . . . 76

4.23 Distância de ligação Cd-N2 e Cd-O13 [Å] dos complexos hexacoordenados $\left[\mathrm{Cd}\left(\mathrm{C}_{4} \mathrm{H}_{5} \mathrm{~N}_{3} \mathrm{O}\right)\left(\mathrm{H}_{2} \mathrm{O}\right)_{5}\right]^{2+}$ e $\left[\mathrm{Cd}\left(\mathrm{C}_{4} \mathrm{H}_{5} \mathrm{~N}_{3} \mathrm{O}\right)\left(\mathrm{H}_{2} \mathrm{O}\right)_{4}\right]^{2+}$ obtidos no presente trabalho utilizando o código CP-PAW após relaxação estrutural do sistema. . . . . . . . . . . . . . . . 77

4.24 Valores de $V_{z z}\left[10^{21} \mathrm{~V} / \mathrm{m}^{2}\right]$, e $\eta$ obtidos com o código CP-PAW, para os complexos $\left[\mathrm{Cd}\left(\mathrm{C}_{5} \mathrm{H}_{5} \mathrm{~N}_{5}\right)\left(\mathrm{H}_{2} \mathrm{O}\right)_{3}\right]^{2+}$ e $\left[\mathrm{Cd}\left(\mathrm{C}_{5} \mathrm{H}_{5} \mathrm{~N}_{5}\right)\left(\mathrm{H}_{2} \mathrm{O}\right)_{5}\right]^{2+}$. Apresentamos também os valores experimentais [51] obtidos com TDPAC. 79 
4.25 Valores de $V_{z z}\left[10^{21} \mathrm{~V} / \mathrm{m}^{2}\right]$ e $\eta$ obtidos com o código CP-PAW, para o Cd dos complexos $\left[\mathrm{Cd}\left(\mathrm{C}_{5} \mathrm{H}_{5} \mathrm{~N}_{5} \mathrm{O}\right)\left(\mathrm{H}_{2} \mathrm{O}\right)_{3}\right]^{2+},\left[\mathrm{Cd}\left(\mathrm{C}_{5} \mathrm{H}_{5} \mathrm{~N}_{5} \mathrm{O}\right)\left(\mathrm{H}_{2} \mathrm{O}\right)_{5}\right]^{2+}$ e $\left[\mathrm{Cd}\left(\mathrm{C}_{5} \mathrm{H}_{5} \mathrm{~N}_{5} \mathrm{O}\right)\left(\mathrm{H}_{2} \mathrm{O}\right)_{4}\right]^{2+}$. Apresentamos também os valores experimentais [51] obtidos com TDPAC. . . . . . . . . 80

4.26 Valores de $V_{z z}\left[10^{21} \mathrm{~V} / \mathrm{m}^{2}\right]$ e $\eta$ obtidos com o código CP-PAW, para o Cd do complexo $\left[\mathrm{Cd}\left(\mathrm{C}_{5} \mathrm{H}_{6} \mathrm{~N}_{2} \mathrm{O}_{2}\right)\left(\mathrm{H}_{2} \mathrm{O}\right)_{n}\right]^{2+}$. Apresentamos também os valores experimentais [51] obtidos com TDPAC. . . . . . . 81

4.27 Valores de $V_{z z}\left[10^{21} \mathrm{~V} / \mathrm{m}^{2}\right]$ e $\eta$ obtidos com o código CP-PAW, para o Cd dos complexos $\left[\mathrm{Cd}\left(\mathrm{C}_{4} \mathrm{H}_{5} \mathrm{~N}_{3} \mathrm{O}\right)\left(\mathrm{H}_{2} \mathrm{O}\right)_{5}\right]^{2+}$ e $\left[\mathrm{Cd}\left(\mathrm{C}_{4} \mathrm{H}_{5} \mathrm{~N}_{3} \mathrm{O}\right)\left(\mathrm{H}_{2} \mathrm{O}\right)_{4}\right]^{2+}$. Apresentamos também os valores experimentais [51] obtidos com

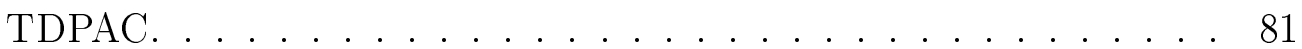

4.28 Valores de $V_{z z}\left[10^{21} \mathrm{~V} / \mathrm{m}^{2}\right]$ e $\eta$ obtidos com o código CP-PAW, no sítio de Cd coordenado com o H4 da adenina e O14 da timina e $N^{\text {adenina }} O_{5}^{\text {agua }}$ conforme figura $4.29 . \ldots \ldots \ldots$. . . . . . 83

4.29 Valores de $V_{z z}\left[10^{21} \mathrm{~V} / \mathrm{m}^{2}\right]$ e $\eta$ obtidos com o código CP-PAW, no sítio de Cd coordenado com $H^{\text {guanina }}[\mathrm{NO}]^{\text {citosina }},[\mathrm{NO}]^{\text {guanina }} \mathrm{O}_{4}^{\text {agua }}$ e $[N]^{\text {guanina }} O_{5}^{\text {agua }}$ o $\mathrm{H} 4$ da adenina e $\mathrm{O} 14$ da timina e $N^{\text {adenina }} O_{5}^{\text {agua }}$ conforme figura $4.30 \ldots \ldots \ldots \ldots$. . . . . . . . . . 84

4.30 Compilação dos valores de $V_{z z}, \eta$ nos sítios de Cd em todos os sistemas aqui estudados. Apresentamos também os valores experimentais preliminares inferidos por TDPAC. . . . . . . . 88 


\section{Lista de Figuras}

1.1 Desenho ilustrativo em 2D das bases púricas (adenina e guanina) e pirimídicas (citosina e timina) do DNA. . . . . . . . 2

1.2 Desenho ilustrativo em 2D dos pares de bases AT e GC do DNA, (figura extraída de http://www.enq.ufsc.br/labs/probio/disc_eng_bioq/trabalhos_pos2003, acessado em 18/03/11.) ...................... 3

1.3 Em (a) esquema ilustrativo do metal divalente (íon $C d^{2+}$ ) ligado diretamente na base nitrogenada do DNA. Em (b) temos a ilustração do metal intercalado com os pares de bases e em (c) esquema proposto na literatura para as interações entre os íons metálicos com diferentes nucleotídeos da molécula de DNA. As figuras (b) e (c) foram retiradas das referências [16] e [4] respectivamente. . . . . . . 5

2.1 Representação esquemática das contribuições da pseudo função de onda,$\left|\tilde{\psi}_{i}\right\rangle$, função de onda parcial, $\left|\phi_{q}\right\rangle$ e pseudo função de onda parcial, $\left|\tilde{\phi}_{q}\right\rangle$, para a função de onda total (AE) no método PAW (eq.2.27). (Figura retirada da referência [35] . . . . . . . . . . . 23 
4.1 Representação esquemática dos sistemas estudados: a) base nitrogenada isolada; b) base nitrogenada com um átomo de $\mathrm{Cd}$; c) base nitrogenada com um átomo de $\mathrm{Cd}$ e moléculas de $\mathrm{H}_{2} \mathrm{O}$; d) pares de bases nitrogenadas com um átomo de $\mathrm{Cd}$ e moléculas de $\mathrm{H}_{2} \mathrm{O}$. As bases estudadas foram a adenina, citosina, timina e guanina e o número de moléculas de $\mathrm{H}_{2} \mathrm{O}$ foi variado entre 3 e 5 . . . . . . . 38

4.2 Adenina isolada com geometria otimizada pelo CP-PAW. . . . . . . 40

4.3 Guanina isolada com geometria otimizada pelo CP-PAW. . . . . . . 41

4.4 Citosina isolada com geometria otimizada pelo CP-PAW. . . . . . . 43

4.5 Timina isolada com geometria otimizada pelo CP-PAW. . . . . . . 44

4.6 Gradiente de Campo Elétrico $V_{z z}$, em módulo, nos sítios de nitrogênio em função da energia de corte da base de ondas planas para a molécula de adenina isolada. . . . . . . . . . . 46

4.7 Gradiente de Campo Elétrico $V_{z z}$, em módulo, nos sítios de nitrogênio e oxigênio em função da energia de corte da base de ondas planas para a molécula de guanina isolada . . . . . . . . . 47

4.8 Gradiente de Campo Elétrico $V_{z z}$, em módulo, nos sítios de hidrogênio, oxigênio e nitrogênio em função da energia de corte da base de ondas planas para a molécula de citosina isolada. . . . . . . . . . . 47

4.9 Gradiente de Campo Elétrico $V_{z z}$, em módulo, nos sítios de nitrogênio e oxigênio em função da energia de corte da base de ondas planas para a molécula de citosina isolada. . . . . . . . . . 48

4.10 Valores de $V_{z z}, V_{y y}$ e $V_{x x}$ dos átomos de nitrogênio da molécula de adenina. . . . . . . . . . . . . . . . . . 49

4.11 Valores de $V_{z z}, V_{y y}$ e $V_{x x}$ dos átomos de nitrogênio e oxigênio da molécula de guanina. . . . . . . . . . . . . . . . 49 
4.12 Valores de $V_{z z}, V_{y y}$ e $V_{x x}$ dos átomos de nitrogênio da molécula de timina. ........................... 53

4.13 Valores de $V_{z z}, V_{y y}$ e $V_{x x}$ dos átomos de nitrogênio e oxigênio da molécula de citosina. . . . . . . . . . . . . . . . 54

4.14 Sítios de ligação dos metais na molécula: a) adenina;b) guanina, conforme sugerido na referência [4]. . . . . . . . . . . . . . 58

4.15 Sítios de ligação dos metais na molécula: a) citosina;b) timina, conforme sugerido na referência $[4] \ldots \ldots \ldots \ldots$

4.16 (a) $C d^{+2}$ ligado no sítio N2 da adenina antes da otimização de geometria e em (b) a estrutura após a otimização de geometria. Em (c) o $C d^{+2}$ ligado no sítio N4 da adenina antes da otimização e em (d) geometria obtida após otimização de geometria. As distâncias de ligação Cd-Adenina estão em verde. . . . . . . . . . . . . . . . 60

4.17 (a) $C d^{+2}$ ligado no sítio N2 da guanina antes da otimização de geometria e em (b) a estrutura após a otimização de geometria. As distâncias de ligação Cd-Guanina estão em verde. . . . . . . . . . 62

4.18 (a) $C d^{+2}$ ligado no sítio N2 da citosina antes da otimização de geometria e em (b) a estrutura após a otimização de geometria. As distâncias de ligação Cd-Citosina estão em verde. . . . . . . . . . . 64

4.19 (a) Estrutura Cd com timina antes da otimização de energia. (b) Estrutura otimizada com o CP-PAW. . . . . . . . . . . . 65

$4.20 V_{z z}, V_{y y}$ e $V_{x x}$ no Cd ligado ao sítio N2 da adenina. . . . . . . 66

$4.21 V_{z z}, V_{y y}$ e $V_{x x}$ do Cd ligado no sítio N4 da adenina. . . . . . . . 66

4.22 Valores de $V_{z z}, V_{y y}$ e $V_{x x}$ do Cd ligado no sítio N2 da guanina. . . 69

4.23 Valores de $V_{z z}, V_{y y}$ e $V_{x x}$ do Cd ligado no sítio N2 da citosina. . . . 70

4.24 Valores de $V_{z z}, V_{y y}$ e $V_{x x}$ do Cd ligado no sítio O15 da timina. . . . 71 
4.25 Estruturas otimizadas dos complexos com o Cd ligado ao sítio N2 da $\mathrm{C}_{5} \mathrm{H}_{5} \mathrm{~N}_{5}$ em: a) pentacoordenado, $\left[\mathrm{Cd}\left(\mathrm{C}_{5} \mathrm{H}_{5} \mathrm{~N}_{5}\right)\left(\mathrm{H}_{2} \mathrm{O}\right)_{3}\right]^{2+}$; b) hexacoordenado $\left[\mathrm{Cd}\left(\mathrm{C}_{5} \mathrm{H}_{5} \mathrm{~N}_{5}\right)\left(\mathrm{H}_{2} \mathrm{O}\right)_{5}\right]^{2+} \ldots \ldots \ldots$. . . . . 74

4.26 Estruturas otimizadas dos complexos com o Cd ligado ao sítio N2 e O16 da $\mathrm{C}_{5} \mathrm{H}_{5} \mathrm{~N}_{5} \mathrm{O}$ em: a) tetracoordenado, $\left[\mathrm{Cd}\left(\mathrm{C}_{5} \mathrm{H}_{5} \mathrm{~N}_{5} \mathrm{O}\right)\left(\mathrm{H}_{2} \mathrm{O}\right)_{3}\right]^{2+}$; b) hexacoordenado $\left[\mathrm{Cd}\left(\mathrm{C}_{5} \mathrm{H}_{5} \mathrm{~N}_{5} \mathrm{O}\right)\left(\mathrm{H}_{2} \mathrm{O}\right)_{5}\right]^{2+}$; c) hexacoordenado $\left[\mathrm{Cd}\left(\mathrm{C}_{5} \mathrm{H}_{5} \mathrm{~N}_{5} \mathrm{O}\right)\left(\mathrm{H}_{2} \mathrm{O}\right)_{4}\right]^{2+} \ldots \ldots \ldots \ldots \ldots \ldots$

4.27 Estrutura otimizada do complexo com o Cd hexacoordenado $\left[\mathrm{Cd}\left(\mathrm{C}_{5} \mathrm{H}_{6} \mathrm{~N}_{2} \mathrm{O}_{2}\right)\left(\mathrm{H}_{2} \mathrm{O}\right)_{5}\right]^{2+}$ ligado ao sítio $\mathrm{O} 15$ da $\mathrm{C}_{5} \mathrm{H}_{6} \mathrm{~N}_{2} \mathrm{O}_{2} \ldots \ldots \ldots \ldots \ldots$

4.28 Estruturas otimizadas dos complexos com o Cd ligado ao sítio N2 e O13 da $\mathrm{C}_{4} \mathrm{H}_{5} \mathrm{~N}_{3} \mathrm{O}$ em: a) hexacoordenado, $\left[\mathrm{Cd}\left(\mathrm{C}_{4} \mathrm{H}_{5} \mathrm{~N}_{3} \mathrm{O}\right)\left(\mathrm{H}_{2} \mathrm{O}\right)_{5}\right]^{2+}$; b) hexacoordenado, $\left[\mathrm{Cd}\left(\mathrm{C}_{4} \mathrm{H}_{5} \mathrm{~N}_{3} \mathrm{O}\right)\left(\mathrm{H}_{2} \mathrm{O}\right)_{4}\right]^{2+} \ldots \ldots \ldots 78$

4.29 Estrutura otimizada do Cd ligado ao par de base adenina-timina: a) Cd entre as bases; b) Cd ligado ao sítio N2 da adenina. . . . . . 83

4.30 Estrutura otimizada do Cd ligado ao par guanina-citosina: a) Cd entre as bases; b) Cd ligado ao sítio N2 e O da guanina; c) Cd ligado somente ao sítio $\mathrm{N} 2$ da guanina. . . . . . . . . . . . . . 85

4.31 Valores de $V_{z z}\left[X 10^{21} \mathrm{~V} / \mathrm{m}^{2}\right]$ obtidos através de cálculos ab initio de estrutura eletrônica (CP-PAW) nos sítios de Cd em todos os sistemas estudados neste trabalho. Apresentamos também os valores experimentais obtidos por TDPAC para as bases nitrogenadas e famílias de camundongos infectados com a T. Cruzi [18]. . . . . 87

4.32 Valores de $\eta$ obtidos através de cálculos ab initio de estrutura eletrônica (CP-PAW) nos sítios de Cd em todos os sistemas estudados neste trabalho. Apresentamos também os valores experimentais obtidos por TDPAC para as bases nitrogenadas e famílias de camundongos infectados com a T. Cruzi [18] . . . . . . . . . . 89 
4.33 DOS total e projetada nos sítios de Cd e sítios dos ligantes do Cd para: a) adenina com o Cd ligado ao sítio N2 e coordenação seis (figura 4.25b); b) adenina com o Cd ligado ao sítio N2 e coordenação seis e timina (figura 4.29b). . . . . . . . . . . . . . . . 91

4.34 Orbitais moleculares para a adenina com Cd ligado ao N2 e cinco moléculas de água: a) $H O M O$; b) $L U M O$; c) $H O M O-1$; d) $L U M O$ +1. Os átomos de nitrogênio estão em verde, carbono em cinza, oxigênio em vermelho e o $\mathrm{Cd}$ em preto. . . . . . . . . . . . . 92

4.35 Orbitais moleculares para o par A-T com Cd ligado ao N2 e cinco moléculas de água: a) HOMO ; b) LUMO; c) HOMO -1; d) LUMO +1. Os átomos de nitrogênio estão em verde, carbono em cinza, oxigênio em vermelho e o $\mathrm{Cd}$ em preto. . . . . . . . . . . . . 92

4.36 DOS total e projetada nos sítios de Cd e sítios dos ligantes do Cd para: a) timina com o Cd ligado ao sítio O15 e coordenação seis (figura 4.27); b) timina com o Cd ligado ao sítio O15 e coordenação seis e adenina (figura 4.29a). . . . . . . . . . . . . . 93

4.37 Orbitais moleculares para a timina com Cd ligado ao O15 e 5 moléculas de água: a) HOMO; b) LUMO; c) HOMO -1; d) HOMO -2. Os átomos de nitrogênio estão em verde, carbono em cinza, oxigênio em vermelho e o $\mathrm{Cd}$ em preto. . . . . . . . . . . . . . 94

4.38 Orbitais moleculares para o par T-A com Cd ligado ao O14 e H4: a) $H O M O$; b) LUMO; c) HOMO -1; d) HOMO -2. Os átomos de nitrogênio estão em verde, carbono em cinza, oxigênio em vermelho e o $\mathrm{Cd}$ em preto. . . . . . . . . . . . . . . 95 
4.39 DOS total e projetada nos sítios de Cd e sítios dos ligantes do Cd para: a) guanina com o Cd ligado ao sítio N2 e O e coordenação seis (figura 4.26c); b) guanina com o Cd ligado ao sítio N2 e O e coordenação seis e citosina (figura 4.30b) . . . . . . . . . . . 96

4.40 Orbitais moleculares para a guanina com Cd ligado ao N2 e O16 e 4 moléculas de água: a) HOMO; b) LUMO; c) HOMO -1. Os átomos de nitrogênio estão em verde, carbono em cinza, oxigênio em vermelho e o $\mathrm{Cd}$ em preto. . . . . . . . . . . . 97

4.41 DOS total e projetada nos sítios de Cd e sítios dos ligantes do Cd para: a) guanina com o Cd ligado ao sítio N2 e coordenação seis (figura 4.26b); b) guanina com o Cd ligado ao sítio N2 e coordenação seis e citosina (figura 4.30c). . . . . . . . . . . . 97

4.42 Orbitais moleculares para a guanina com Cd ligado ao N2 e 5 moléculas de água: a) $H O M O$; b) $L U M O$; c) $H O M O$-1; d) $H O M O$ -2. Os átomos de nitrogênio estão em verde, carbono em cinza, oxigênio em vermelho e o $\mathrm{Cd}$ em preto. . . . . . . . . . . . 98

4.43 Orbitais moleculares para o par G-C com Cd ligado ao N2 e O15 e 4 moléculas de água: a) HOMO; b) LUMO; c) HOMO -1; d) HOMO -2. Os átomos de nitrogênio estão em verde, carbono em cinza, oxigênio em vermelho e o $\mathrm{Cd}$ em preto. . . . . . . . . 98

4.44 Orbitais moleculares para o par G-C com Cd ligado ao N2 e 5 moléculas de água: a) HOMO; b) LUMO; c) HOMO -1; d) LUMO +1. Os átomos de nitrogênio estão em verde, carbono em cinza, oxigênio em vermelho e o $\mathrm{Cd}$ em preto. . . . . . . . . . . . . 99 
4.45 Orbitais moleculares para a citosina com Cd ligado ao N2 e O e 4 moléculas de água: a) $H O M O$; b) $L U M O$; c) $H O M O$-1; d) LUMO +1. Os átomos de nitrogênio estão em verde, carbono em cinza, oxigênio em vermelho e o $\mathrm{Cd}$ em preto. . . . . . . . . . . . . . 99

4.46 Orbitais moleculares para a citosina com Cd ligado ao N2 e 5 moléculas de água: a) $H O M O$; b) $L U M O$; c) $H O M O$-1; d) LUMO +1. Os átomos de nitrogênio estão em verde, carbono em cinza, oxigênio em vermelho e o $\mathrm{Cd}$ em preto. . . . . . . . . . . . 100

4.47 Orbitais moleculares para o par C-G com Cd ligado entre as bases: a) $H O M O$; b) $L U M O$; c) $H O M O$-1; d) $L U M O+1$. Os átomos de nitrogênio estão em verde, carbono em cinza, oxigênio em vermelho e o $\mathrm{Cd}$ em preto. ...................... 100

4.48 DOS total e projetada nos sítios de Cd e sítios dos ligantes do Cd para: a) citosina com o Cd ligado ao sítio N2 e O e coordenação seis (figura 4.28a); b) citosina com o Cd ligado ao sítio N2 e coordenação seis (figura 4.28b); c) Cd ligado entre o par de base C-G (figura 4.30a).101

A.1 Esquema ilustrativo dos decaimentos ${ }^{111} \mathrm{In} \rightarrow{ }^{111} \mathrm{Cd}$ e ${ }^{111 m} \mathrm{Cd} \rightarrow \rightarrow^{111}$ Cd. Figura extraída da ref. [60]. . . . . . . . . . . . 107 


\section{Bibliografia}

[1] A. L. Lehninger, D. L. Nelson e M. M. Cox. Lehninger principles of biochemistry. W. H. Freeman, 4th edição, (2005).

[2] V. Serebrov, R. J. Clarke, H. J. Gross e L. Kisselev. Biochemistry 2001 40, 6680 (2001).

[3] B. Alberts. Molecular Biology of the Cell. Garland Science, 4th edição, (2002).

[4] N. Hadjiliadis e E. Sletten et. al. Metal Complex-DNA interactions. Ed. Wiley, United Kingdom, (2009).

[5] G. L. Eichhorn e Y. A. Shin. J. Am. Chem. Soc. 90, 7323 (1968).

[6] T. Yamane e N. Davidson. J. Am. Chem. Soc. 83, 2599 (1961).

[7] N. A. Frøysten e E. Sletten. J. Am. Chem. Soc. 116, 3240 (1994).

[8] Beryllium, Cadmium and Mercury Exposures in the Glass Manufacturing Industry. IARC, International Agency for Research on Cancer, vol. 58 edição, (1993).

[9] G. S. Manning. Q. Rev. Biophys. 11, 179 (1978).

[10] Jaroslav V. Burda, Jirı Sÿponer e Pavel Hobza. J. Phys. Chem. 100, 7250 (1996). 
[11] Jiri Sÿponer, Jaroslav V. Burda, Michal Sabat, Jerzy Leszczynski e Pavel Hobza. J. Phys. Chem. A 102, 5951 (1998).

[12] M. Schreiber e L. Gonzalez. J. Comp. Chem. 28, 2299 (2007).

[13] Y. Wu, R. Sa, Q. Li, Y. Wei e K. Wu. Chem. Phys. Lett. 467, 387 (2009).

[14] G.Schatz e A. Weidinger. Nuclear Condensed Matter Physics. Willey and Sons, New York, (1996).

[15] L. Hemmingsen e T. Butz. Perturbed Angular Correlations of $\gamma$-rays (PAC) Spectroscopy - Encyclopedia of Inorganic Chemistry. Willey and Sons, (2008).

[16] B. Luisi et. al. Science 265, 520 (1994).

[17] C. E. Housecroft e A. G. Sharpe. Inorganic Chemistry. Pearson Education, 3rd edição, (2008).

[18] A. dos Santos Silva. Avaliação do Padrão de Resposta de Imunoglobulinas em Diferentes Linhagens de Camundongos Frente à Infecção por T. cruzi. Tese de mestrado, IPEN, São Paulo, (2006).

[19] J. Neves. Diagnóstico e tratamento das doenças infecciosas e parasitárias. Guanabara Koogan, 2rd edição, (1983).

[20] S. Goldenberg e M. A. Krieger. Doença de Chagas: Novas perspectivas no diagnóstico imunológico. Biotecnologia Ciência e Desenvolvimento, 1 edição, (1997).

[21] L. A. C. Passos. Análise do determinismo Genético da resistência de camundongos infectados experimentalmente com a cepa $Y$ de Trypanosoma cruzi. Tese de doutorado, Unicamp, Campinas, (2003).

[22] P. E. Blöchl. J. Chem. Phys. 103, 7422 (1995). 
[23] R. Car e M. Parrinello. Phys. Rev. Lett. 55, 2493 (1985).

[24] P. E. Blöchl. Phys. Rev. B 50, 17953 (1994).

[25] J. Kohanoff. Electronic Structure Calculations for Solids and Molecules Theory and Computational Methods. Cambridge Universtiy Press, (2006).

[26] M. Born e J. R. Oppenheimer. Adv. Phys. 84, 457 (1927).

[27] P. Hohenberg e W. Kohn. Phys. Rev. B 136, 864 (1964).

[28] W. Kohn e L.J. Sham. Phys. Rev. A 140, 1133 (1965).

[29] R. Lelis de Sousa. Dissociação da molécula de água sobre superfícies de silício: estudo teórico. Tese de doutorado, IFUSP, São Paulo, (2010).

[30] J. D. M. Vianna, A. Fazzio e S. A. Canuto. Teoria Quântica de Moléculas e Sólidos. Editora Livraria da Física, (2004).

[31] D. M. Ceperley e B. J. Alder. Phys. Rev. Lett. 45, 566 (1980).

[32] J. P. Perdew, K. Burke e M. Ernzerhorf. Phys. Rev. Lett. 77, 3865 (1996).

[33] G. Pastore, E. Smargiassi e F. Buda. Phys. Rev. A 44, 6334 (1991).

[34] P. E. Blöchl e M. Parrinello. Phys. Rev. B 45, 9413 (1992).

[35] A. Reyes Huamantinco. Estudo da Superfície Au(111) e da Adsorção de CH3S em Au(111) através do Método PAW. Tese de mestrado, IFUSP, São Paulo, (2003).

[36] P. Margl, K. Schwarz e P. E. Blöchl. Firsts Principles Calculations of Organometallic Compounds - Computations for the nano-scale. (1993). 
[37] T. P. Das e E. L. Han. Nuclear Quadrupole Resonance Spectroscopy. Academic Press.

[38] W. Witthuhn e W. Engel. Topics in Current Physics - Hyperfine Interactions of Radioactive Nuclei. Springer-Verlag, (1983).

[39] I. S. Oliveira e A. P. Guimarães. Revista Brasileira de Ensino de Fúsica. 22, $353(2000)$.

[40] M. B. Gonçalves. Efeitos de Estado Sólido e Ligações de Hidrogênio sobre o Gradiente de Campo Elétrico no Núcleo de Imidazol. Tese de mestrado, USP, São Paulo, (2006).

[41] H.M. Petrilli, P.E. Blöchl, P. Blaha e K. Schwarz. Phys. Rev. B 57, 14690 (1998).

[42] G. Wu, S. Dong, R. Ida e N. Reen. J. Am. Chem. Soc. 124, 1768 (2002).

[43] N. Russo, E. Sicilia, M. Toscano e A. Grand. J. Mol. Struct. 563, 125 (2001).

[44] D. N. Mahato, A. Dubey, R. H. Pink, R. H. Scheicher, S. R. Badu, K. Nagamine, E. Torikai, H. P. Saha, Lee Chow, M. B. Huang e T. P. Das. hyperfine Interactions 181, 81 (2008).

[45] P. Pyykkö. Molec. Phys. 99, 1617 (2001).

[46] H. Haas e H. M. Petrilli. Phys. Rev. B 61, 13588 (2000).

[47] L. A. Errico, M. Rentería e H. M. Petrilli. Physica B 389, 37 (2007).

[48] P. Atkins e J. de Paula. Atkin's Physical Chemistry - 8th Edition. Oxford University Press, (2006). 
[49] L. Clowney, S.C Jain, A.R Srinivasan, J. Westbrook, W.K Holson e H.M Berman. J. Am. Chem. Soc. 118, 509 (1996).

[50] Z. Hossain e F. Huq. J. Inorg. Biochem. 90, 97 (2002).

[51] A. W. Carbonari, A. dos Santos Silva e A. L. Lapolli, (2010). Comunicação privada.

[52] L. A. Errico, M. Rentería e H. M. Petrilli. Phys. Rev. B 75, 155209 (2007).

[53] W.W. Rudolph e C.C. Pye. J. Phys. Chem. B 102, 3564 (1998).

[54] P. A. Ochoa, M. I. Rodriguez-Tapiador, S. S. Alexandre, C. Pastor e F. Zamora. J. Inorg. Biochem. 99, 1540 (2005).

[55] M. B. Gonçalves, R. di Felice, O. K. Poleshchuk e H. M. Petrilli. hyperfine Interactions 181, 53 (2008).

[56] Astrogildo de Carvalho Junqueira. Investigação do Gradiente de Campo Elétrico nas Ligas $\mathrm{Nb}_{3} \mathrm{M}\left(\mathrm{M}=\mathrm{Al}\right.$, In, Si, Ge, Sn) e $\mathrm{T}_{3} \mathrm{Al}$ (T=Ti, $\mathrm{Zr}, \mathrm{Hf}$, $V, N b, T a)$ pela Técnica de Correlação Angular $\gamma-\gamma$ Perturbada. Tese de mestrado, IPEN, São Paulo, (1999).

[57] H. Frauenfelder e R. M. Steffen. Alpha, Beta and Gamma-Ray Spectroscopy. North Holland, (1965).

[58] L. Hemmingsen, K. N. Sas e E. Danielsen. Chem. Rev. 104, 4027 (2004).

[59] I. Sergueev, U. van Bürck, A. I. Chumakov, T. Asthalter, G. V. Smirnov, H. Franz, R. Rüffer e W. Petry. Phys. Rev. B 73, 24203 (2006).

[60] Emiliano Luiz Muñoz. Tese de doutorado, Universidad Nacional de La Plata, Argentina, (2011). 